
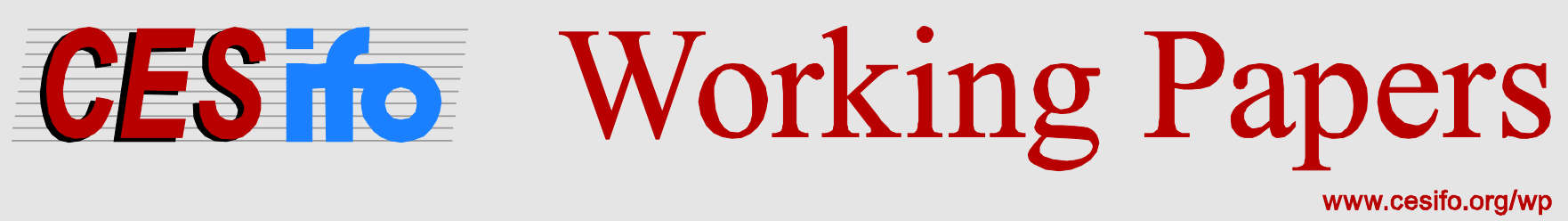

\title{
Das House-Kapital: A Theory of Wealth-to-Income Ratios
}

\author{
Volker Grossmann \\ Thomas Steger
}

\author{
CESIFO WORKING PAPER NO. 5844 \\ CATEgory 6: Fiscal Policy, MaCROECONOMICS AND GROWTH \\ APRIL 2016
}

An electronic version of the paper may be downloaded

- from the SSRN website:

- from the RePEc website:

- from the CESifo website:

wWw.SSRN.com

Www.RePEc.org

www.CESifo-group.org/wp 


\title{
Das House-Kapital: A Theory of Wealth-to-Income Ratios
}

\begin{abstract}
This paper provides a novel macroeconomic model that is specifically designed to investigate the evolution of housing wealth. To capture the importance of land as an input factor for housing production and for the evolution of wealth in a growing economy, the analysis builds on three premises: (1) the overall land endowment is fixed; (2) the production of new houses requires land as an essential input, whereas replacement investment does not; (3) land employed for real estate development must be permanently withdrawn from alternative uses. The calibrated model replicates the historical evolution of housing wealth after Word War II remarkably accurately and accounts for the close connection of house prices to land prices in the data. It suggests a considerable further increase in housing wealth, relative to income, that is associated with a future surge in land prices and house prices. The model also provides new insights into the dynamics of non-residential wealth.
\end{abstract}

JEL-Codes: E100, E200, O400.

Keywords: wealth-to-income ratios, housing wealth, non-residential wealth, house prices, land prices.

Volker Grossmann

University of Fribourg

Department of Economics

Bd. de Pérolles 90

Switzerland - 1700 Fribourg

volker.grossmann@unifr.ch
Thomas Steger

Leipzig University

Institute for Theoretical Economics

Grimmaische Strasse 12

Germany - 04109 Leipzig

steger@wifa.uni-leipzig.de

April 11, 2016 (Version 1.1) 


\section{Introduction}

This paper provides a novel macroeconomic model that is specifically designed to investigate the evolution of housing wealth. The proposed model replicates, with remarkable accuracy, the historical evolution of housing wealth relative to income after Word War II. It also enables us to think about the future trajectory of housing wealth. In addition, the model provides insights into the dynamics of non-residential wealth, the second major private wealth component, relative to income.

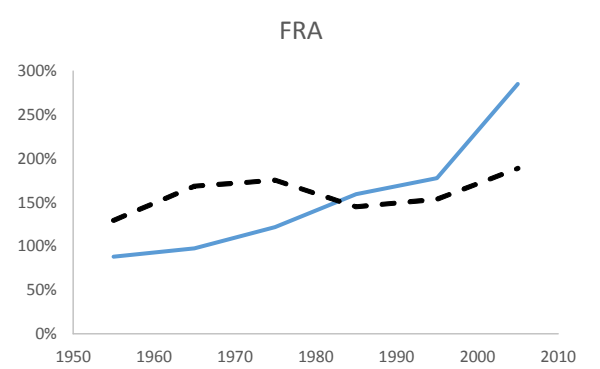

UK

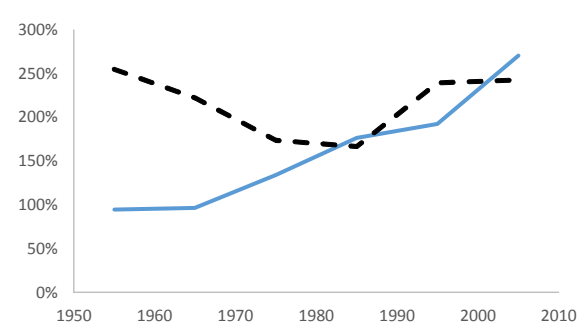

GER

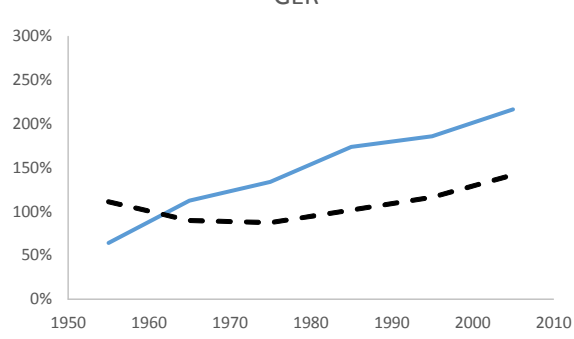

USA

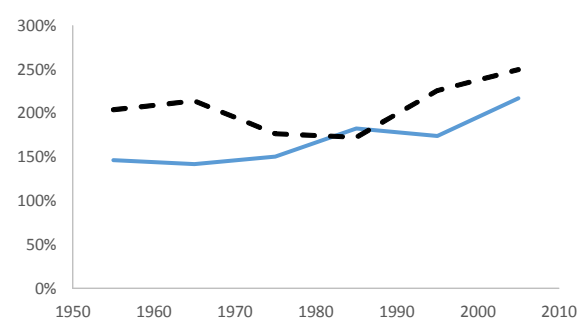

Figure 1. Evolution of the ratios of housing wealth to income (solid blue lines) and non-residential wealth to income (dashed black lines) in France, Germany, UK, and the USA.

Notes. To smooth out cyclical variations, decadal averages are employed. Income: net domestic product. Non-residential wealth: private wealth minus housing wealth minus net foreign assets. Housing wealth: gross housing assets (incl. the value of land), i.e. not reduced by mortgages and other financial liabilities of private households.

Data source: Piketty and Zucman (2014b).

Aggregate wealth-to-income ratios have increased in major industrialized countries since World War II (Piketty and Zucman, 2014a, 2015). Housing wealth is especially important for understanding this development. Figure 1 shows the evolution of the two 
major components of private wealth relative to aggregate income ("net domestic product", NDP), housing wealth and non-residential wealth, for France, Germany, the UK, and the USA after World War II. Two characteristics are striking and widely discussed. First, the rise in the overall private wealth-to-income ratio was more pronounced in European economies than the US (e.g., Piketty and Zucman, 2014a). Second, housing wealth increased considerably more than non-residential wealth (e.g., Bonnet et al., 2014). This last observation is consistent with rising real house prices since World War II, as documented by Knoll, Schularick and Steger (2014). They show that the surge in house prices goes hand in hand with rising land prices and argue that the price channel of rising land valuations has played a major role for the observed surge in wealth-to-income ratios.

The evolution of the wealth-to-income ratio and its decomposition is important for at least two reasons. First, Piketty (2014) stresses that a rising wealth-to-income ratio, assuming that the interest rate remains largely constant, changes the functional income distribution to the advantage of capital income recipients. Moreover, given that wealth is not uniformly distributed across the population, a rising wealth-to-income ratio is associated with a more unequal distribution of personal income. Rognlie (2015) demonstrates that the increase in the economy-wide capital income share is driven exclusively by the housing sector. Stiglitz (2015) points to the important role of land prices in the process of rising wealth-to-income ratios and increasing inequality of wealth and income. Once more, both land prices and the housing sector appear pivotal. Second, the wealth-to-income ratio appears to be a key determinant for the size of the financial sector. Philippon (2015) documents a long-term surge in the size of the finance industry, measured either by finance income or the volume of intermediated assets, relative to GDP. Similarly, Jordá, Schularick and Taylor (2016) document a rising share of real estate lending in total bank credit and argue that the growth of finance has been closely linked to an explosion of mortgage lending to households in the last quarter of the twentieth century. Gennaioli, Shleifer and Vishny (2014) argue that the growth of finance can in fact be explained by a rising wealth-to-income ratio, as one key function of the financial sector is to preserve the stock of wealth and not just to finance the addition to wealth. By focusing on the long run evolution of housing wealth, this paper therefore clarifies one real and fundamental 
driving force for the process of financialization.

We address the following research questions: How large is the private wealth-toincome ratio in the long run and how will it evolve? ${ }^{1}$ How does the composition of the private wealth-to-income ratio (housing and non-residential wealth) look like? How do population dynamics and technological progress contribute to the observed evolution of the two major wealth-to-income ratios? To discuss these questions, we construct a new dynamic macroeconomic model, which we refer to as the House Capital Model, that is designed to analyze the evolution of different wealth components. Our theory places considerable emphasis on modelling the housing sector and land as an input factor. This enables us to capture important mechanisms that impact on the evolution of wealth-toincome ratios. The proposed model rests on three premises:

Premise 1 (Fixed Land Endowment). The overall land endowment is given by nature. The total amount of land that can be used economically, therefore, is fixed in the long run.

Premise 2 (Land in Housing Production). (i) A house is a bundle of the underlying land plot and the residential structure. Setting up new housing projects requires land as an essential input. (ii) Replacement investments do not, however, require land as an input.

Premise 3 (Land Rivalry). Land that is used as an input in the production of new houses is permanently withdrawn from alternative economic uses, unless existing house are demolished.

Premise 1 represents a general law of nature. This has been acknowledged by previous researchers who model land and long run economic growth, starting with Nichols (1970). A sceptic may argue that land-augmenting technical change, land reclamation, and land development due to infrastructure investment can enlarge the available amount of land. ${ }^{2}$

\footnotetext{
${ }^{1}$ Throughout this paper, we do not consider foreign capital. Foreign capital played a substantial role in Britain and France in the late 19th and early 20th century, but not since then. Moreover, we focus exclusively on private rather than public wealth.

${ }^{2}$ Zoning regulations and other restrictions on land use have inhibited the utilization of additional land in recent decades (Glaeser, Gyourko, and Saks, 2005; Glaeser and Gyourko, 2003). Moreover,
} 
This is indeed plausible in the short to medium run. In the long run, however, the total amount of economically usable land is certainly fixed by nature. Increasing land scarcity, already in contemporaneous times, is also compatible with rising prices of farmland and urban residential land, as documented by Knoll et al. (2014) for 14 advanced countries since WWII. Premise $2(i)$ appears largely undisputed and taken into account by existing theories (e.g., Davis and Heathcote, 2005; Favilukis et al., 2015). Premise 2 (ii) is usually not taken into account. We capture the fact that replacement investments do not require land by distinguishing between the extensive and the intensive margin of residential investment. It will be argued that only an enlargement of the housing stock along the extensive margin, i.e. setting up new housing projects, requires land. This distinction enables us to avoid the long run inconsistency that arises from Premises 1 $\& 3$, together with the (common) assumption that all investments in the housing stock, including replacement investment, require land. Premise 3 simply describes the fact that land represents a rivalrous input: a plot of land that is underneath a house cannot, at the same time, host a manufacturing plant. As a result, land that is employed for setting up new housing projects resembles an exhaustible resource.

The interaction between scarce land and housing production in a growing economy, resulting from Premises 1-3, will materialize in a modern version of Ricardo's (1817) famous principle of scarcity. Ricardo was mainly concerned with agricultural land and the production of corn to feed a growing population. ${ }^{3}$ In modern times, societies are confronted more with residential investments to meet the increasing demand for housing services under the constraint of scarce land. Thus, the evolution of the land price impacts on the house price and thereby on the evolution of housing wealth. It also determines the value of non-residential wealth, which includes the value of land not used for residential purposes. If one assumes, by contrast, that a given (time-invariant) number of new pieces of land becomes available for housing production each period and land is not used in other

Saiz (2010) shows, by employing geographical, satellite-generated data for U.S. metropolitan cities, that residential development is effectively curtailed by the availability of suitable land. He also stresses the positive interaction between (exogenous) land scarcity and (endogenous) regulations, implying that geographically constrained areas tend to be also highly regulated.

${ }^{3}$ Ricardo (1817) argued that, over the long run, economic growth benefits landlords disproportionately, as the owners of the fixed factor. Since land is unequally distributed across the population, Ricardo reasoned that market economies would produce rising inequality. 
sectors, then the increasing scarcity of land in a growing economy and its role in wealth accumulation cannot be captured in an appropriate manner.

Our model can be outlined as follows. Three different types of wealth are distinguished: physical capital, non-residential land, and residential ("house") capital. ${ }^{4}$ Housing capital includes residential land, required to set up a housing project, and residential structures. The housing stock can be expanded along the extensive margin (setting up new housing projects) and along the intensive margin (enlarging existing housing projects by building larger residential buildings). As it becomes increasingly difficult to build houses upwards (i.e. constructing larger residential buildings on a given amount of land), there are decreasing returns to scale along the intensive margin. This creates profits (residual incomes) for housing services producers, which provide incentives for real estate development in the first place, despite perfect competition. Land can be allocated either to the housing sector or used for the production of a non-residential consumption good. The overall land endowment is treated as a fixed factor. Moreover, land that is devoted to the production of new houses is permanently withdrawn from alternative economic uses. In this sense, land devoted to housing production shares characteristics of an exhaustible resource. The land price is fully endogenous and responds to economic growth driven by technical change and rising population density.

By calibrating the model and solving it numerically, we are able to describe the evolution of the different wealth-to-income ratios, the land price, and the house price over time. The numerical analysis employs the relaxation algorithm to solve the model for transitional dynamics (Trimborn, Koch and Steger, 2008). This technique allows us to calculate the transitional dynamics implied by the non-linear differential equation system. ${ }^{5}$

The calibrated model replicates the post WWII increase in the two major wealthto-income ratios remarkably well. It also suggests a considerable further increase of the private wealth-to-income ratios in the future. Assuming an intermediate capital income

\footnotetext{
${ }^{4}$ The model therefore enables us to quantify the major components of the overall wealth-to-GDP ratio, distinguishing between non-residential wealth and housing wealth, as shown in Figure 1.

${ }^{5}$ This procedure is extended to analyze sizeable transitions that are driven by large shocks in state variables and substantial exogenous movements in population size and total factor productivities, which appropriate for the period after WWII.
} 
tax rate that is similar to the current US level and depending on the subjective discount rate, the implied long run housing wealth-to-income ratio ranges from 357 to 478 percent. ${ }^{6}$ Regarding the non-residential wealth-to-income ratio, our analysis also points to a future increase, although this is weaker compared to housing wealth. While the average nonresidential wealth-to-NDP ratio in the 2000s was about 250 percent for the US, we obtain long run values ranging between 292 to 353 percent. Hence, the implied total private wealth-to-income ratio ranges from 650 to 830 percent in the long run, which may be compared to the US value of 465 percent in the 2000s. Our model also implies that land prices and house prices will rise further in the future as long as the economy exhibits growth.

The implied total wealth-to-income ratio exceeds slightly the range of values suggested by Piketty (2014). For instance, assuming a net savings rate, $s$, of about 10 percent and real GDP per capita growth rate, $g$, of about 1.5 percent, the (private) wealth-to-income ratio, $s / g$, would rise to $600-700$ percent. Provided that the real interest rate, $r$, does not adjust, this would result in a rising capital income share $(r s / g)$ and, given that capital is unequally distributed, in rising income inequality. ${ }^{7}$ His projections are based on a Solowtype framework that does not distinguish between housing wealth and non-residential wealth. The framework implicitly treats land as an accumulable factor (i.e. being part of physical capital) and does not feature land and house prices.

There is an extensive and growing theoretical literature on housing and macroeconomics (Piazzesi and Schneider, 2016). Instead of providing an exhaustive overview, we highlight some of the more recent contributions. Hornstein (2008, 2009) employs a general equilibrium model to explain the surge in house prices in the US between 1975 and 2005. Davis and Heathcote (2005) build a multi-sector stochastic growth model with a housing sector to explain the business cycle dynamics of residential investment. Favilukis et al. (2015) construct a stochastic two-sector general equilibrium model of housing and non-housing production to explain the surge and the subsequent decline of the price-torent ratio in the US housing market between 2000 and 2010. Li and Zeng (2010) employ

\footnotetext{
${ }^{6}$ According to Figure 1, the average housing wealth-to-NDP ratio (across FRA, GER, and UK) is about 255 percent (trend value in 2005), while it amounts to a somewhat lower 217 percent for the U.S.

${ }^{7}$ Krusell and Smith (2015) have debated these propositions. However, our model is not subject to their criticisms.
} 
a two-sector neoclassical growth model with housing to explain a rising real house price driven by comparably slow technical progress in the construction sector. Borri and Reichlin (2016) use a two-sector, life-cycle economy with bequests to explain the increasing wealth-to-income ratio and wealth inequality driven by rising construction costs that are also caused by comparably slow technological progress in the construction sector. We depart from the previous literature in two important respects. First, we distinguish between the extensive and the intensive margin of housing production. This distinction is particularly important if there is depreciation of housing capital. ${ }^{8}$ Second, none of the previous contributions rests on the assumption that Premises 1-3 hold simultaneously. We demonstrate why this is critical for understanding the dynamics of housing wealth in the long run. Most importantly, we capture an important stylized fact of long run house price dynamics. Knoll et al. (2014) have demonstrated that about 80 percent of the house price surge in developed economies after WWII can be attributed to rising land prices, while only 20 percent are due to rising construction costs. ${ }^{9}$

The paper is organized as follows. Section 2 presents our new macroeconomic model with a housing sector. Section 3 derives important asset price implications, defines the general equilibrium and the variables of interest. It also characterizes the long run equilibrium analytically. Section 4 calibrates the model, derives numerical long-run implications, and provides the transition paths for the variables of interest. Section 5 compares our macroeconomic model to the canonical macroeconomic model with a housing sector. The last section concludes.

\section{The Model}

Consider a perfectly competitive, closed economy. Time is continuous and indexed by $t \geq 0$. The innovation of our macroeconomic model is the housing sector. This sector encompasses different types of firms that interact in the production of housing services.

\footnotetext{
${ }^{8}$ Sachs and Boone (1988) circumvent the inherent difficulty associated with land as an input in the housing sector by assuming that the stock of house capital does not depreciate. Matsuyama (1990) does not explicitly model land as a production factor.

${ }^{9}$ Similarly, Davis and Heathcote (2007) show that the price of residential land has increased considerably more than house prices during 1975-2005 in the US (almost fourfold), whereas construction costs have increased only slightly.
} 
The technical and legal prerequisite to produce housing services is provided by real estate development firms. Their activity comprises the purchase of a piece of land, securitized in the form of a land ownership deed, and infrastructure investment to develop land for residential purposes. Setting up new housing projects diminishes the amount of land that can be employed elsewhere in the economy. The overall amount of land is treated as fixed. Housing services are produced by combining a developed real estate and residential buildings ("structures"). Structures are produced by employing materials (like cement) and labor. The non-residential sector produces a consumption (numeraire) good by combining capital, labor, and land. Like in standard (one-sector) models, the numeraire good can be used for capital investment as well.

\subsection{Firms}

\subsubsection{The Numeraire Good Sector}

The numeraire good $(Y)$ sector produces final output, that can be used for consumption and investment purposes, according a standard Cobb-Douglas production function:

$$
Y_{t}=B_{t}^{Y}\left(K_{t}^{Y}\right)^{\alpha}\left(L_{t}^{Y}\right)^{\beta}\left(Z_{t}^{Y}\right)^{1-\alpha-\beta}
$$

where $K_{t}^{Y}, L_{t}^{Y}$ and $Z_{t}^{Y}$ denote the amounts of physical capital, labor and land employed as input in the $Y$ sector at time $t$, respectively. Total factor productivity (TFP) $B_{t}^{Y}>0$ may increase over time and $\alpha, \beta>0$ denote constant technology parameters that satisfy $\alpha+\beta<1$. Physical capital is broadly defined to include non-residential structures and is only employed in the $Y$ sector. The capital resource constraint is given by $K_{t}^{Y} \leq K_{t}$, where $K_{t}$ denotes the total supply of physical capital in terms of the numeraire good. In equilibrium $K_{t}^{Y}=K_{t}$ will turn out to hold. Given that capital depreciates at rate $\delta^{K} \geq 0$, gross physical capital investment reads as $I_{t}^{K} \equiv \dot{K}_{t}+\delta^{K} K_{t} \cdot{ }^{10} K_{0}$ is given.

\footnotetext{
${ }^{10} \mathrm{~A}$ dot above a variable denotes the partial derivative with respect to time.
} 


\subsubsection{Housing Sector and the Characteristics of Land}

Producing housing services requires to combine activities along the extensive margin, i.e., real estate development in the form of an ex ante investment in the stock of houses, and along the intensive margin, i.e., producing new residential buildings that may depreciate over time. There is free entry into the housing sector. Enlarging the stock of houses along the extensive margin requires additional parcels of land which are being incorporated into the newly built houses. Real estate development inevitably implies that land is withdrawn from the alternative use in the $Y$ sector.

Real Estate Development (Extensive Margin) The "number" of houses (housing projects) at time $t$ is denoted by $N_{t}$, a real number. This variable captures the extensive margin of the housing stock. Increasing $N_{t}$ requires to purchase land (associated with a building permit) and to incur adjustment costs in terms of the numeraire good (e.g., private infrastructure investment). The number of land units that must be put underneath each house is given by $\psi>0 .{ }^{11}$ Total land usage in the housing sector is given by $Z_{t}^{N} \equiv \psi N_{t}$. The resource constraint reads as $Z_{t}^{N}+Z_{t}^{Y} \leq Z$, implying that the alternative use of land in the $Y$ sector is limited by $Z_{t}^{Y} \leq Z_{t}-\psi N_{t}$. Land input in the $Y$ sector, $Z_{t}^{Y}$, can increase at some point in time $t$ if the stock of houses decreases $\left(\dot{N}_{t}<0\right)$.

There are also adjustment costs in terms of the numeraire good, capturing infrastructure investment, that are convex in the change of the number of housing projects, $\dot{N}_{t}$. Let $P_{t}^{Z}$ denote the price per unit of land. The $\operatorname{costs} \mathcal{C}\left(\tilde{I}_{t}^{N}, P_{t}^{Z}\right)$ of increasing the number of houses at time $t$ by

$$
\dot{N}_{t}=\tilde{I}_{t}^{N}
$$

amounts to

$$
\mathcal{C}\left(\tilde{I}_{t}^{N}, P_{t}^{Z}\right)=\psi P_{t}^{Z} \tilde{I}_{t}^{N}+\frac{\xi}{2}\left(\tilde{I}_{t}^{N}\right)^{2}
$$

$\xi>0$. Notice that $\tilde{I}_{t}^{N} \lesseqgtr 0$ depending on whether $\dot{N}_{t} \lesseqgtr 0$. Adjustment costs are given by $\frac{\xi}{2}\left(\tilde{I}_{t}^{N}\right)^{2} \equiv I_{t}^{N}$. The convex adjustment cost component makes $N_{t}$ a state variable.

\footnotetext{
${ }^{11}$ We abstract from heterogeneity of real estates. This feature greatly simplifies the analysis as we do not have to keep track of the history of houses. It is furthermore clearly indicated as we are not interested in the size distribution of firms in the housing sector.
} 
If we assumed that $\xi=0$, then $N_{t}$ would turn into a jump variable which appears economically less plausible. Investment $\operatorname{costs} \mathcal{C}$ for real estate development are financed by issuing equity and are eventually covered by the profit stream of new housing projects. The stock market valuation of the typical housing project at time $t$ is denoted by $q_{t}^{N}$. $N_{0}$ is given.

As will become apparent, the land requirement per house, as measured by parameter $\psi$, does not affect the long run wealth-to-income ratios. ${ }^{12}$ The distinction between the enlargement of the housing stock along the extensive margin (which requires a fixed amount of land) and the intensive margin (which does not require land) allows us to treat the total available amount of land as fixed (Premise 1 - land endowment) despite continuous depreciation of the housing stock (along the intensive margin). This feature provides a key advantage vis-à-vis the canonical approach that is important when it comes to the analysis of the long run evolution, as explained in detail in Section 5.

Land that has not been used in the process of real estate development is devoted to the alternative land use (land area $Z^{Y}$ ), such as office space and land devoted to goods production, including agriculture, manufacturing (except construction), and services (except housing).

Construction and Housing Services (Intensive Margin) Producing housing services requires to combine a developed real estate with residential buildings (structures). At the microeconomic level, the developed real estate represents the fixed input, whereas structures represent the variable input in the production of housing services. As it becomes increasingly difficult to build houses upwards, it appears natural to assume that the production of housing services, at the level of single housing project, is characterized by decreasing returns to scale. Let $x_{t}$ denote the amount of structures per housing project at time $t$. An amount $x_{t}$ of structures produces housing services $h_{t}$ per house according to

$$
h_{t}=B_{t}^{h}\left(x_{t}\right)^{\gamma}
$$

\footnotetext{
${ }^{12}$ We show in the Online-Appendix $\mathrm{A}$ that $\psi$ also does not affect the labor share in total income, the economy's savings rate and the factor allocation in the long run.
} 
$0<\gamma<1$, where $B_{t}^{h}>0$ is a (possibly time-variant) productivity parameter. Total supply of housing services is $N_{t} h_{t}$. There are two admissible institutional settings describing the relationship between housing services producers and real estate developers. First, both activities are organized within the same firm. Second, housing services producers buy real estates from real estate developers at the price $q_{t}^{N}$ that, in equilibrium, equals the present value of future profits accruing from a housing project.

There is a representative construction firm producing structures that are rented out to the housing services producers. It combines materials $M_{t}$ and labor $L_{t}^{X}$ according to a constant-returns-to-scale technology. We assume that the production of one unit of construction materials (e.g., cement) requires $p_{t}^{M}$ units of final output at time $t$. That is, the extraction of construction material is implicitly assumed to require capital, labor, and land with a similar technology as in the numeraire good sector. Technological progress in the use of materials means a decrease in $p_{t}^{M}$ or an increase in $B_{t}^{M} \equiv 1 / p_{t}^{M}$. Let $\delta^{X}>0$ denote the depreciation rate of structures (residential buildings) and

$$
I_{t}^{X}=B_{t}^{X}\left(M_{t}\right)^{\eta}\left(L_{t}^{X}\right)^{1-\eta}
$$

gross investment in structures, $0<\eta<1$, where $B_{t}^{X}>0$ is a (possibly time-variant) productivity parameter. The total stock of residential structures, denoted by $X_{t}$, therefore evolves according to

$$
\dot{X}_{t}=I_{t}^{X}-\delta^{X} X_{t}=B_{t}^{X}\left(M_{t}\right)^{\eta}\left(L_{t}^{X}\right)^{1-\eta}-\delta^{X} X_{t},
$$

with $X_{0}$ being given. The overall stock of cumulated residential buildings, $X_{t}$, cannot exceed the amount of residential buildings that is employed by all housing services firms, i.e., $N_{t} x_{t} \leq X_{t}$. 


\subsubsection{Households}

Preferences and Non-accumulable Endowments There is an infinitely living, representative household with intertemporal utility

$$
U=\int_{0}^{\infty}\left(\log C_{t}+\theta \log S_{t}\right) e^{-\rho t} \mathrm{~d} t
$$

where $C_{t}$ and $S_{t}$ denote total consumption of the numeraire good and housing services at time $t$, respectively, $\rho>0$ is the subjective discount rate, and $\theta>0$ indicates the relative preference for housing services. ${ }^{13}$

The household inelastically supplies the remaining land, not (yet) purchased by the housing sector, to the numeraire good sector. Initially, with total land size $Z$, these are $Z_{0}^{Y}=Z-\psi N_{0}>0$ units of land. Households also supply inelastically $L_{t}$ units of labor at time $t$ to a perfect labor market. The labor resource constraint is $L_{t}^{X}+L_{t}^{Y} \leq L_{t}$. We allow $L_{t}$ to increase temporarily and assume that it remains constant in the long run.

Assets, Taxes, and Intertemporal Budget Constraint Households own the entire stock of financial assets, consisting of bonds that provide firms in the numeraire sector with physical capital $\left(K_{t}\right)$, shares issued by housing services firms $\left(q_{t}^{N} N_{t}\right)$, and ownership claims on construction firms $\left(q_{t}^{X} X_{t}\right)$, where $q_{t}^{X}$ denotes the shadow price per unit of $X$ associated with constraint (6). The total asset holding, $A_{t}$, of the representative individual is thus given by

$$
A_{t}=K_{t}+q_{t}^{N} N_{t}+q_{t}^{X} X_{t}
$$

Although initial values of stocks $K_{0}, N_{0}$ and $X_{0}$ are given, total initial asset holding, $A_{0}$, is endogenous because asset prices $q_{0}^{N}$ and $q_{0}^{X}$ are endogenous.

To enable a careful model calibration, it is important to account for capital income taxation. The reason is that a tax on capital income affects the rate at which the

\footnotetext{
${ }^{13}$ The instantaneous utility function is a (monotonic transformation of a) linearly homogenous function, preferences are homothetic. There exists a (positive and normative) representative consumer who owns the aggregate wealth and articulates the aggregate demand functions (e.g. Mas-Colell, Whinston and Green 1995, Chapter 4). Consequently, the individual distribution of assets and land does not play a role for the evolution of aggregates. The model can be employed to investigate the personal income distribution in addition to the functional income distribution along the lines of Caselli and Ventura (2000).
} 
profit stream of firms and land returns are discounted. We assume that both capital income and returns from land ownership are taxed at the constant rate $\tau_{r}$, whereas labor income is taxed at the constant tax rate $\tau_{w}$. For simplicity, we do not model government consumption or public investment and assume that the tax revenue is redistributed lump sum to households.

Let $w_{t}, r_{t}, R_{t}^{Z}, p_{t}$, and $T_{t}$ denote the wage rate, the interest rate, the rental rate of land, the (relative) price per unit of housing services, and the lump-sum transfer at time $t$, respectively. The intertemporal household budget constraint may then be expressed as

$$
\dot{A}_{t}=\left(1-\tau_{r}\right)\left(r_{t} A_{t}+R_{t}^{Z} Z_{t}^{Y}\right)+\left(1-\tau_{w}\right) w_{t} L_{t}-C_{t}-p_{t} S_{t}+T_{t},
$$

where the value of initial assets is given by $A_{0}=K_{0}+q_{0}^{N} N_{0}+q_{0}^{X} X_{0}$.

\section{Equilibrium Analysis}

This section highlights important equilibrium implications that result from the decisions of firms in the housing sector, defines the general equilibrium and characterizes the economy's steady state.

\subsection{Decisions in the Housing Sector and Asset Prices}

Let the rental rate of structures at time $t$ be denoted by $R_{t}^{X}$. The instantaneous profit resulting from a housing project on a developed real estate that accrues to housing services producers, noting production function (4), depends on the amount of employed structures and is given by $\pi_{t} \equiv p_{t} B_{t}^{h}\left(x_{t}\right)^{\gamma}-R_{t}^{X} x_{t}$. The necessary first order condition for profit maximization yields the inverse demand schedule for structures per house

$$
R_{t}^{X}=p_{t} B_{t}^{h} \gamma\left(x_{t}\right)^{\gamma-1},
$$

implying positive profits that amount to

$$
\pi_{t}=(1-\gamma) p_{t} B_{t}^{h}\left(x_{t}\right)^{\gamma}
$$


At time $t$, the representative real estate developer maximizes the present discounted value (PDV) of housing services producers' profit stream, $N \pi$, minus real estate development costs, $\mathcal{C}$, i.e. solves

$$
\max _{\left\{\tilde{I}_{s}^{N}\right\}_{s=t}^{\infty}} \int_{t}^{\infty}\left(\pi_{s} N_{s}-\mathcal{C}\left(\tilde{I}_{s}^{N} ; P_{s}^{Z}\right)\right) e^{\int_{t}^{s}-r_{v} \mathrm{~d} v} \mathrm{~d} s \quad \text { s.t. } \quad \dot{N}_{s}=\tilde{I}_{s}^{N},(3), N_{0} \geq 0 \text { given. }
$$

The shadow price per house associated with constraint (2) is equal to the stock market evaluation of a real estate, $q_{t}^{N}$.

Lemma 1 The stock of houses and the stock market valuation of a real estate evolve according to

$$
\begin{gathered}
\dot{N}_{t}=\frac{q_{t}^{N}-\psi P_{t}^{Z}}{\xi}, \\
\frac{\dot{q}_{t}^{N}}{q_{t}^{N}}+\frac{\pi_{t}}{q_{t}^{N}}=r_{t} .
\end{gathered}
$$

All formal results are proven in the Appendix. According to (13), if the value of a housing project is sufficiently large relative to the land price (i.e. if $q_{t}^{N} / P_{t}^{Z}>\psi$ ), the number of houses is being enlarged, i.e., $\dot{N}_{t}>0$. The no-arbitrage condition (14) says that the sum of the growth rate in the share price (capital gains) and the dividend per share paid to the owners of real estate firms must equal the rate of return to bonds. In equilibrium, households are indifferent between investing in housing projects or purchasing bonds. ${ }^{14}$ Ruling out bubbles by imposing an appropriate endpoint condition, the stock market valuation of a real estate is given by the PDV of the profit stream:

$$
q_{t}^{N}=\int_{t}^{\infty} \pi_{s} e^{\int_{t}^{s}-r_{v} \mathrm{~d} v} \mathrm{~d} s
$$

Construction firms rent the entire stock of structures to housing services producers by charging $R_{t}^{X}$ per unit of structures. The representative construction firm maximizes the PDV of the cash flow, defined as the difference between rental income $R^{X} X$ and the costs of gross investment, $p^{M} M+w L^{X}$. That is, the representative construction firm

\footnotetext{
${ }^{14}$ Since all kinds of capital income are taxed at the same rate, $\tau_{r}$ does not enter (14).
} 
solves

$$
\max _{\left\{M_{s}, L_{s}^{X}\right\}_{s=t}^{\infty}} \int_{t}^{\infty}\left(R_{s}^{X} X_{s}-p_{s}^{M} M_{s}-w_{s} L_{s}^{X}\right) e^{\int_{t}^{s}-r_{v} \mathrm{~d} v} \mathrm{~d} s \quad \text { s.t. } \quad(6), X_{0} \geq 0 \text { given. }
$$

The equilibrium rate of return of one unit of residential buildings is then described by

Lemma 2 The shadow price per unit of structures evolves according to

$$
\frac{\dot{q}_{t}^{X}}{q_{t}^{X}}+\frac{R_{t}^{X}}{q_{t}^{X}}-\delta^{X}=r_{t} .
$$

Ruling out bubbles by imposing an appropriate endpoint condition, the value of one unit of $X$ equals the PDV of future rental returns, accounting for the depreciation rate $\delta^{X}$ of structures, i.e.,

$$
q_{t}^{X}=\int_{t}^{\infty} R_{s}^{X} e^{\int_{t}^{s}-\left(r_{v}+\delta^{X}\right) \mathrm{d} v} \mathrm{~d} s
$$

Due to the constant returns to scale technology (5) and perfectly competitive markets, the value of total gross output in the construction sector must equal the total factor costs in construction, i.e.,

$$
q_{t}^{X} I_{t}^{X}=p_{t}^{M} M_{t}+w_{t} L_{t}^{X}
$$

Finally, the price of land, $P_{t}^{Z}$, equals the PDV of income from renting one unit of land to the producers in the $Y$ sector. It reads as $P_{t}^{Z}=\int_{t}^{\infty} R_{\tau}^{Z} e^{\int_{t}^{s}-r_{v} \mathrm{~d} v} \mathrm{~d} s$, implying that the following no-arbitrage condition must hold

$$
\frac{\dot{P}_{t}^{Z}}{P_{t}^{Z}}+\frac{R_{t}^{Z}}{P_{t}^{Z}}=r_{t} .
$$

The house price is conceptualized as the sum of the value of a housing project $\left(q_{t}^{N}\right)$ and the value of the employed structure associated with a real estate (valued at $q_{t}^{X} x_{t}$ ), i.e.,

$$
P_{t}^{H} \equiv q_{t}^{N}+q_{t}^{X} x_{t}
$$




\subsection{Definition of Equilibrium}

Definition 1. A general equilibrium is a sequence of quantities, a sequence of prices, and a sequence of operating profits of housing services producers

$$
\begin{gathered}
\left\{Y_{t}, K_{t}^{Y}, X_{t}, N_{t}, x_{t}, h_{t}, M_{t}, L_{t}^{Y}, L_{t}^{X}, Z_{t}^{Y}, C_{t}, S_{t}, A_{t}\right\}_{t=0}^{\infty}, \\
\left\{p_{t}, P_{t}^{Z}, q_{t}^{N}, q_{t}^{X}, w_{t}, r_{t}, R_{t}^{Z}, R_{t}^{X}\right\}_{t=0}^{\infty},\left\{\pi_{t}\right\}_{t=0}^{\infty}
\end{gathered}
$$

for initial conditions $K_{0}>0, N_{0}>0, X_{0}>0$, such that

1. the representative individual maximizes lifetime utility, i.e. solves

$$
\max _{\left\{C_{t}, S_{t}\right\}_{t=0}^{\infty}} \int_{0}^{\infty}\left(\log C_{t}+\theta \log S_{t}\right) e^{-\rho t} \mathrm{~d} t \quad \text { s.t. }(9), \lim _{t \rightarrow \infty} A_{t} \exp \left(-\int_{0}^{t}\left(1-\tau_{r}\right) r_{s} \mathrm{~d} s\right) \geq 0 ;
$$

2. the representative firm in the numeraire goods $(Y)$ sector maximizes profits taking factor prices as given (i.e., factor prices equal marginal products);

3. the representative real estate developer solves profit maximization problem (12), taking the sequence of land prices $\left\{P_{t}^{Z}\right\}_{t=0}^{\infty}$ as given;

4. housing services producers maximize profits at each time $t$, taking the price of housing services, $p_{t}$, and the rental rate of structures, $R_{t}^{X}$, as given;

5. the representative firm in the construction $(X-)$ sector solves profit maximization problem (16), taking the sequences of rental rate of structures $\left\{R_{t}^{X}\right\}_{t=0}^{\infty}$ and wage rates $\left\{w_{t}\right\}_{t=0}^{\infty}$ as given;

6. there are no arbitrage possibilities to use land, i.e. (20) holds;

7. the bond market, the land market, the market for structures, and the land market clear at any $t$, i.e.,

$$
\begin{aligned}
K_{t}^{Y} & =K_{t}, \\
Z_{t}^{Y} & =Z-\psi N_{t}, \\
N_{t} x_{t} & =X_{t}, \\
L_{t}^{X}+L_{t}^{Y} & =L_{t} ;
\end{aligned}
$$

8. the financial asset market clears at any $t$, i.e. (8) holds;

9. the market for housing services clears at any $t$, i.e.,

$$
S_{t}=N_{t} h_{t}=N_{t} B^{h}\left(x_{t}\right)^{\gamma}
$$


10. the market for the numeraire good clears at any $t$, i.e. ${ }^{15}$

$$
Y_{t}=C_{t}+I_{t}^{K}+I_{t}^{N}+p_{t}^{M} M_{t}
$$

\subsection{Aggregate Income and Wealth-to-Income Ratios}

The gross domestic product $(G D P)$ is given by the value of total consumption, $C_{t}+p_{t} S_{t}$, plus the value of total investment, $I_{t}^{K}+I_{t}^{N}+q_{t}^{X} I_{t}^{X}$, i.e.,

$$
G D P_{t} \equiv C_{t}+p_{t} S_{t}+I_{t}^{K}+I_{t}^{N}+q_{t}^{X} I_{t}^{X}
$$

Using (19), (27) and (28) gives us

$$
G D P_{t}=Y_{t}+p_{t} N_{t} h_{t}+w_{t} L_{t}^{X}
$$

The net domestic product $(N D P)$ equals GDP net of depreciation,

$$
N D P_{t} \equiv G D P_{t}-\delta^{K} K_{t}-\delta^{X} q_{t}^{X} X_{t}
$$

Total private wealth, $W_{t}$, is the sum of asset holdings, $A_{t}$, and the value of nonresidential land $P_{t}^{Z} Z_{t}^{Y}$, i.e., $W_{t} \equiv A_{t}+P_{t}^{Z} Z_{t}^{Y}$. Noting (8) and (21) total private wealth may be expressed as

$$
W_{t}=P_{t}^{H} N_{t}+K_{t}+P_{t}^{Z} Z_{t}^{Y}
$$

where $P_{t}^{H} N_{t}$ (the house price times the number of houses) represents housing capital and $K_{t}+P_{t}^{Z} Z_{t}^{Y}$ captures non-residential wealth.

We now define wealth-to-income ratios. We use fraktur (or Gothic) scripture with superscript GDP and NDP to denote wealth-to-GDP and wealth-to-NDP ratios, respectively. Piketty (2014) and Piketty and Zucman (2014a, 2014b, 2015) report wealth-to-

\footnotetext{
${ }^{15}$ Equilibrium condition 10 is redundant, according to Walras' law. To exclude conceptual or calculation errors, we prove, in Online-Appendix A.2, that the long run equilibrium derived from conditions 1-9 fulfills condition 10. Online-Appendix A.1 summarizes the dynamic system.
} 
NDP ratios, as we do in Figure 1.

The housing wealth-to-GDP ratio is denoted by $\mathfrak{H}_{t}^{G D P}$ (speak "fraktur $H^{\prime \prime}$ ) and may be expressed as

$$
\mathfrak{H}_{t}^{G D P} \equiv \frac{P_{t}^{H} N_{t}}{G D P_{t}}=\frac{q_{t}^{N} N_{t}+q_{t}^{X} X_{t}}{G D P_{t}}=\frac{A_{t}-K_{t}}{G D P_{t}} .
$$

The non-residential wealth-to-GDP ratio, denoted by $\mathfrak{N}_{t}^{G D P}$, is the sum of the ratio of physical capital to GDP, $\mathfrak{K}_{t}^{G D P} \equiv K_{t} / G D P_{t}$, and the ratio of the value of non-residential land (farm land and other productive, non-residential land property) to GDP ("nonresidential land wealth-to-GDP ratio"), $\mathfrak{Z}_{t}^{G D P} \equiv P_{t}^{Z} Z_{t}^{Y} / G D P_{t}$, i.e.,

$$
\mathfrak{N}_{t}^{G D P} \equiv \frac{K_{t}+P_{t}^{Z} Z_{t}^{Y}}{G D P_{t}}=\mathfrak{K}_{t}^{G D P}+\mathfrak{Z}_{t}^{G D P}
$$

The total (private) wealth-to-GDP ratio, $\mathfrak{W}_{t}^{G D P}$, reads as

$$
\mathfrak{W}_{t}^{G D P} \equiv \frac{W_{t}}{G D P_{t}}=\mathfrak{H}_{t}^{G D P}+\mathfrak{N}_{t}^{G D P}
$$

To calculate wealth-to-NDP ratios from wealth-to-GDP ratios, we divide $\mathfrak{H}_{t}^{G D P}, \mathfrak{K}_{t}^{G D P}$, $\mathfrak{Z}_{t}^{G D P}, \mathfrak{N}_{t}^{G D P}, \mathfrak{W}_{t}^{G D P}$ by the ratio of net income to gross income ("NDP-to-GDP ratio"), $\iota_{t} \equiv N D P_{t} / G D P_{t}$. We denote wealth-to-NDP ratios by $\mathfrak{H}_{t}^{N D P} \equiv \mathfrak{H}_{t}^{G D P} / \iota_{t}, \mathfrak{K}_{t}^{N D P} \equiv$ $\mathfrak{K}_{t}^{G D P} / \iota_{t}, \mathfrak{Z}_{t}^{N D P} \equiv \mathfrak{Z}_{t}^{G D P} / \iota_{t}, \mathfrak{N}_{t}^{N D P} \equiv \mathfrak{N}_{t}^{G D P} / \iota_{t}, \mathfrak{W}_{t}^{N D P} \equiv \mathfrak{W}_{t}^{G D P} / \iota_{t}$.

\subsection{Long Run Equilibrium}

We now derive analytical results for the long run equilibrium. Denote population density at time $t$ as $D_{t} \equiv L_{t} / Z$, which is supposed to be time-invariant in the long run. Also suppose the vector of productivity parameters, $\mathbf{B}_{t} \equiv\left(B_{t}^{Y}, B_{t}^{h}, B_{t}^{X}, B_{t}^{M}\right)$, does not change in the long run. ${ }^{16}$ In this case, any long run equilibrium is characterized by zero growth rates of all stock variables. Superscript $(*)$ denotes long run equilibrium values.

\footnotetext{
${ }^{16}$ Population size and sectoral productivities may, however, grow for an arbitrary long period of time.
} 
Proposition 1. (Existence) Suppose that

$$
\varrho \equiv \frac{\beta}{1-\alpha}-\frac{\gamma(1-\eta)}{1-\gamma \eta}>0
$$

holds. Then there exists a unique, non-trivial long run equilibrium in which

$$
\frac{L^{Y *}}{Z^{Y *}}>D
$$

Assumption (A1) holds for any reasonable calibration of the model. The allocation of labor and land is characterized by fractions $l^{X} \equiv L^{X} / L, l^{Y} \equiv L^{Y} / L, \mathfrak{z}^{N} \equiv Z^{N} / Z$, and $\mathfrak{z}^{Y} \equiv Z^{Y} / Z$. Equilibrium property (36) is equivalent to $\mathfrak{z}^{Y *}<l^{Y *}$ and $\mathfrak{z}^{N *}>l^{X *}$. The share of land devoted to the housing sector, $\mathfrak{z}^{N}$, exceeds the share of labor devoted to the housing sector, $l^{X *}$, whereas the opposite holds in the rest of the economy. The housing sector is endogenously land-intensive, whereas the rest of the economy is labor-intensive.

Proposition 2. (Prices). Under (A1), in long run equilibrium,

(i) the price for housing services, $p^{*}$, is decreasing in $B^{X}, B^{h}, B^{M}$, and increasing in both $D$ and $B^{Y}$;

(ii) the wage rate, $w^{*}$, is decreasing in $D$, independent of $B^{X}, B^{h}, B^{M}$, and increasing in $B^{Y}$;

(iii) the return to land, $R^{Z *}$, the land price, $P^{Z *}$, and the house price, $P^{H *}$, are increasing in both $D$ and $B^{Y}$, and independent of $B^{X}, B^{h}, B^{M}$;

(iv) the long run interest rate reads as

$$
r^{*}=\frac{\rho}{1-\tau_{r}}
$$

An increase in population density, $D$, means that labor becomes more abundant and land becomes scarcer, in turn lowering the wage rate and raising both the return per unit of land and its price. Consequently, since the housing sector is land-intensive, the price for housing services rises with $D$. An increase in TFP of the $Y$ sector, $B^{Y}$, raises output 
of the numeraire good for a given factor allocation, thus increasing the relative long run price for housing services, $p^{*}$. It also transmits into higher (long run) factor returns, $w^{*}$, $R^{Z *}$, like in standard one-sector models. Higher productivity parameters in the housing sector (increase in $B^{X}, B^{h}$, or $B^{M}$ ) lower the price of housing services. While the direct effects of productivity improvements on the long run wage rate, $w^{*}$, are positive, there is a counteracting and balancing effect on the value of the marginal product of labor in the construction sector through a decrease in the price for housing services. Thus, $w^{*}$ as well as the long run return to land, $R^{Z *}$, remain unchanged. In the long run, the land price and the house price change proportionally to the rental rate of land, $R^{Z *}$, when population density or TFP parameters change. Finally, the Keynes-Ramsey rule implies that the long run after-tax interest rate equals the subjective discount rate, $\left(1-\tau_{r}\right) r^{*}=\rho$.

Proposition 3. (Wealth-to-GDP ratios and NDP-to-GDP ratio). Under (A1), in long run equilibrium, the housing wealth-to-GDP ratio is

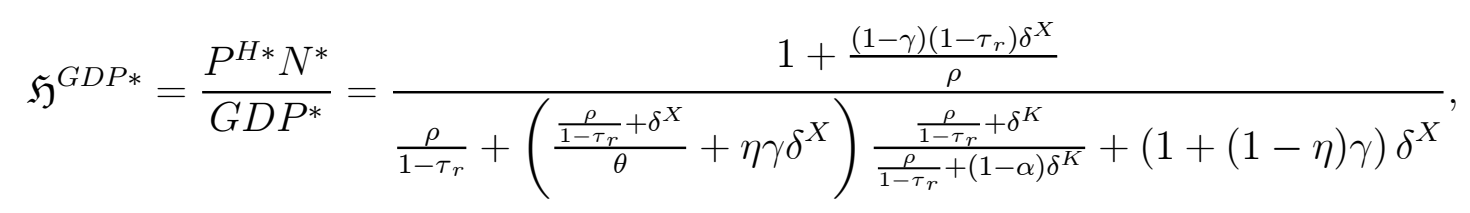

the physical-capital-to-GDP ratio is

$\mathfrak{K}^{G D P *}=\frac{K^{*}}{G D P^{*}}=\alpha\left(\frac{\rho}{1-\tau_{r}}+\delta^{K}+\frac{\left(\frac{\rho}{1-\tau_{r}}+\delta^{X}(1+(1-\eta) \gamma)\right)\left(\frac{\rho}{1-\tau_{r}}+(1-\alpha) \delta^{K}\right)}{\frac{\rho}{\frac{1-\tau_{r}}{\theta}+\delta^{X}}+\eta \gamma \delta^{X}}\right)^{-1}$,

the non-residential land wealth-to-GDP ratio is

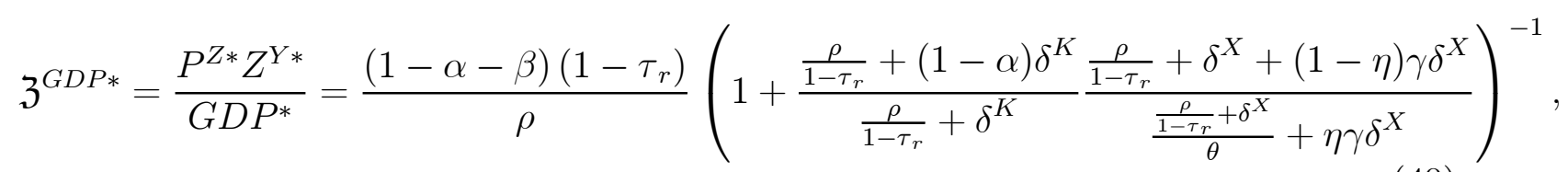


and the NDP-to-GDP ratio is

$$
\iota^{*} \equiv \frac{N D P^{*}}{G D P^{*}}=\frac{1+\frac{1}{\theta}}{1+\frac{\left(\frac{1}{\theta}+\frac{\eta \gamma \delta^{X}}{1-\tau_{r}+\delta^{X}}\right)\left(\frac{\rho}{1-\tau_{r}}+\delta^{K}\right)}{\frac{\rho}{1-\tau_{r}}+(1-\alpha) \delta^{K}}+\frac{(1-\eta) \gamma \delta^{X}}{\frac{\rho}{1-\tau_{r}}+\delta^{X}}} .
$$

Thus, $\mathfrak{H}^{G D P *}, \mathfrak{K}^{G D P *}, \mathfrak{Z}^{G D P *}$, and $\iota^{*}$ are independent of $D, \mathbf{B}, \psi$.

Corollary 1. Under (A1), in long run equilibrium, the non-residential wealth-to-GDP ratio, $\mathfrak{N}^{G D P *}=\mathfrak{K}^{G D P *}+\mathfrak{Z}^{G D P *}$, the total wealth-to-GDP ratio, $\mathfrak{W}^{G D P *}=\mathfrak{H}^{G D P *}+\mathfrak{N}^{G D P *}$, and wealth-to-NDP ratios $\mathfrak{H}^{N D P *}, \mathfrak{K}^{N D P *}, \mathfrak{Z}^{N D P *}, \mathfrak{N}^{N D P *}, \mathfrak{W}^{N D P *}$ are independent of $D, \mathbf{B}, \psi$.

Proposition 3 and Corollary 1 reflect that the long run factor allocation is independent of population density, $D$, and technology parameters, B and $\psi$. An increase in population density, $D$, changes the marginal product of labor and the return to land equally in the housing sector and the $Y$ sector, leaving the factor allocation unchanged. Moreover, reflecting homothetic preferences, changes in technological parameters $\mathbf{B}$ and $\psi$ do not induce structural change and leave the factor allocation unaffected as well. ${ }^{17}$

Remark 1. The steady state results reported above are conditional on the assumption that the productivity parameters $\mathbf{B}_{t} \equiv\left(B_{t}^{Y}, B_{t}^{h}, B_{t}^{X}, B_{t}^{M}\right)$ do not grow in the long run. They may, nonetheless, grow for an arbitrary long period of time. In fact, the numerical experiment, described in Section 4, assumes that productivities $B^{Y}$ and $B^{X}$ increase temporarily and this exogenous technical change extends over centuries. One could, alternatively, allow for permanent exponential growth of $B^{Y}$ and $B^{X}$. In this case, a steady state does still exist, given that a specific steady state condition is satisfied, as is typical for multi-sector growth models. The results in Proposition 3 and Corollary 1, namely the existence of finite wealth-to-income ratios in the long run that are independent

\footnotetext{
${ }^{17}$ That the long run land allocation is unaffected by population density means that more structures are built per unit of land. That is, houses are "higher" rather than more numerous in more densely populated and in more advanced regions, reflecting the opportunity costs of land in its alternative use in the $Y$-sector. See Proposition A.1 in Online-Appendix A.3.
} 
of TFP-levels, would still hold.

By calibrating the model, we are able to quantify the long run wealth-to-income ratios, as discussed by Piketty (2014) and Piketty and Zucman (2014a, 2015), from a unifying theoretical model of different wealth components.

\section{Numerical Analysis}

The House Capital Model is evaluated numerically. Subsection 4.1 describes the calibration strategy and documents the data sources. Subsection 4.2 reports the quantitative long run wealth-to-income ratios. ${ }^{18}$ Subsection 4.3 describes the evolution of housing wealth (relative to NDP) and non-residential wealth (relative to NDP) as well as the evolution of land prices and house prices.

\subsection{Calibration}

The set of country specific parameters comprises the capital income tax rate, $\tau_{r}$, and the initial conditions, $K_{0}, N_{0}$ and $X_{0}$. The set of country-specific, exogenous, time-varying variables comprises the population density, $D_{t}$, and TFP parameters, $B_{t}^{Y}$ and $B_{t}^{X}$. The remaining parameters are viewed as being general and set to match the relevant empirical characteristics of the US economy. The calibration strategy does not assume that the US currently is in long run equilibrium.

Optimal household decisions imply that, at any time $t$, the marginal rate of substitution between the two consumption goods equals the relative price, $p=\theta C / S$ (see the proof of Proposition 1). Data on housing expenditures for the US indicate that the ratio of households' housing expenditures to total consumption expenditures,

$$
\frac{p S}{C+p S}=\frac{\theta}{1+\theta}
$$

\footnotetext{
${ }^{18}$ As side products, we obtain the long run values of income shares, sectoral allocation shares for labor and land, and investment rates. These are reported in the Online-Appendix A.4, Table A.1.
} 
is quite stable over time for the period 1960-2012 and equals, on average, about 18 percent (Knoll et al., 2014). The value is very close to the average values for the UK, France and Germany. Setting the expression in (42) to 0.18 suggests $\theta=0.22$.

We next turn to depreciation rates $\left(\delta^{X}\right.$ and $\left.\delta^{K}\right)$. For the housing sector (residential structures), Hornstein (2009, p. 13) suggests, by referring to data from the US Bureau of Economic Analysis (2004), that $\delta^{X}=0.015$. The depreciation rate of physical capital, $\delta^{K}$, can be inferred from the definition of gross investment in physical capital, $I^{K}=\dot{K}+\delta^{K} K$, i.e.,

$$
\delta^{K}=\frac{I^{K}}{K}-\frac{\dot{K}}{K}
$$

We assume that, off-steady state, physical capital investment is 10 percent of the physical capital stock, $I^{K} / K=0.1 .^{19}$ Assuming that the average annual growth rate of physical capital, $\dot{K} / K$, was about three percent (the sum of the long term GDP per capita growth rate of two percent and the population growth rate of one percent), we arrive at $\delta^{K}=0.07$, according to $(43) .^{20}$

Turning to concavity parameters of production function in the $Y$ sector, we start by noting that $\beta$ equals, in equilibrium, the expenditure share for labor in the $Y$ sector, i.e., $\beta=w L^{Y} / Y$; see (67) in Appendix. Define $H \equiv p N h+w L^{X}$ as the contribution of the housing sector (housing services and residential construction) to GDP. According to (30), we can thus write $G D P=Y+H$. Using $L^{Y} / L=1-l^{X}, Y=G D P-H$, and denoting the labor share in GDP by $\mathfrak{L} \equiv w L / G D P$, we get

$$
\beta=\frac{\left(1-l^{X}\right) \mathfrak{L}}{1-\frac{H}{G D P}} .
$$

\footnotetext{
${ }^{19}$ The average ratio of US non-residential investment to GDP for the period 1969-2014 amounts to 12.6 percent (Bureau of Economic Analysis, 2015c, Tab. 1.1.10), with little variation over time. Consequently, suppose $\mathfrak{s}^{K} \equiv I^{K} / G D P=0.126$. According to Piketty and Zucman (2014b, Tab. US.6c), in the US, the non-residential wealth-to-NDP ratio was $\mathfrak{N}^{N D P} \approx 2$ (e.g. in the period 1960-2010, 1970-2010 or 1980-2010). Unfortunately, the data does not allow us to decompose non-residential wealth into physical capital and land. Accounting for depreciation, it is reasonable to assume that the physical capitalto-GDP ratio, $\mathfrak{K}^{G D P}<\mathfrak{K}^{N D P}=\mathfrak{N}^{N D P}-\mathfrak{Z}^{N D P}$, is somewhere between $100-150$ percent. Assuming $\mathfrak{K}^{G D P}=1.26$, we arrive at $I^{K} / K=\mathfrak{s}^{K} / \mathfrak{K}^{G D P}=0.1$.

${ }^{20}$ The value also seems reasonable according to the evidence on depreciation rates for 36 manufacturing sectors, reported in House and Shapiro (2008).
} 
According to Bureau of Economic Analysis (2015a), the average value-added of housing and (residential and non-residential) construction as percentage of GDP in the period 1998-2001 (prior to the housing boom) in the US was, on average, 9.1 percent and 4.4 percent, respectively. With respect to the second component, we approximate the valueadded of residential construction as fraction of GDP, in line with our model. The ratio of residential to total investment in structures during 1998-2001 was 61 percent (calculated from Bureau of Economic Analysis, 2015b), which gives us a value-added of residential construction relative to GDP, $q^{X} I^{X} / G D P$, of $0.61 \times 4.4=2.7$ percent. Thus, we set $H / G D P$ to $9.1+2.7 \approx 12$ percent. According to Henderson (2015, Tab. 2.1), the US employment share in construction decreased from 4.8 percent in 2004 to 4.1 percent in 2014. Taking an intermediate value of 4.5 percent and multiplying it by the fraction of residential investment in total investment in structures (61 percent), we arrive at $l^{X}=0.045 \times 0.61=0.027$. According to Karabarbounis and Neiman $(2014$, "CLS KN merged"), the corporate US labor share in total income was pretty stable in the period 1975-2008, only recently declining in a more pronounced way. The average value for the period 1975-2012 was 62 percent. Using $1-H / G D P=0.88, l^{X}=0.027$ and $\mathfrak{L}=0.62$, we arrive at $\beta=(1-0.027) \times 0.62 / 0.88=0.69$, according to $(44)$.

According to (4), (11) and (27), the ratio of housing services producers' profits to their revenue is $\pi /(p h)=1-\gamma$. Unfortunately, we know little about the profit-to-revenue ratio in the housing services sector. We assume that it is equal to 10 percent, i.e. set $\gamma=0.9$. We checked that our results are rather insensitive with respect to reasonable variations of $\gamma$.

We next address the output elasticity of materials in the construction sector, $\eta$. From the first-order condition with respect to labor in the construction sector (see (62) in Appendix and use (5)), we have $w L^{X}=(1-\eta) q^{X} I^{X}$. Using $w L^{X}=l^{X} \mathfrak{L}^{L} G D P$, we obtain

$$
\eta=1-\frac{w L^{X}}{q^{X} I^{X}}=1-\frac{l^{X} \mathfrak{L}}{q^{X} I^{X} / G D P} .
$$


Recalling $q^{X} I^{X} / G D P=0.027, \mathfrak{L}=0.62$, and $l^{X}=0.027$, we obtain $\eta=0.38 .{ }^{21}$

The long run interest rate, $r^{*}=\frac{\rho}{1-\tau_{r}}$, plays an important role for long run asset prices, including the land price. As the return to equity contains a risk premium and land or firm ownership is at risk (albeit not modelled here explicitly) of expropriation by government action or devaluation because of natural disaster or environmental damage, we shall set the subjective discount rate at a value that is in the middle or at the upper end of the typical range used in calibration exercises. We compare results for $\rho=0.02$ vis-à-vis $\rho=0.03$.

Regarding policy instruments, the tax on wage income is purely redistributive and has no incentive effects. Thus, it does not enter the reduced-form dynamic system (summarized in Online-Appendix A.1). The capital income tax rate is reported in Piketty and Zucman (2014b). It slightly fluctuates over time. Consider average tax rates between 1970-2010, for Germany this gives us $\tau_{r}=0.18$, for France $\tau_{r}=0.19$, and for the US $\tau_{r}=0.22$. The capital tax rate for the UK is not available in Piketty and Zucman (2014b). According to the OECD tax database (2015), the net top statutory dividend tax rate "to be paid at the shareholder level, taking account of all types of reliefs and gross-up provisions at the shareholder level" is similar in the US and the UK. Capital tax rates are thus similar in the four considered countries and around 0.2. As we cannot predict future changes in tax rates, we employ $\tau_{r}=0.2$ for all displayed transitional dynamics.

Finally, we need to specify $\alpha$. We relate to the evidence by Rognlie (2015, Fig. 6), who decomposes the net capital share of corporate sector value-added in the US into the return on equipment, structures, land, and pure profits (time series since 1950). He reports that pure profits fluctuate around zero, whereas the land income share is fluctuating around 0.04. The US corporate sector incorporates the housing sector. Thus, the average land

\footnotetext{
${ }^{21}$ The amount of land per house, $\psi$, does not affect the long run factor allocation, factor prices, wealth-to-income ratios or income shares. For transitional dynamics, we set the arbitrary value of $\psi=1$. Similarly, the parameter that captures the importance of residential land development costs $\xi$ does not have an impact on the long-run equilibrium either. It does, however, impact on the speed of $N$-dynamics along the transition. We set $\xi=100$.
} 
income share (of 0.04) is an average of the land income share in the non-residential sector, $R^{Z} Z^{Y} / Y=1-\alpha-\beta$ (according to (68) in Appendix), and the land income share in the housing sector, $\mathfrak{I} \equiv R^{Z} Z^{N} / H$ (recall that $Y$ is value-added in the non-residential sector and $H=p N h+w L^{X}$ is value-added in the housing sector). Consequently, $\alpha$ is given by

$$
(1-\alpha-\beta)\left(1-\frac{H}{G D P}\right)+\mathfrak{I} \frac{H}{G D P}=0.04
$$

As shown in Online-Appendix A.4, the long run land income share in the housing sector is, for $\gamma=0.9, \eta=0.38, \delta^{X}=0.015$ and $r^{*}=0.36$ (implied by an intermediate value for the subjective discount rate, $\rho=0.025$, and $\tau_{r}=0.3$ ), given by $\mathfrak{I}^{*} \approx 0.1$. Using $\mathfrak{I}=0.1$ together with $\beta=0.69$ and $H / G D P=0.12$ in (46) suggests $\alpha=0.28$.

\subsection{Long Run Implications}

Consistent with Figure 1, and following Piketty (2014) and Piketty and Zucman (2014a, 2014b, 2015), we focus on wealth-to-NDP ratios in the remainder of this paper. Table 1 shows (in percent) long run implications as resulting from the calibrated House Capital Model, assuming alternative subjective discount rates, $\rho$, and capital income tax rates, $\tau_{r} \cdot{ }^{22}$

The annual average of the housing wealth-to-NDP ratio, $\mathfrak{H}^{N D P}$, in the 2000s was 217 percent in the US with a peak of 254 percent in 2006 before the financial crisis. $^{23}$ In the UK, Germany and France, $\mathfrak{H}^{N D P}$ was 271 percent, 217 percent and 285 percent in the 2000s, respectively. The calibrated model under $\tau_{r}=0.2$ implies the long run value, $\mathfrak{H}^{N D P *}$, to be 357 percent for $\rho=0.03$ and 478 percent for $\rho=0.02$. Our analysis thus suggests that, in the longer run, the US housing capital rises considerably above the pre-crisis level if the capital income tax rate remains similar. It also suggests that for the

\footnotetext{
${ }^{22}$ In addition, Table A.1 in Online-Appendix A.4 displays the long run values of income shares $\left(\mathfrak{L}^{*}\right.$, $\left.r^{*} \mathfrak{H}^{*}, r^{*} \mathfrak{N}^{*}\right)$, sectoral allocation variables $\left(l^{X *}, \mathfrak{z}^{N *}\right)$, as well as the total investment rate, $\mathfrak{s}^{*} \equiv\left(I^{K *}+\right.$ $\left.I^{N *}+q^{X *} I^{X *}\right) / G D P^{*}$ and its components $\mathfrak{s}^{K *}=I^{K *} / G D P^{*}$ and $\mathfrak{s}^{H *} \equiv \mathfrak{s}^{*}-\mathfrak{s}^{K *}$.

${ }^{23}$ With respect to stylized facts on wealth-to-income ratios, we again refer to the data provided by Piketty and Zucman (2014b) in the remainder of the paper.
} 
other countries $\mathfrak{H}^{N D P}$ is currently considerably below the long run value $\mathfrak{H}^{N D P *}$.

The implied non-residential wealth-to-NDP ratio is $\mathfrak{N}^{N D P *}=349$ percent for $\rho=0.03$ and to $\mathfrak{N}^{N D P *}=440$ percent for $\rho=0.02$. About three quarters are attributed to physical capital and one quarter to non-residential land wealth. In the 2000s, $\mathfrak{N}^{N D P}$ was 249 percent in the US, 241 percent in the UK, 139 percent in Germany, and 190 percent in France. The implied future increase from current levels partly reflects the growing importance of land scarcity in the process of economic development. However, as discussed in some detail in the next subsection, the fact that we do not distinguish rural and urban land may contribute to an unrealistically high long run non-residential land wealth-to-NDP ratio, $\mathfrak{Z}^{N D P *}$. Without further amendments, if the current tax system remains in place, the implied long run wealth-to-NDP ratio, $\mathfrak{W}^{N D P^{*}}$, is in the range from 706 to 918 percent, depending on the subjective discount rate, $\rho$. The sensitivity of long run wealth-to-GDP ratios to $\rho$ is rooted in the fact that the PDV of asset values, particularly land that does not depreciate, is heavily dependent on the rate at which future returns are discounted.

\begin{tabular}{|c|c||c|c|c|c|c|c|c|c|}
\hline$\rho$ & $\tau_{r}$ & $\mathfrak{H}^{N D P *}$ & $\mathfrak{K}^{N D P *}$ & $\mathfrak{Z}^{N D P *}$ & $\overline{\mathfrak{Z}}^{N D P *}$ & $\mathfrak{N}^{N D P *}$ & $\overline{\mathfrak{N}}^{N D P *}$ & $\mathfrak{W}^{N D P *}$ & $\overline{\mathfrak{W}}^{N D P *}$ \\
\hline \hline 0.02 & 0.15 & 498 & 320 & 136 & 42 & 456 & 362 & 954 & 860 \\
\hline 0.03 & 0.15 & 374 & 274 & 88 & 27 & 361 & 301 & 735 & 675 \\
\hline \hline 0.02 & 0.2 & 478 & 313 & 127 & 40 & 440 & 353 & 918 & 830 \\
\hline 0.03 & 0.2 & 357 & 267 & 82 & 25 & 349 & 292 & 706 & 650 \\
\hline \hline 0.02 & 0.25 & 457 & 306 & 119 & 37 & 425 & 343 & 882 & 800 \\
\hline 0.03 & 0.25 & 340 & 259 & 76 & 24 & 335 & 283 & 676 & 623 \\
\hline
\end{tabular}

Table 1. Long run implications for wealth-to-NDP ratios.

Notes: All values are expressed in percent. Results are based on the following set of parameters: $\alpha=0.28, \beta=0.69, \gamma=0.9, \eta=0.38, \theta=0.22, \delta^{X}=0.015, \delta^{K}=0.07$. Recall $\mathfrak{H}^{N D P *}=\frac{P^{H *} N^{*}}{N D P^{*}}, \mathfrak{K}^{N D P *}=\frac{K^{*}}{N D P^{*}}, \mathfrak{Z}^{N D P *}=\frac{P^{Z *} Z^{Y *}}{N D P^{*}}, \mathfrak{N}^{N D P *}=\mathfrak{K}^{N D P *}+\mathfrak{Z}^{N D P *}, \mathfrak{W}^{N D P *}=\frac{W^{*}}{N D P^{*}}=$ $\mathfrak{H}^{N D P *}+\mathfrak{N}^{N D P *}, \overline{\mathfrak{Z}}^{N D P *}=\kappa \mathfrak{Z}^{N D P *}, \overline{\mathfrak{N}}^{N D P *}=\mathfrak{K}^{N D P *}+\overline{\mathfrak{Z}}^{N D P *}$, and $\overline{\mathfrak{W}}^{N D P *} \equiv \mathfrak{H}^{N D P *}+$ $\overline{\mathfrak{N}}^{N D P *}$ with land price correction factor $\kappa=0.31$, as explained in Online-Appendix A.5. 
Table 1 also displays the sensitivity of wealth-to-income ratios with respect to capital income taxation. We start with lowering $\tau_{r}$ to 15 percent. As the long run interest rate, $r^{*}$, is slightly reduced, the implied wealth-to-NDP ratios increase somewhat.The implied housing wealth-to-NDP ratio, $\mathfrak{H}^{N D P *}$, now becomes almost 500 percent for $\rho=0.02$ and associated long run wealth-to-NDP ratio, $\mathfrak{W}^{N D P *}$, is 954 percent without amending nonresidential land wealth. These values may be considered as upper bounds. Raising $\tau_{r}$ to 25 percent, $\rho=0.03$ implies that $\mathfrak{H}^{N D P *}$ is 340 percent, which may be considered as lower bound.

\subsection{Transitional Dynamics Post WWII}

The calibrated model is solved numerically to first investigate the dynamics of housing wealth $\mathfrak{H}_{t}^{N D P}=P_{t}^{H} N_{t} / N D P_{t}$. We discuss the historical evolution after World War II and provide projections until 2100. Subsequently, the implications for non-residential wealth relative to $\mathrm{NDP}, \mathfrak{N}_{t}^{N D P}=\left(K_{t}+P_{t}^{Z} Z_{t}^{Y}\right) / N D P_{t}$, are reported.

\subsubsection{Housing Wealth}

Figure 2 displays the evolution of the housing wealth-to-NDP ratio, $\mathfrak{H}_{t}^{N D P}$, for the four countries under consideration. The dotted (red / purple) lines represent the empirical data, as already shown in Figure 1, whereas the solid (blue) lines display the modelbased time paths. The underlying experiment can be described as follows: First, we feed country-specific population (density) growth, as reported by Piketty and Zucman (2014b), into the model. ${ }^{24}$ We also feed in a country-specific time path for TFP parameters $B^{X}$ and $B^{Y}$ such that, given exogenous population growth and endogenous capital accumulation, aggregate income growth between 1955 and 2010 coincides with the respective growth rates, reported in Piketty and Zucman $(2014 \mathrm{~b}) .{ }^{25}$ That is, economic growth is driven

\footnotetext{
${ }^{24}$ We account for the German reunification by raising both population size and land size accordingly. For US, UK and France, we normalize land size to $Z=1$, whereas for Germany we let land size increase over time to $Z=1.4$.

${ }^{25}$ Population size, $L_{t}$, and total factor productivities $B_{t}^{X}$ and $B_{t}^{Y}$ increase smoothly over time according to a logistic function.
} 
by exogenous population growth, exogenous technical progress, and endogenous capital accumulation. Growth is transitory, but may extend over several centuries. Second, initial state variables are set to match initial wealth-to-income ratios. Specifically, $N_{0}$ and $X_{0}$ are set such that model-based $\mathfrak{H}_{0}^{N D P}$ matches the respective empirical value in the year 1955, assuming identical proportional deviations from the initial steady state (given $L_{0}, B_{0}^{Y}$ and $B_{0}^{X}$ ) for both $N_{t}$ and $X_{t}$. Similarly, $K_{0}$ is set such that model-based $\mathfrak{N}_{0}^{N D P}$ matches the respective empirical value in $1955 .{ }^{26}$ Otherwise, the set of parameters is as described in Section 4.1. We let the simulation run from 1955 until 2100. The model gives us country specific time paths for the ratio of housing wealth to income from 1955 until 2100. This experiment is conducted separately for France, Germany, United Kingdom and the USA.
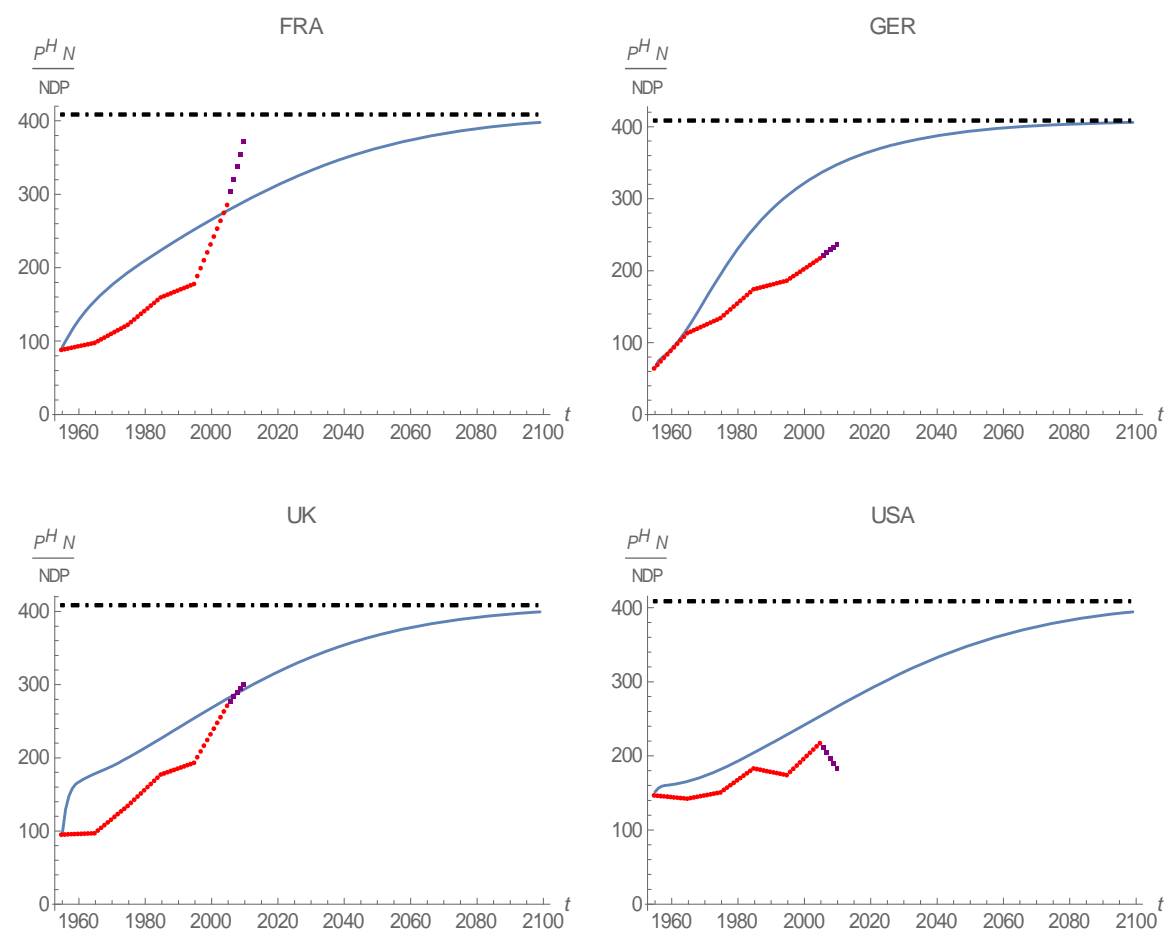

Figure 2. Housing wealth (relative to NDP) from 1955 until 2100.

\footnotetext{
${ }^{26}$ These initial state variables are specified as percentage of the initial long run equilibrium values, $K_{0}^{*}, X_{0}^{*}, N_{0}^{*}$, that would result for initial population size and productivity levels, $L_{0}, B_{0}^{Y}, B_{0}^{X}$. This assumption appears especially plausible for European economies shortly after World War II.
} 
Notes. (1) Dotted line: empirical series (red: linear interpolation between decadal averages starting in 1955 until 2005; purple: linear interpolation between the 2005 value and the actual 2010 value). Solid (blue) line: implied series resulting from the calibrated House Capital Model. (2) Country specific parameters: $N_{0}$ and $X_{0}$ are set such that model-based and empirical values for $P_{0}^{H} N_{0} / N D P_{0}$ coincide, assuming the same proportional deviations from the initial steady state. $K_{0}$ is set such that model-based and the empirical values for $\left(K_{0}+P_{0}^{Z} Z_{0}^{Y}\right) / N D P_{0}$ coincide. Population grows according to a logistic function such that empirical population growth, taken from Piketty and Zucman (2014b), between 1955 and 2010 is matched for each country. Total factor productivity parameters $B_{t}^{Y}$ and $B_{t}^{X}$ increase over time according to logistic functions such that GDP, taken from Piketty and Zucman (2014b), grows in accordance with empirical data between 1955 and 2010, given (exogenous) population growth and (endogenous) capital accumulation. Land size is normalized to $Z=1$ except for Germany where $Z=1.4$ after the reunification. (3) Common parameters: $B^{h}=B^{M}=1, \rho=0.025$. Other parameters as in Table 1 with $\psi=1$ and $\xi=100$.

Overall, the model matches the empirical series quite accurate given that only information about initial state variables, population growth and aggregate income growth enters the experiment. There are, of course, deviations between the empirical data and the model results. The strongest deviation can be observed for Germany that starts with $\mathfrak{H}_{1955}^{N D P} \approx 0.65$ and in recent times shows $\mathfrak{H}_{2005}^{N D P} \approx 2.19$, whereas the model implies $\mathfrak{H}_{2005}^{N D P} \approx 3.33$. Given $\mathfrak{H}_{1955}^{N D P} \approx 0.65$, Germany starts with the lowest value of the housing stock, which appears reasonable with respect to war destructions during World War II. ${ }^{27}$ The model economy then builds up the housing stock quite rapidly, despite convex (quadratic) land transformation costs. The model-based values nearly match the empirical observations in 2005 for FRA and UK. ${ }^{28}$ For the US the empirical value in 2005 is about $\mathfrak{H}_{2005}^{N D P} \approx 2.18$, while the model implies $\mathfrak{H}_{2005}^{N D P} \approx 2.50$, a deviation of about

\footnotetext{
${ }^{27}$ Piketty and Zucman $(2014 \mathrm{~b})$ report war destructions of about 50 percent for the housing stock and about 27 percent for physical capital.

${ }^{28}$ Notice that the last five entries (in purple color) represent interpolations between the 2005 decadal average and the actual value in 2010 .
} 
15 percent. The long run value is the same for every economy, given that we assume a unique $\tau_{r}=0.2$, and amounts to about 410 percent. The model therefore gives us, for the first time, a notion about the long run housing wealth-to-income ratio and the specific trajectory that converges to this asymptotic value. According to Corollary 1, population growth and / or TFP growth affects the transition to the steady state values, but not the steady state values itself.

\subsubsection{Non-Residential Wealth}

We now report the implications of the above sketched experiment for non-residential wealth. It is important to notice that the House Capital Model rests on one simplifying assumption that is important when it comes to non-residential wealth. It does not distinguish between urban and rural land. That is, there is one single region that hosts both production and housing. This region should in fact be interpreted as predominantly urban, given that about 70 to 80 percent of the population in advanced countries lives in cities. Therefore, the House Capital Model values the entire non-residential land, which comprises non-residential urban and non-residential rural land in reality, at the urban land price. ${ }^{29}$ This land valuation bias does not affect housing wealth, but it affects nonresidential wealth, $\mathfrak{N}_{t}^{N D P}=\left(K_{t}+P_{t}^{Z} Z_{t}^{Y}\right) / N D P_{t}$. As a result, non-residential wealth is overestimated due to an overvaluation of (non-residential) land, $P_{t}^{Z} Z_{t}^{Y}$. A simple and conceptually straightforward possibility to amend this valuation bias, explained in detail in Online-Appendix A.5, is to value non-residential land, $Z_{t}^{Y}$, at an adjusted land price $\bar{P}_{t}^{Z}$ that is a weighted average price of land across urban and rural regions (assuming a price wedge between the two regions). It can be represented as $\bar{P}_{t}^{Z}=\kappa P_{t}^{Z}$, where a value $\kappa=0.31$ appears reasonable, as explained in Online-Appendix A.5.30

\footnotetext{
${ }^{29}$ The same criticism applies, of course, to any other one-regional macro model with production and housing. The issue of land heterogeneity and associated land price differentials has already been brought up in the context of macroeconomics and housing by Sachs and Boone (1988).

${ }^{30}$ Online-Appendix A.6 considers the case where $\kappa=1$.
} 

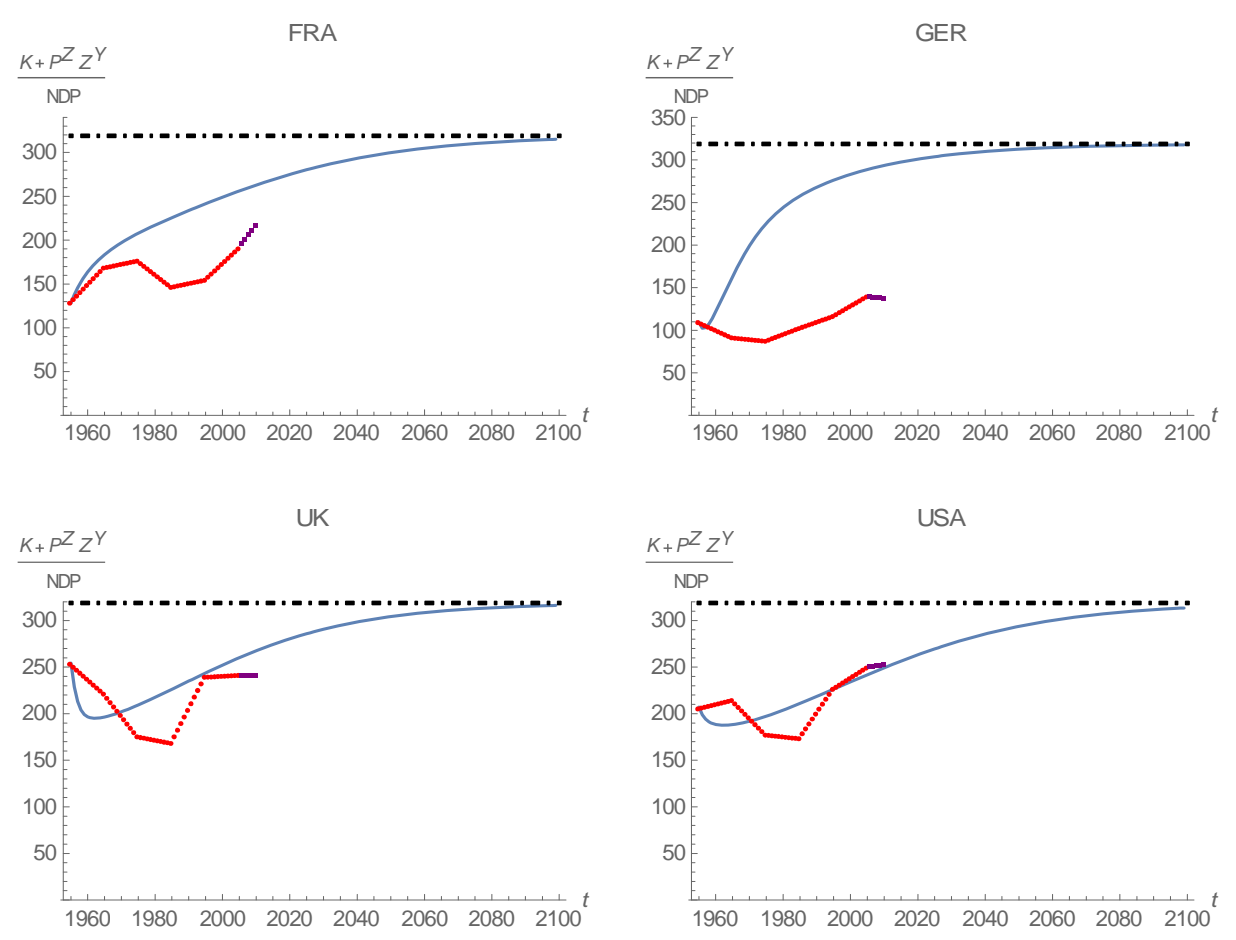

Figure 3. Non-residential wealth (relative to NDP) from 1955 until 2100.

Notes. (1) Dotted line: empirical series (red: linear interpolation between decadal averages starting in 1955 until 2005; purple: linear interpolation between the 2005 value and the actual 2010 value). Solid (blue) line: implied series resulting from the calibrated House Capital Model. (2) Country specific parameters: $N_{0}$ and $X_{0}$ are set such that model-based and empirical values for $P_{0}^{H} N_{0} / N D P_{0}$ coincide, assuming the same proportional deviations from the initial steady state. $K_{0}$ is set such that model-based and the empirical values for $\left(K_{0}+P_{0}^{Z} Z_{0}^{Y}\right) / N D P_{0}$ coincide. Population grows according to a logistic function such that empirical population growth, taken from Piketty and Zucman (2014b), between 1955 and 2010 is matched for each country. Total factor productivity parameters $B_{t}^{Y}$ and $B_{t}^{X}$ increase over time according to logistic functions such that GDP, taken from Piketty and Zucman (2014b), grows in accordance with empirical data between 1955 and 2010, given (exogenous) population growth and (endogenous) capital accumulation. Land size is normalized to $Z=1$ except for Germany where $Z=1.4$ after the reunification. (3) Common parameters: $B^{h}=B^{M}=1, \rho=0.025$. Other parameters as in Table 1 with $\psi=1$ and $\xi=100$. (4) Land price $P_{t}^{Z}$ is adjusted according to $\bar{P}_{t}^{Z}=\kappa P_{t}^{Z}$ 
with $\kappa=0.31$ as explained in Online-Appendix A.5.

Figure 3 displays the evolution of non-residential wealth, relative to NDP, $\mathfrak{N}_{t}^{N D P}$, for the four countries under consideration. The dotted (red / purple) lines show the empirical data, as already shown in Figure 1, whereas the solid (blue) lines display the model-based time paths. The model tracks the empirical series quite accurate with one exception. For Germany the model implies a strong increase, whereas the data show a moderate U-shaped development. Given $\mathfrak{N}_{1955}^{N D P} \approx 1.05$, Germany starts with the lowest value of physical capital, which again appears reasonable with respect to war destructions during World War II. The model economy builds up the capital stock quite rapidly. This implication would be different, if one assumed (convex) adjustment costs for physical capital (as we did for the stock of houses, $N$ ) - a feature that we left out for simplicity, reflecting our focus on housing capital. The same feature would improve the picture for France that starts with only a slightly higher value of $\mathfrak{N}_{1955}^{N D P} \approx 1.27$. Again, the model implies a somewhat faster increase in non-residential wealth, relative to income, compared to empirical data. In 2005 the empirical value is about 190 percent, while the model displays a value of about 255 percent. The match is remarkably good for UK and the US. Especially for the US economy the model traces the U-shaped pattern very well. The underlying mechanism behind this U-shaped evolution is that economic growth affects at first NDP (the denominator of the wealth-to-NDP ratios). The accumulation of physical capital as well as the rising valuation of land, however, lack behind the NDP development such that the numerator of the wealth-to-NDP ratio responds with some delay.

\subsubsection{Land Prices and House Prices}

Land and the allocation of land play a prominent role in the underlying model. Given that the overall land endowment is fixed (Premise 1) and that land represents a rivalrous factor (Premise 3), land is becoming scarcer and more expensive as the economy grows. The model demonstrates that the price channel of increased land valuations plays a 
critical role in the process of pushing up wealth-to-NDP ratios. On the one hand, the ratio of non-residential wealth to NDP, $\mathfrak{N}_{t}^{N D P}$, rises in the process of economic growth simply because it contains a sizable land wealth component $P_{t}^{Z} Z_{t}^{Y}$. On the other hand, rising land prices push the house price up and this price channel triggers an increase in the ratio of housing wealth to NDP, $\mathfrak{H}_{t}^{N D P}$.
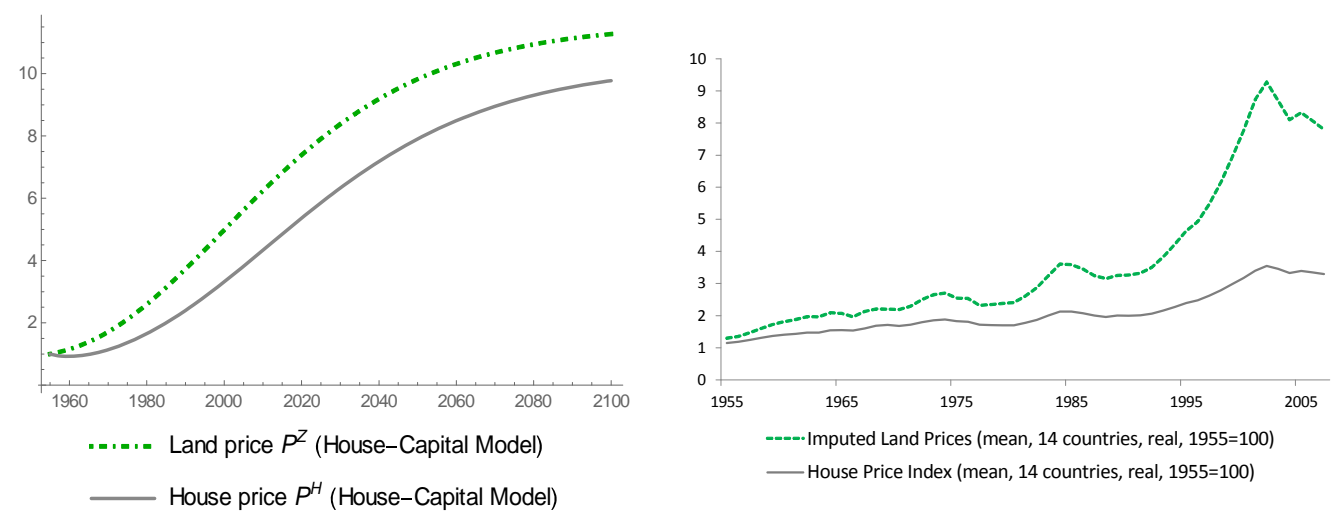

Figure 4. Evolution of land prices and house prices ("average economy"): calibrated model (left panel) and empirical data (right panel).

Notes: Left panel: Evolution of the land price, $P_{t}^{Z}$, and the house price, $P_{t}^{H}$, as resulting from the model (1955 values $=1) . K_{t}, N_{t}$ and $X_{t}$ start at 80 percent of their (initial) steady state levels; $L_{t}$ increases, in total, by a factor of 1.75 and $B_{t}^{Y}$ and $B_{t}^{X}$ increase by a factor of 3.5 according to logistic functions; $B^{h}=B^{M}=1, \rho=0.025, \tau_{r}=0.2$, and other parameters as in Table 1 with $\psi=1$ and $\xi=100$. Right panel: Empirical land price (imputed) and real house price data (mean across 14 advanced countries), taken from Knoll et al. (2014).

Figure 4 (left panel) displays the evolution of the land price, $P_{t}^{Z}$, and the house price, $P_{t}^{H}$, as implied by the calibrated model, assuming that the labor force grows, in total, by a factor of 1.75 and total factor productivity rises by a factor of 3.5 according to logistic functions. These increases are supposed to capture those in advanced countries as a whole. The model yields an overall increase in the land price, between 1955 and 2010 by a factor of about 6.2 , whereas in the data it increases somewhat more, by a factor of 
7.8. As regards the house price, the model produces an overall increase between 1955 and 2010 by a factor of about 4.2, whereas the data display a somewhat lower increase by a factor of 3.3. That is, the model captures one important stylized fact, namely that the land price increases by more than the house price and therefore accounts for the major share of the surge in house prices. ${ }^{31}$

\section{The Canonical Macro-Housing Model}

We finally sketch a canonical version of the typical macroeconomic model with a housing sector, as it has been recently employed, among others, in Davis and Heathcote (2005), Hornstein (2009), Iacoviello and Neri (2010), Favilukis et al. (2015), and Borri and Reichlin (2016). Subsequently, the major differences between the canonical model and our House Capital Model are highlighted.

\subsection{Setup}

The economy is perfectly competitive and comprises two sectors. The numeraire $(Y)$ sector combines capital, $K_{t}^{Y}$, and labor, $L_{t}^{Y}$, but not land, to produce a final output good according to

$$
Y_{t}=B_{t}^{Y}\left(K_{t}^{Y}\right)^{\alpha}\left(L_{t}^{Y}\right)^{1-\alpha}
$$

$B_{t}^{Y}>0,0<\alpha<1$. The numeraire good can be either consumed or invested. The housing sector produces housing services that are sold to households. Housing services per period of time, $S_{t}$, are proportional to the stock of houses $H_{t}$, i.e., $S_{t}=b H_{t}$ with $b>0$. Without loss of generality we set $b=1$. The production of houses employs a fixed amount of (additional) land together with a variable amount of structures. The fixed amount of residential land becomes exogenously available each period. The stock

\footnotetext{
${ }^{31}$ Davis and Heathcote (2007) show that the price of residential land has increased considerably more than house prices during 1975-2005 in the US (almost fourfold), whereas the costs of structures have increased only slightly. Knoll et al. (2014) demonstrate, focusing on 14 countries between 1950 and 2012 , that 80 percent of the increase in house prices can be attributed to rising land prices and only 20 percent to rising construction costs.
} 
of houses accumulates according to $\dot{H}_{t}=I_{t}^{H}-\delta^{H} H_{t}$, where $I_{t}^{H}$ denotes gross investment and $\delta^{H}>0$ the depreciation rate of the housing stock. Gross additions to the housing stock are described by a constant-returns to scale technology,

$$
I_{t}^{H}=B_{t}^{H} X_{t}^{\beta} \bar{Z}^{1-\beta}
$$

$B^{H}>0,0<\beta<1$, where $X_{t}$ is the amount of structures that are combined with a fixed quantity of (additional) land, $\bar{Z}$, that is inelastically supplied each period. Residential structures (a flow) are produced according to

$$
X_{t}=B_{t}^{X}\left(K_{t}^{X}\right)^{\gamma}\left(L_{t}^{X}\right)^{1-\gamma}
$$

$B^{X}>0,0<\gamma<1$, by combining capital, $K^{X}$, and labor, $L^{X}$. Consequently, the evolution of the housing stock $H$ is described by

$$
\dot{H}_{t}=\underbrace{\tilde{B}_{t}^{H}\left(K_{t}^{X}\right)^{\beta \gamma}\left(L_{t}^{X}\right)^{\beta(1-\gamma)} \bar{Z}^{1-\beta}}_{=I_{t}^{H}}-\delta^{H} H,
$$

where $\tilde{B}_{t}^{H} \equiv B_{t}^{H}\left(B_{t}^{X}\right)^{\beta}$. The exogenous and time-invariant supply of (additional) residential land, $\bar{Z}$, used as specific factor in housing production, is supposed to capture the idea that there is a time-invariant amount of (new) pieces of land available each period. According to Favilukis et al. (2015, p. 13), "a constant quantity [...] of new land/permits suitable for residential development is available each period". Davis and Heathcote (2005) point to the "declining relative returns to agricultural use" (p. 756) as a potential source of new land. ${ }^{32}$

Households maximize utility and firms maximize profits. Intertemporal utility of the representative consumer is again given by (7). Let $q_{t}^{H}$ denote the house price at time $t$.

\footnotetext{
${ }^{32}$ The canonical model could alternatively be interpreted as a model with two consumption goods, one flow good and one durable (capturing something else than house capital) that is produced by making use of an intermediate product and a specific factor that could as well be viewed as specific labor (like in the Ricardo-Viner model).
} 
Total wealth, denoted by $A_{t}$, comprises capital and houses, i.e.,

$$
A_{t}=K_{t}+q_{t}^{H} H_{t}
$$

where $K_{0}>0$ and $H_{0}>0$ are given. Again, let $r_{t}$ denote the rate of return of financial assets, $w_{t}$ the wage rate, $R_{t}^{Z}$ the land rent, and $p_{t}$ the price of housing services, respectively. Household wealth then accumulates according to

$$
\dot{A}_{t}=r_{t} A_{t}+w_{t} L_{t}+R_{t}^{Z} \bar{Z}-p_{t} S_{t}-C_{t}
$$

where $p_{t}$ denotes the price of one unit of housing services. The resource constraints (holding with equality in equilibrium) are given by

$$
\begin{aligned}
K_{t}^{X}+K_{t}^{Y} & \leq K_{t} \\
L_{t}^{X}+L_{t}^{Y} & \leq L_{t}
\end{aligned}
$$

and market clearing in the numeraire good sector requires

$$
Y_{t}=C_{t}+I_{t}^{K}=C_{t}+\dot{K}_{t}+\delta^{K} K_{t}
$$

$G D P_{t}$ for this economy is the sum of value-added of the numeraire good sector, $Y_{t}$, the housing services sector, $p_{t} H_{t}$, and the construction sector (building new houses with value $\left.q_{t}^{H} I_{t}^{H}\right) \cdot 33$

$$
G D P_{t} \equiv Y_{t}+p_{t} H_{t}+q_{t}^{H} I_{t}^{H}
$$

In Online-Appendix B we summarize the dynamic system of the Canonical Model and derive analytical results for the long run equilibrium.

\footnotetext{
${ }^{33}$ Alternatively, one can define GDP according to its use: $G D P_{t}=C_{t}+p_{t} S_{t}+I_{t}^{K}+q_{t}^{H} I_{t}^{H}$, which leads to (56), according to (55) and $S_{t}=H_{t}$.
} 


\subsection{Comparison with the House Capital Model}

The Canonical Model, due to its lean structure, represents an attractive and important analytical tool to study a large set of research questions. The House Capital Model, on the other hand, is a bit more complex and appears to have advantages especially when it comes to research questions that focus on the long run. We now highlight the major differences between the two models.

\subsubsection{Land Availability and Land Allocation}

Canonical Model The quantity of (additional) land that is employed every period in the housing sector, $\bar{Z}$, is exogenous and time invariant. Land is not used elsewhere in the economy, that is there is no endogenous land allocation. This automatically implies that the amount of land allocated to the housing sector does not change along the transition. What may change along the transition to the steady state is the quantity of complementary factors: $K_{t}^{X}$ and $L_{t}^{X}$.

House Capital Model The economy-wide amount of land is fixed. The land allocation is, however, endogenous. Land can be either employed in the $Y$ sector, $Z_{t}^{Y}$, or in the housing sector, amounting to $Z_{t}^{N}=\psi N_{t}$. The quantity of land allocated to the housing sector is time-varying and endogenous. This difference in the land allocation (exogenous and time-invariant vs. endogenous and time-varying) has important implications for the evolution of the land price, as explained below.

\subsubsection{Cumulated Land in a Stationary Housing Sector}

Canonical Model Let us assume a stationary steady state with a positive and constant housing stock and a positive depreciation rate $\delta^{H}>0$. The cumulated amount of land that is incorporated in the housing sector converges to infinity as time goes to infinity. This is not compatible with Premise 1 (fixed overall land endowment) above and may be viewed as long run inconsistency. 
House Capital Model Let us assume a stationary steady state with a positive and constant housing stock and a positive depreciation rate of residential buildings $\delta^{X}>0$. The cumulated quantity of land that is incorporated in the housing stock is $Z_{t}^{N}=\psi N_{t}$, a finite number, even for time approaching infinity. Hence, the House Capital Model is consistent with Premise 1 and the long run inconsistency is avoided.

This aspect may appear of second-order importance in the context of business cycle phenomena. When it comes to analyzing the long run evolution of residential and nonresidential wealth, we think this point must be taken seriously.

\subsubsection{Extensive and Intensive Margin of Housing Production}

Canonical Model The housing stock is a one-dimensional object. It appears appropriate to interpret an increase in the housing stock as an increase along the extensive margin because this process requires land. The alternative interpretation would imply that there is a single house that is enlarged continuously upwards. ${ }^{34}$

House Capital Model The housing stock can be enlarged along the extensive margin (increasing the number of houses) and along the intensive margin (increasing the size of the typical houses). Only the enlargement along the extensive margin requires land as an input (Premise 2).

The distinction between the extensive and intensive margin has two advantages: (i) It allows us to avoid the long run inconsistency, as explained above; (ii) It enables a distinction between the destruction of the housing stock either along the extensive margin (e.g., through a nuclear incident) or along the intensive margin (e.g., through a moderate earth-quake). This distinction may be employed in future research.

\footnotetext{
${ }^{34}$ This interpretation is not crucial, however, for the description of the major differences between the two models.
} 


\subsubsection{Land Price Dynamics}

Canonical Model Given that each parcel of land used in housing production is permanently incorporated in the respective house, land plots can only be used once such that the land price, $P_{t}^{Z}$, equals the competitive land rent, $R_{t}^{Z}$, i.e., $P_{t}^{Z}=R_{t}^{Z}=p_{t}\left(\partial I_{t}^{H} / \partial \bar{Z}\right)$ (Davis and Heathcote, 2005; Favilukis et al., 2015). How does the land price evolve in response to a destruction in the housing stock? Given that, by assumption, the initial housing stock is below the steady state level, $H_{0}<H^{*}$, the economy allocates a large amount of capital, $K_{t}^{X}$, and labor, $L_{t}^{X}$, to the construction sector. This construction boom enables to build up the housing stock. As the economy converges to the steady state, the construction boom diminishes, implying that capital and labor are being reallocated to the alternative sector. Because land, along the transition to the steady state, is combined with less and less $K_{t}^{X}$ and $L_{t}^{X}$ the marginal productivity of land, $\left(\partial I_{t}^{H} / \partial \bar{Z}\right)$, declines. ${ }^{35}$ Moreover, the price of housing services, $p_{t}$, declines too as the supply in the housing market is being enlarged. Taken together, the land price $P_{t}^{Z}=p_{t}\left(\partial I_{t}^{H} / \partial \bar{Z}\right)$ unambiguously decreases along the transition to the steady state, as illustrated in Figure 5 (a).

House Capital Model Each unit of land can be either permanently incorporated in a house or can be employed for an infinite sequence of periods in the $Y$ sector. The equilibrium land price, excluding bubbles, equals the PDV of an infinite land rent earned in the $Y$ sector: $P_{t}^{Z}=\int_{t}^{\infty} R_{\tau}^{Z} e_{t}^{\int_{t}^{s}-r_{v} \mathrm{~d} v} \mathrm{~d} s$.

\footnotetext{
${ }^{35}$ Recall that gross residential investments may be expressed as: $I_{t}^{H}=\tilde{B}_{t}^{H}\left(K_{t}^{X}\right)^{\beta \gamma}\left(L_{t}^{X}\right)^{\beta(1-\gamma)} \bar{Z}^{1-\beta}$.
} 
(a) Canonical Model: $H_{0}=0.8 H^{*}$

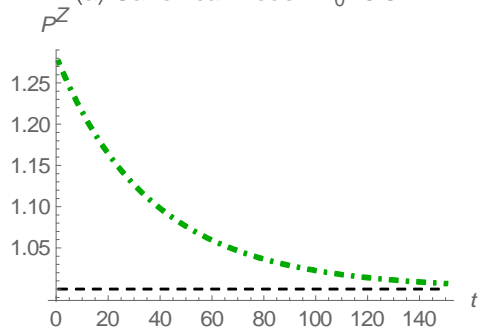

(c) House-Capital Model: $N_{0}=0.8 N^{*}, X_{0}=X^{*}$ $P^{Z}$

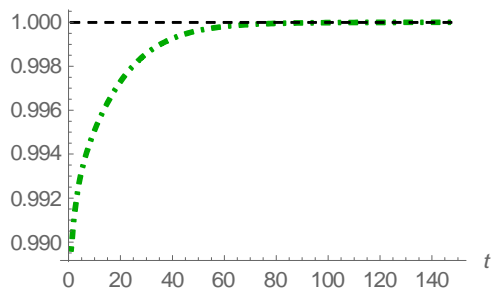

(b) House-Capital Model: $N_{0}=0.8 N^{*}, X_{0}=0.8 X$

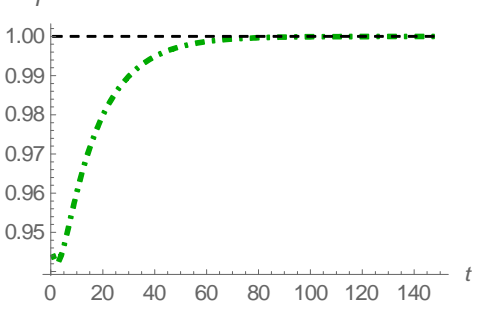

(d) House-Capital Model: $N_{0}=N^{*}, X_{0}=0.8 X^{*}$ $P^{Z}$

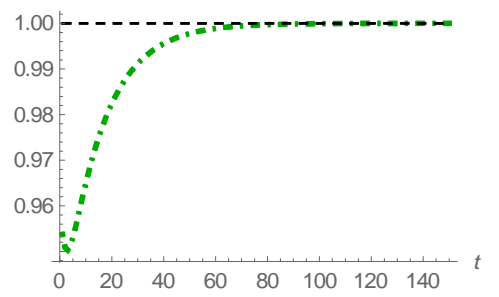

Figure 5. Evolution of the land prices in response to housing stock destruction: Canonical Model and House Capital Model.

Notes: Panel (a): Canonical Model, initial housing stock $H_{0}=0.8 H^{*}$, set of parameters: $\rho=0.025, \gamma=0.7, \delta^{H}=0.015, \delta^{K}=0.07, \alpha=0.4, \beta=0.5, \theta=0.22, L=\bar{Z}=B^{Y}=B^{X}=1$. Panel (b): House Capital Model: $N_{0}=0.8 N^{*}$ and $X_{0}=0.8 X^{*}$; Panel (c): House Capital Model: $N_{0}=0.8 N^{*}$ and $X_{0}=X^{*}$; Panel (d): House Capital Model: $N_{0}=N^{*}$ and $X_{0}=0.8 X^{*}$; Panels (b) - (d): set of parameters other than initial states as in Figures 2-4 except $B^{Y}=B^{X}=L=Z=1$.

Figures 5 (b) and (c) show that the land price increases along the transition to the steady state in response to a destruction of the housing stock. The reasoning is basically the same as before, but now leads to a different conclusion. The construction boom, to rebuild the housing stock, leads to a temporary increase in the residential investment rate, $\mathfrak{s}_{t}^{H} \equiv\left(I_{t}^{N}+q_{t}^{X} I_{t}^{X}\right) / G D P_{t}$. This implies that (i) labor is reallocated to the construction sector and (ii) physical capital is temporarily decumulated (a standard implication of multi-sector models with multiple state variables). That is, non-residential land, $Z^{Y}$, is initially combined with a small amount of complementary factors, implying that $R_{t}^{Z}$ is low early on. As the construction boom diminishes, more and more labor returns to the 
$Y$ sector and $K$ accumulates back to its initial steady state level. As both $L^{Y}$ and $K$ are complementary to $Z^{Y}$, the land rent and, with some delay, the land price increases. This pattern is largely independent of whether the shock applies to both margins, Figure 5 (b), to the extensive margin only, Figure 5 (c), or to the intensive margin only, Figure 5 (d). The implication of rising land prices in response to a destruction of the housing stock is economically plausible and in line with the empirical evidence of rising land and house prices after World War II (Knoll et al., 2014).

\subsubsection{Housing Wealth and Non-Residential Wealth}

Canonical Model Housing wealth is given by $q_{t}^{H} H_{t}$. This wealth component comprises the cumulated quantity of land that is incorporated in the housing stock. The housing wealth-to-NDP ratio is $\mathfrak{H}_{t}^{N D P}=q_{t}^{H} H_{t} / N D P_{t}$. This is similar to the House Capital Model (both residential land and structures included). The non-residential wealth-to-NDP ratio is given by $\mathfrak{N}_{t}^{N D P}=\mathfrak{K}_{t}^{N D P}=K_{t} / N D P_{t}$. That is, land outside the housing sector, i.e., the value of non-residential land, is missing (i.e. $\left.\mathfrak{Z}_{t}^{N D P} \equiv 0\right) \cdot{ }^{36}$

House Capital Model Residential land, $\psi N_{t}=Z_{t}-Z_{t}^{Y}$, enters housing wealth since land is incorporated in houses, recall $\mathfrak{H}_{t}^{G D P}=\left(q_{t}^{N} N_{t}+q_{t}^{X} X_{t}\right) / N D P_{t}$. Non-residential land, $Z_{t}^{Y}$, enters non-residential wealth, recall $\mathfrak{N}_{t}^{N D P}=\left(K_{t}+P_{t}^{Z} Z_{t}^{Y}\right) / N D P_{t}$. This matches the assignment of land in the different wealth components according to national accounting.

Models that do not capture land as an input in the non-residential sector ( $Y$ sector) cannot adequately attribute rising non-residential wealth to rising land prices associated with land scarcity. Rising land prices are, however, important for both the evolution of housing wealth and the evolution of non-residential wealth.

\footnotetext{
${ }^{36}$ Sometimes $K_{t}$ is interpreted to capture physical assets including land, like in standard macroeconomic models without explicit land considerations.
} 


\section{Conclusion}

We have proposed a novel dynamic general equilibrium model to examine the evolution of two major wealth-to-income ratios (housing wealth and non-residential wealth), land prices, and house prices over time. Our theory rests on three premises: (1) fixed overall land endowment; (2) land as an essential input in housing production, except for replacement investment; (3) land rivalry between non-residential and residential production. The housing stock can be expanded along an extensive margin (setting up new housing projects) and along an intensive margin (enlarging existing housing projects). This distinction allows us to simultaneously capture Premises 1-3. The model is consistent with the close association between land prices and house prices in the data. It points to the importance of land for understanding the dynamics of wealth and its distributions. This point was already made by Ricardo (1817), who reasoned that economic growth primarily benefits the owners of the fixed factor land.

The calibrated model replicates the post World War II increase in the housing-wealthto-income ratio remarkably well. It suggests a considerable further increase in housing wealth, relative to income, that is associated with a future surge in land prices and house prices. Moreover, it implies a significant future increase in the non-residential wealth-toincome ratio.

The analytical framework developed in this paper has many applications. The House Capital Model is potentially useful for investigating the interaction between the composition of wealth and the dynamics of the wealth distribution. The composition of wealth is also likely to be important for an enhanced understanding of business cycles. For instance, specific capital goods, such as specialized machines, appear less suitable than land or houses as collateral for lending. Therefore, the wealth composition may impact on the propagation of business cycle shocks. The House Capital Model can also be employed to study public finance topics, such as the effects of property taxation and regulation of rent on residential investment, house prices, and land prices. Finally, the model can be applied to study the interaction between migration, house prices, and residential construction in 
a multi-region model.

\section{Appendix: Proofs}

Proof of Lemma 1. Using (3), the current-value Hamiltonian associated with real estate development problem (12) together with the necessary first-order conditions can then be expressed as

$$
\begin{gathered}
\mathcal{H}^{N}=\pi N-\psi P^{Z} \tilde{I}^{N}-\frac{\xi}{2}\left(\tilde{I}^{N}\right)^{2}+q^{N} \tilde{I}^{N} \\
{\left[\frac{\partial \mathcal{H}^{N}}{\partial \tilde{I}^{N}}=\right]-\psi P^{Z}-\xi\left(\tilde{I}^{N}\right)+q^{N}=0} \\
{\left[-\frac{\partial \mathcal{H}^{N}}{\partial N}=\right]-\pi=\dot{q}^{N}-r q^{N} .}
\end{gathered}
$$

Combining (2) and (58) confirms (13). (14) follows from (59). This concludes the proof.

Proof of Lemma 2. The current-value Hamiltonian of the representative construction firm associated with (16) together with the necessary first-order conditions can then be expressed as

$$
\begin{gathered}
\mathcal{H}^{X}=R^{X} X-p^{M} M-w L^{X}+q^{X}\left[B^{X} M^{\eta}\left(L^{X}\right)^{1-\eta}-\delta^{X} X\right] \\
{\left[\frac{\partial \mathcal{H}^{X}}{\partial M}=\right]-p^{M}+\eta q^{X} B^{X}\left(\frac{L^{X}}{M}\right)^{1-\eta}=0,} \\
{\left[\frac{\partial \mathcal{H}^{X}}{\partial L^{X}}=\right]-w+(1-\eta) q^{X} B^{X}\left(\frac{M}{L^{X}}\right)^{\eta}=0,} \\
{\left[-\frac{\partial \mathcal{H}^{X}}{\partial X}=\right]-R^{X}+\delta^{X} q^{X}=\dot{q}^{X}-r q^{X} .}
\end{gathered}
$$

(17) follows from (63). This concludes the proof. 
Proof of Proposition 1. Define $D^{Y} \equiv L^{Y} / Z^{Y}$. We first establish ${ }^{37}$

Lemma A.1. Suppose that (A1) holds and the (relative) price of housing services, $p$, is given. Then there exists a unique, nontrivial solution for the long run labor-to-land ratio in the $Y$ sector, that is given by

$$
D^{Y}=\left(\frac{\left(\eta B^{M}\right)^{\frac{\gamma \eta}{1-\gamma \eta}}\left(\frac{B^{X} \gamma}{r+\delta^{X}}\right)^{\frac{\gamma}{1-\gamma \eta}}\left(B^{h} p\right)^{\frac{1}{1-\gamma \eta}}\left(\frac{1-\eta}{\beta}\right)^{\frac{\gamma(1-\eta)}{1-\gamma \eta}}}{\left(\frac{\alpha}{r+\delta^{K}}\right)^{\frac{\alpha}{1-\alpha}}\left(B^{Y}\right)^{\frac{1}{1-\alpha}}\left(\frac{\psi(1-\alpha-\beta)}{1-\gamma}\right)^{\frac{1-\gamma}{1-\gamma \eta}}}\right)^{\frac{1}{\varrho}} \equiv \tilde{D}^{Y}(p, \mathbf{B})
$$

Function $\tilde{D}^{Y}$ is increasing in $p, B^{X}, B^{h}, B^{M}$, and decreasing in $B^{Y}$.

Proof. The typical final output firm maximizes profits given by

$$
\Pi=B^{Y}\left(K^{Y}\right)^{\alpha}\left(L^{Y}\right)^{\beta}\left(Z^{Y}\right)^{1-\alpha-\beta}-\left(r+\delta^{K}\right) K^{Y}-w L^{Y}-R^{Z} Z^{Y}
$$

Using $K^{Y}=K$, the necessary first-order conditions are

$$
\begin{gathered}
{\left[\alpha \frac{Y}{K^{Y}}=\right] \alpha B^{Y} K^{\alpha-1}\left(L^{Y}\right)^{\beta}\left(Z^{Y}\right)^{1-\alpha-\beta}=r+\delta^{K},} \\
{\left[\beta \frac{Y}{L^{Y}}=\right] \beta B^{Y} K^{\alpha}\left(L^{Y}\right)^{\beta-1}\left(Z^{Y}\right)^{1-\alpha-\beta}=w,} \\
{\left[(1-\alpha-\beta) \frac{Y}{Z^{Y}}=\right](1-\alpha-\beta) B^{Y} K^{\alpha}\left(L^{Y}\right)^{\beta}\left(Z^{Y}\right)^{-\alpha-\beta}=R^{Z} .}
\end{gathered}
$$

Combining (66) and (67), leads to

$$
K=\frac{\alpha}{\beta} \frac{w}{r+\delta^{K}} L^{Y}
$$

Substituting (69) into (66) and (68), we obtain

$$
w=\beta\left(\frac{\alpha}{r+\delta^{K}}\right)^{\frac{\alpha}{1-\alpha}}\left(B^{Y}\right)^{\frac{1}{1-\alpha}}\left(\frac{Z^{Y}}{L^{Y}}\right)^{\frac{1-\alpha-\beta}{1-\alpha}},
$$

\footnotetext{
${ }^{37}$ We typically omit the time index $t$ in this Appendix.
} 


$$
R^{Z}=(1-\alpha-\beta) B^{Y}\left(\frac{\alpha}{\beta} \frac{w}{r+\delta^{K}}\right)^{\alpha}\left(\frac{L^{Y}}{Z^{Y}}\right)^{\alpha+\beta}
$$

respectively.

The current-value Hamiltonian for the household optimization problem (equilibrium condition 1 in Definition 1) reads as

$$
\mathcal{H}=\log C+\theta \log S+\lambda\left[\left(1-\tau_{r}\right)\left(r A+R^{Z} Z\right)+\left(1-\tau_{w}\right) w L-C-p S\right]
$$

where $\lambda$ is the multiplier (co-state variable) associated with financial asset holding, $A$. Necessary optimality conditions are $\partial \mathcal{H} / \partial C=\partial \mathcal{H} / \partial S=0$ (control variables), $\dot{\lambda}=$ $\rho \lambda-\partial \mathcal{H} / \partial A$ (co-state variable), and the corresponding transversality condition. Thus,

$$
\begin{gathered}
\lambda=\frac{1}{S}, \\
\frac{\theta}{S}=\lambda p, \\
\frac{\dot{\lambda}}{\lambda}=\rho-\left(1-\tau_{r}\right) r .
\end{gathered}
$$

Combining (73) and (74), we have

$$
C=\frac{p S}{\theta}
$$

whereas combining (73) and (75) yields

$$
\frac{\dot{C}}{C}=\left(1-\tau_{r}\right) r-\rho
$$

We seek for a steady state without long run growth. Setting $\dot{C}=0$ in (77) gives us the long run interest rate

$$
r^{*}=\frac{\rho}{1-\tau_{r}} .
$$

Setting $\dot{N}=0$ in (13) implies, for the long run,

$$
q^{N}=\psi P^{Z}
$$


Substituting (11) into (14) and using $\dot{q}^{N}=0$, we have

$$
q^{N}=\frac{(1-\gamma) p B^{h} x^{\gamma}}{r}
$$

Setting $\dot{P}^{Z}=\dot{q}^{X}=0$ in (20) and (17), respectively, we obtain, for the long run,

$$
\begin{gathered}
P^{Z}=\frac{R^{Z}}{r}, \\
q^{X}=\frac{R^{X}}{r+\delta^{X}} .
\end{gathered}
$$

Setting $\dot{X}=0$ in (6) and using $X=N x$, we have

$$
x=\frac{B^{X} M^{\eta}\left(L^{X}\right)^{1-\eta}}{\delta^{X} N}
$$

To prove Lemma A.1, where the relative consumer goods price $p$ is taken as exogenously given, we ignore the consumer demand side. First, combine (61) with (82) and use $p^{M}=1 / B^{M}$ to obtain

$$
M=L^{X}\left(\frac{\eta B^{M} R^{X} B^{X}}{r+\delta^{X}}\right)^{\frac{1}{1-\eta}}
$$

Substitute next (83) into (10) to find

$$
R^{X}=p B^{h} \gamma\left(\frac{B^{X} M^{\eta}\left(L^{X}\right)^{1-\eta}}{\delta^{X} N}\right)^{\gamma-1}
$$

Substituting (85) into (84) yields a useful expression for $M$ :

$$
M=\left(L^{X}\right)^{\frac{\gamma(1-\eta)}{1-\gamma \eta}}\left(\frac{\gamma \eta p B^{M} B^{h}\left(\delta^{X} N\right)^{1-\gamma}\left(B^{X}\right)^{\gamma}}{r+\delta^{X}}\right)^{\frac{1}{1-\gamma \eta}}
$$

Combining (62) with (82) and (84) we obtain

$$
w=(1-\eta)\left(\eta B^{M}\right)^{\frac{\eta}{1-\eta}}\left(\frac{R^{X} B^{X}}{r+\delta^{X}}\right)^{\frac{1}{1-\eta}}
$$


Substituting (85) into (87) leads to

$$
w=(1-\eta)\left(\eta B^{M}\right)^{\frac{\eta}{1-\eta}}\left(\frac{\gamma p B^{h}}{r+\delta^{X}}\right)^{\frac{1}{1-\eta}}\left(B^{X}\right)^{\frac{\gamma}{1-\eta}}\left(\delta^{X} N\right)^{\frac{1-\gamma}{1-\eta}} M^{\frac{\eta(\gamma-1)}{1-\eta}}\left(L^{X}\right)^{\gamma-1}
$$

Substituting (86) into (88) gives us a useful expression for $w$ :

$$
w=(1-\eta)\left(\eta B^{M}\right)^{\frac{\gamma \eta}{1-\gamma \eta}}\left(\frac{\gamma B^{h} p}{r+\delta^{X}}\right)^{\frac{1}{1-\gamma \eta}}\left(B^{X}\right)^{\frac{\gamma}{1-\gamma \eta}}\left(\frac{N \delta^{X}}{L^{X}}\right)^{\frac{1-\gamma}{1-\gamma \eta}}
$$

Combining (89) with (70) and leads to

$$
\begin{aligned}
\frac{L^{X}}{N} & =\frac{(1-\eta)^{\frac{1-\gamma \eta}{1-\gamma}}\left(\eta B^{M}\right)^{\frac{\gamma \eta}{1-\gamma}}\left(\frac{\gamma B^{h} p}{r+\delta^{X}}\right)^{\frac{1}{1-\gamma}}\left(B^{X}\right)^{\frac{\gamma}{1-\gamma}} \delta^{X}}{\left[\beta\left(\frac{\alpha}{r+\delta^{K}}\right)^{\frac{\alpha}{1-\alpha}}\left(B^{Y}\right)^{\frac{1}{1-\alpha}}\right]^{\frac{1-\gamma \eta}{1-\gamma}}}\left(\frac{L^{Y}}{Z^{Y}}\right)^{\frac{1-\alpha-\beta}{1-\alpha} \frac{1-\gamma \eta}{1-\gamma}} \\
& \equiv \Phi\left(\frac{L^{Y}}{Z^{Y}}, p, \mathbf{B}\right)
\end{aligned}
$$

where $\mathbf{B} \equiv\left(B^{Y}, B^{X}, B^{h}, B^{M}\right)$ is the vector of productivity parameters. Note that $\Phi$ is increasing as a function of $L^{Y} / Z^{Y}$. Moreover, $\Phi$ is strictly concave as a function of $L^{Y} / Z^{Y}$ if and only if (A1) holds. Substituting (80) and (81) into (79), we obtain

$$
[\pi=](1-\gamma) p B^{h} x^{\gamma}=\psi R^{Z}
$$

Inserting (83) and (71) into (91), we get

$$
\frac{(1-\gamma) p B^{h}}{w}\left(\frac{B^{X} M^{\eta}\left(L^{X}\right)^{1-\eta}}{\delta^{X} N}\right)^{\gamma}=\frac{\psi(1-\alpha-\beta) B^{Y}}{w^{1-\alpha}}\left(\frac{\alpha}{\beta} \frac{1}{r+\delta^{K}}\right)^{\alpha}\left(\frac{L^{Y}}{Z^{Y}}\right)^{\alpha+\beta}
$$

Substituting (70) and (88) into the right-hand side and left-hand side of (92), respectively, yields

$$
\frac{(1-\gamma) M^{\frac{\eta(1-\gamma \eta)}{1-\eta}}\left(L^{X}\right)^{1-\eta \gamma}}{(1-\eta)\left(\eta p B^{M} B^{h}\right)^{\frac{\eta}{1-\eta}}\left(\frac{\gamma}{r+\delta^{X}}\right)^{\frac{1}{1-\eta}}\left(B^{X}\right)^{\frac{\gamma \eta}{1-\eta}}\left(\delta^{X} N\right)^{\frac{1-\gamma \eta}{1-\eta}}}=\frac{\psi(1-\alpha-\beta)}{\beta} \frac{L^{Y}}{Z^{Y}}
$$


Now substitute (86) into (93) to find

$$
\begin{aligned}
\frac{L^{X}}{N} & =\psi v \frac{L^{Y}}{Z^{Y}}, \text { with } \\
v & \equiv \frac{(1-\alpha-\beta)(1-\eta) \gamma \delta^{X}}{\beta(1-\gamma)\left(r+\delta^{X}\right)}
\end{aligned}
$$

According to (A1), $v<1 .^{38}$ Finally, combine the right-hand sides of (90) and (94) to confirm (64).

According to (94) and $L^{Y} / Z^{Y}=\tilde{D}^{Y}(p, \mathbf{B})$, we have

$$
\frac{L^{X}}{N}=\psi v \tilde{D}^{Y}(p, \mathbf{B})
$$

Using $L^{Y}=D^{Y} Z^{Y}$ and $L^{X}=N \psi v D^{Y}, L^{X}+L^{Y}=L$ and $Z^{Y}=Z-\psi N$ we obtain

$$
\begin{gathered}
\frac{N}{Z}=\frac{1}{\psi(1-v)}\left(1-\frac{D}{\tilde{D}^{Y}(p, \mathbf{B})}\right), \\
\mathfrak{z}^{Y}=\frac{Z^{Y}}{Z}=\frac{1}{1-v}\left(\frac{D}{\tilde{D}^{Y}(p, \mathbf{B})}-v\right), \\
\frac{N}{Z^{Y}}=\frac{1}{\psi} \frac{\frac{\tilde{D}^{Y}(p, \mathbf{B})}{D}-1}{1-v \frac{\tilde{D}^{Y}(p, \mathbf{B})}{D}},
\end{gathered}
$$

From $L^{X}=N \psi v D^{Y}, D=L / Z$ and (97), we also have

$$
\frac{L^{X}}{L}=\frac{v}{1-v}\left(\frac{\tilde{D}^{Y}(p, \mathbf{B})}{D}-1\right) .
$$

Thus, as $L^{Y} / L=1-L^{X} / L$,

$$
\frac{L^{Y}}{L}=\frac{1}{1-v}\left(1-v \frac{\tilde{D}^{Y}(p, \mathbf{B})}{D}\right) .
$$

${ }^{38} \mathrm{It}$ is easy to show that $v<1$ is equivalent to

$$
\frac{\beta}{1-\alpha}-\frac{\gamma(1-\eta)}{1-\gamma \eta} \underbrace{\frac{\delta^{X}}{(1-\gamma) r}+\delta^{X}}_{<1}>0 .
$$


According to (27) and (80), we can write for the long run:

$$
q^{N} N=\frac{(1-\gamma) p S}{r}
$$

Moreover, combining (10) with (27), we have $R^{X} N x=\gamma p S$. Combining $X=N x$, (82) and (83) we thus find that for the long run:

$$
q^{X} X=\frac{R^{X} N x}{r+\delta^{X}}=\frac{\gamma p S}{r+\delta^{X}}
$$

Using (69), (102) and (103) in (8) leads to long run total asset value:

$$
A=\frac{\alpha}{\beta} \frac{w L^{Y}}{r+\delta^{K}}+\frac{(1-\gamma) p S}{r}+\frac{\gamma p S}{r+\delta^{X}}
$$

Next, substituting (83) into condition (27) and using (86) gives us

$$
p S=N\left(B^{h} p\right)^{\frac{1}{1-\gamma \eta}}\left(B^{X}\right)^{\frac{\gamma}{1-\gamma \eta}}\left(\frac{L^{X}}{N} \frac{1}{\delta^{X}}\right)^{\frac{\gamma(1-\eta)}{1-\gamma \eta}}\left(\frac{\gamma \eta B^{M}}{r+\delta^{X}}\right)^{\frac{\gamma \eta}{1-\gamma \eta}}
$$

The total tax revenue that is redistributed to households reads as

$$
T=\tau_{r} r A+\tau_{r} R^{Z} Z^{Y}+\tau_{w} w L
$$

Combining (76) and (9) with $\dot{A}=0$, we obtain

$$
\left(\frac{1}{\theta}+1\right) p S=r A+w L+R^{Z} Z^{Y}
$$

Substituting (104) into (107) and using (106) leads to

$$
\left(\frac{1}{\theta}+\frac{\gamma \delta^{X}}{r+\delta^{X}}\right) p S=w\left(\frac{\alpha}{\beta} \frac{r L^{Y}}{r+\delta^{K}}+L\right)+R^{Z} Z^{Y}
$$


Inserting (70) into (71) leads to

$$
R^{Z}=(1-\alpha-\beta)\left(\frac{\alpha}{r+\delta^{K}}\right)^{\frac{\alpha}{1-\alpha}}\left(B^{Y}\right)^{\frac{1}{1-\alpha}}\left(\frac{L^{Y}}{Z^{Y}}\right)^{\frac{\beta}{1-\alpha}}
$$

By substituting (70), (105) and (109) into (108) we obtain

$$
\begin{aligned}
& \left(\frac{1}{\theta}+\frac{\gamma \delta^{X}}{r+\delta^{X}}\right) \frac{N}{Z^{Y}}\left(B^{h} p\right)^{\frac{1}{1-\gamma \eta}}\left(B^{X}\right)^{\frac{\gamma}{1-\gamma \eta}}\left(\frac{L^{X}}{N} \frac{1}{\delta^{X}}\right)^{\frac{\gamma(1-\eta)}{1-\gamma \eta}}\left(\frac{\gamma \eta B^{M}}{r+\delta^{X}}\right)^{\frac{\gamma \eta}{1-\gamma \eta}}\left(\frac{L^{Y}}{Z^{Y}}\right)^{-\frac{\beta}{1-\alpha}} \\
= & \left(\frac{\alpha}{r+\delta^{K}}\right)^{\frac{\alpha}{1-\alpha}}\left(B^{Y}\right)^{\frac{1}{1-\alpha}}\left[\frac{\alpha r}{r+\delta^{K}}+\beta\left(\frac{L}{L^{Y}}-1\right)+1-\alpha\right] .
\end{aligned}
$$

Substituting $L^{Y} / Z^{Y}=\tilde{D}^{Y}(p, \mathbf{B}),(96)$ and (99) into (110) and recalling the definition of $\varrho$ in (A1) implies, for the long run,

$$
\begin{aligned}
& \frac{\left(\frac{1}{\theta}+\frac{\gamma \delta^{X}}{r^{*}+\delta^{X}}\right)\left(1-\frac{\tilde{D}^{Y}\left(p^{*}, \mathbf{B}\right)}{D}\right)\left(B^{h} p^{*}\right)^{\frac{1}{1-\gamma \eta}}\left(B^{X}\right)^{\frac{\gamma}{1-\gamma \eta}}\left(\frac{v}{\delta^{X}}\right)^{\frac{\gamma(1-\eta)}{1-\gamma \eta}}\left(\frac{\gamma \eta B^{M}}{r^{*}+\delta^{X}}\right)^{\frac{\gamma \eta}{1-\gamma \eta}}}{\psi^{\frac{1-\gamma}{1-\gamma \eta}}\left(v \frac{\tilde{D}^{Y}\left(p^{*}, \mathbf{B}\right)}{D}-1\right) \tilde{D}^{Y}\left(p^{*}, \mathbf{B}\right) \varrho} \\
= & \left(\frac{\alpha}{r^{*}+\delta^{K}}\right)^{\frac{\alpha}{1-\alpha}}\left(B^{Y}\right)^{\frac{1}{1-\alpha}}\left[\frac{\alpha r^{*}}{r^{*}+\delta^{K}}+\beta v\left(\frac{1-\frac{\tilde{D}^{Y}\left(p^{*}, \mathbf{B}\right)}{D}}{v^{\frac{D^{Y}\left(p^{*}, \mathbf{B}\right)}{D}}-1}\right)+1-\alpha\right] \cdot
\end{aligned}
$$

Substituting (78), (64), (95) in (111) we find that long run the long run price for housing services, $p^{*} \equiv \tilde{p}^{*}(\mathbf{B}, D)$, is implicitly given by $0=\Theta\left(p^{*}, \mathbf{B}, D\right)$, where

$$
\Theta(p, \mathbf{B}, D) \equiv \frac{1-\alpha-\beta}{1-\gamma}\left(\frac{1}{\theta}+\frac{\eta \gamma \delta^{X}}{\frac{\rho}{1-\tau_{r}}+\delta^{X}}\right) \frac{\frac{\tilde{D}^{Y}(p, \mathbf{B})}{D}-1}{1-v \frac{\tilde{D}^{Y}(p, \mathbf{B})}{D}}-\frac{\frac{\rho}{1-\tau_{r}}+(1-\alpha) \delta^{K}}{\frac{\rho}{1-\tau_{r}}+\delta^{K}}
$$

Note that $\Theta_{p}(p, \mathbf{B}, D)>0,{ }^{39}$ according to (112). Hence, if $p^{*}>0$ exists, it is unique. Moreover, we have $\tilde{D}^{Y}(0, \mathbf{B})=0$ and $\lim _{p \rightarrow \infty} \tilde{D}^{Y}(p, \mathbf{B}) \rightarrow \infty$, according to (64). Thus, $\lim _{p \rightarrow 0} \Theta(p, \mathbf{B}, D)<0$ and $\lim _{p \rightarrow \infty} \Theta(p, \mathbf{B}, D) \rightarrow-\infty$. Hence, $p^{*}$ is unique.

Setting $\Theta\left(p^{*}, \mathbf{B}, D\right)=0$ implies that

$$
\frac{D}{\tilde{D}^{Y}\left(\tilde{p}^{*}(\mathbf{B}, D), \mathbf{B}\right)}=\frac{\frac{1}{\theta}+\frac{\eta \gamma \delta^{X}}{\frac{\rho}{1-\tau_{r}}+\delta^{X}}+\frac{\frac{\rho}{1-\tau_{r}}+(1-\alpha) \delta^{K}}{\frac{\rho}{1-\tau_{r}}+\delta^{K}} \frac{(1-\eta) \gamma \delta^{X}}{\beta\left(\frac{\rho}{1-\tau_{r}}+\delta^{X}\right)}}{\frac{1}{\theta}+\frac{\eta \gamma \delta^{X}}{\frac{\rho}{1-\tau_{r}}+\delta^{X}}+\frac{1-\gamma}{1-\alpha-\beta} \frac{\frac{\rho}{1-\tau_{r}}+(1-\alpha) \delta^{K}}{\frac{\rho}{1-\tau_{r}}+\delta^{K}}} \equiv \mu .
$$

\footnotetext{
${ }^{39}$ Subscripts on functions denote partial derivatives throughout.
} 
It is easy to show that $\mu \in(v, 1)$ if and only if $v<1$, which holds according to (A1). Thus, also (36) holds under (A1). This concludes the proof.

Proof of Proposition 2. Applying the implicit function theorem to $0=\Theta\left(p^{*}, \mathbf{B}, D\right)$ and using Lemma A.1 confirms part (i). To prove parts (ii) and (iii), use (70), (78) and (109) to find

$$
\begin{gathered}
w^{*}=\beta\left(\frac{\alpha}{\frac{\rho}{1-\tau_{r}}+\delta^{K}}\right)^{\frac{\alpha}{1-\alpha}}\left(B^{Y}\right)^{\frac{1}{1-\alpha}}\left(\frac{\mu}{D}\right)^{\frac{1-\alpha-\beta}{1-\alpha}} \\
R^{Z *}=(1-\alpha-\beta)\left(\frac{\alpha}{\frac{\rho}{1-\tau_{r}}+\delta^{K}}\right)^{\frac{\alpha}{1-\alpha}}\left(B^{Y}\right)^{\frac{1}{1-\alpha}}\left(\frac{D}{\mu}\right)^{\frac{\beta}{1-\alpha}},
\end{gathered}
$$

respectively. Using (81) and again using that $\mu$ is independent of $\mathbf{B}$ and $D$ confirms parts (ii) and (iii). Next, define the "house-price-to-rent ratio" as the ratio of the price of one house with $x_{t}$ units of structures put on $\psi$ units of land to the cost of renting $h_{t}$ units of housing services produced with the same amount of structures, $x_{t}$. Formally,

$$
\mathfrak{p}_{t} \equiv \frac{P_{t}^{H}}{p_{t} h_{t}}=\frac{q_{t}^{N}+q_{t}^{X} x_{t}}{p_{t} h_{t}}
$$

Using (4), (10), (78), (80) and (82) in (116) implies a long run value

$$
\mathfrak{p}^{*}=\frac{1+\frac{(1-\gamma)\left(1-\tau_{r}\right) \delta^{X}}{\rho}}{\frac{\rho}{1-\tau_{r}}+\delta^{X}}
$$

Combining (80) and (125) and using (4) yields

$$
p^{*} h^{*}=\frac{\psi R^{Z *}}{1-\gamma}
$$

The result regarding the house price follows from the fact that $P^{H *}=p^{*} h^{*} \mathfrak{p}^{*}$ and the properties of $R^{Z *}$. Part (iv) just restates (78). This concludes the proof.

Proof of Proposition 3. First, use (98) and (100), to find

$$
\mathfrak{z}^{Y *}=\frac{Z^{Y *}}{Z}=\frac{\mu-v}{1-v}\left[=1-\mathfrak{z}^{N *}\right]
$$




$$
l^{X *}=\frac{L^{X *}}{L}=\frac{v(1-\mu)}{(1-v) \mu}\left[=1-l^{Y *}\right]
$$

respectively. Moreover, according to (97) and (113),

$$
\frac{N^{*}}{Z}=\frac{1-\mu}{\psi(1-v)}
$$

By using (30), we can write for the housing wealth-to-GDP ratio, the non-residential-land to GDP ratio, and the non-residential wealth-to-GDP ratio as

$$
\begin{gathered}
\mathfrak{H}_{t}^{G D P}=\frac{P_{t}^{H} N_{t}}{G D P_{t}}=\frac{\mathfrak{p}_{t}}{1+\frac{Y_{t}}{p_{t} N_{t} h_{t}}+\frac{w_{t} L_{t}^{X}}{p_{t} h_{t} N_{t}}}, \\
\mathfrak{K}_{t}^{G D P}=\frac{K_{t}}{G D P_{t}}=\frac{\frac{K_{t}}{Y_{t}}}{1+\frac{p_{t} N_{t} h_{t}}{Y_{t}}+\frac{w_{t} L_{t}}{Y_{t}} \frac{L_{t}^{X}}{L_{t}}} . \\
\mathfrak{Z}_{t}^{G D P}=\frac{P_{t}^{Z} Z_{t}^{Y}}{G D P_{t}}=\frac{\frac{P_{t}^{Z} Z_{t}^{Y}}{Y_{t}}}{1+\frac{p_{t} N_{t} h_{t}}{Y_{t}}+\frac{w_{t} L_{t}}{Y_{t}} \frac{L_{t}^{X}}{L_{t}}} .
\end{gathered}
$$

According to (78), (79) and (81), in the long run,

$$
q^{N *}=\frac{\psi R^{Z *}}{r^{*}}
$$

Substituting (115) into (118) leads to

$$
p^{*} h^{*}=\frac{\psi(1-\alpha-\beta)}{1-\gamma}\left(\frac{\alpha}{\frac{\rho}{1-\tau_{r}}+\delta^{K}}\right)^{\frac{\alpha}{1-\alpha}}\left(B^{Y}\right)^{\frac{1}{1-\alpha}}\left(\frac{D}{\mu}\right)^{\frac{\beta}{1-\alpha}} .
$$

According to (1), (4) and (69), we have

$$
\frac{Y}{p N h}=\frac{B^{Y}\left(\frac{\alpha}{\beta} \frac{w}{r+\delta^{K}}\right)^{\alpha}\left(\frac{L^{Y}}{Z^{Y}}\right)^{\alpha+\beta} \frac{Z^{Y}}{Z}}{p h \frac{N}{Z}}
$$


Moreover, using $\tilde{D}^{Y}\left(\tilde{p}^{*}(\mathbf{B}, D), \mathbf{B}\right) / D=1 / \mu$ from (113) in (112), we have

$$
\frac{\mu-v}{1-\mu}=\frac{1-\alpha-\beta}{1-\gamma} \frac{\left(\frac{1}{\theta}+\frac{\eta \gamma \delta^{X}}{\frac{\rho}{1-\tau_{r}}+\delta^{X}}\right)\left(\frac{\rho}{1-\tau_{r}}+\delta^{K}\right)}{\frac{\rho}{1-\tau_{r}}+(1-\alpha) \delta^{K}}
$$

Substituting (121), (119), (114), (126) and $L^{Y *} / Z^{Y *}=\tilde{D}^{Y}\left(p^{*}, \mathbf{B}\right)=D / \mu($ recall $(113))$ into (127), and using (128), we get

$$
\frac{Y^{*}}{p^{*} N^{*} h^{*}}=\frac{\left(\frac{1}{\theta}+\frac{\eta \gamma \delta^{X}}{\frac{\rho}{1-\tau_{r}}+\delta^{X}}\right)\left(\frac{\rho}{1-\tau_{r}}+\delta^{K}\right)}{\frac{\rho}{1-\tau_{r}}+(1-\alpha) \delta^{K}}
$$

in long run equilibrium. Moreover,

$$
\frac{w L^{X}}{p h N}=\frac{w}{p h} l^{X} \frac{L / Z}{N / Z}
$$

Substituting (120), (114) and (121) into (130) and using (78), $D=L / Z$ and $v$ as given by (95), we obtain

$$
\frac{w^{*} L^{X *}}{p^{*} N^{*} h^{*}}=\frac{(1-\eta) \gamma \delta^{X}}{\frac{\rho}{1-\tau_{r}}+\delta^{X}} .
$$

Using (117), (129) and (131) in (122) confirms (38).

According to (66), (67), (68) and $L^{Y}=L\left(1-l^{X}\right)$, we have

$$
\begin{aligned}
\frac{K}{Y} & =\frac{\alpha}{r+\delta^{K}}, \\
\frac{w L}{Y} & =\frac{\beta}{1-l^{X}}, \\
\frac{R^{Z} Z^{Y}}{Y} & =1-\alpha-\beta .
\end{aligned}
$$

Using that (78) and (81), in long run equilibrium,

$$
\frac{P^{Z *} Z^{Y *}}{Y^{*}}=\frac{(1-\alpha-\beta)\left(1-\tau_{r}\right)}{\rho} .
$$

Substituting (129), (132), (133) and (135) in (123) and (124), respectively, and using 
(78), (95), (120) and (128) confirm (39) and (40).

Finally, in the long run, investment equals depreciation; thus, the long run net domestic product equals consumption expenditure, $N D P^{*}=C^{*}+p^{*} S^{*}$. The ratio of consumption expenditure to GDP can be written as

$$
\frac{C_{t}+p_{t} S_{t}}{G D P_{t}}=\frac{\frac{C_{t}}{p_{t} S_{t}}+1}{1+\frac{Y_{t}}{p_{t} N_{t} h_{t}}+\frac{w_{t} L_{t}^{X}}{p_{t} N_{t} h_{t}}}
$$

Using (76), (129) and (131) in (136) confirms (41). This concludes the proof.

Proof of Corollary 1. The result immediately follows from Proposition 3, (34) and $(35)$.

\section{References}

[1] Bonnet, Odran, Pierre-Henri Bono, Guillaume Chapelle, and Étienne Wasmer (2014). Does Housing Capital Contribute to Inequality? A Comment on Thomas Piketty's Capital in the 21st Century", Sciences Po Economics Discussion Paper 2014-07.

[2] Borri, Nicola and Pietro Reichlin (2016). The Housing Cost Disease, LUISS University, mimeo.

[3] Bureau of Economic Analysis (2004). BEA Depreciation Estimates, http://www.bea.gov/national/FA2004/Tablecandtext.pdf

[4] Bureau of Economic Analysis (2015a). Value Added by Industry as a Percentage of Gross Domestic Product 1997-2014, released on November 5, 2015, http://www.bea.gov/iTable/iTable.cfm?ReqID $=51 \&$ step $=1 \#$ reqid $=51 \&$ step $=51 \&$ isuri $=1 \& 5114=$ a\& $5102=5$

[5] Bureau of Economic Analysis (2015b). Table 5.2.5.: Gross and Net Domestic Investment by Major Type, Annual Data from 1969 to 2014, released on August 6, 2015, http://www.bea.gov//national/nipaweb/DownSS2.asp 
[6] Caselli, Francesco and Jaume Ventura (2000). A Representative Consumer Theory of Distribution, American Economic Review 90, 909-926.

[7] Davis, Morris A. and Jonathan Heathcote (2005). Housing and the Business Cycle, International Economic Review 46, 751-784.

[8] Davis, Morris A. and Jonathan Heathcote (2007). The Price and Quantity of Residential Land in the United States, Journal of Monetary Economics 54, 2595-2620.

[9] Favilukis, Jack, Sydney Ludvigson and Stijn Van Nieuwerburgh (2015). The Macroeconomic Effects of Housing Wealth, Housing Finance, and Limited Risk Sharing in General Equilibrium, Journal of Political Economy, forthcoming.

[10] Gennaioli, Nicola, Andrei Shleifer, and Robert Vishny. 2014. "Finance and the Preservation of Wealth." Quarterly Journal of Economics 129 (3): 1221-1254.

[11] Glaeser, Edward L. and Joseph Gyourko (2003). The Impact of Building Restrictions on Housing Affordability, Federal Reserve Bank of New York, Economic Policy Review, 21-39.

[12] Glaeser, Edward L., Joseph Gyourko and Raven E. Saks (2005). Why Have House Prices Gone Up? American Economic Review Papers and Proceedings 95, 329-333.

[13] Henderson, Richard (2015). Industry Employment and Output Projections to 2024, Monthly Labor Review, US Bureau of Labor Statistics, December 2015.

[14] Hornstein, Andreas (2008). Notes on a Model of Housing with Collateral Constraints. Federal Reserve Bank of Richmond Working Paper.

[15] Hornstein, Andreas (2009). Problems for a Fundamental Theory of House Prices, Economic Quarterly 95, 1, 1-24.

[16] House, Christopher L. and Matthew D. Shapiro (2008). Temporary Investment Tax Incentives: Theory with Evidence from Bonus Depreciation, American Economic Review 98, 737-768. 
[17] Iacoviello, Matteo and Stefano Neri (2010). Housing Market Spillovers: Evidence from an Estimated DSGE," American Economic Journal: Macroeconomics, 2 , 125164.

[18] Jordà, Òscar, Moritz Schularick and Alan M. Taylor (2016). The Great Mortgaging: Housing Finance, Crises, and Business Cycles, Economic Policy, 107-152.

[19] Karabarbounis, Loukas and Brent Neiman (2014). The Global Decline of the Labor Share, Quarterly Journal of Economics 129, 61-103.

[20] Knoll, Katharina, Moritz Schularick and Thomas Steger (2014), No Price Like Home: Global House Prices, 1870-2012, CEPR Working Paper, DP10166, September 2014.

[21] Krusell, Per and Anthony A. Smith Jr. (2015). Is Piketty's "Second Law of Capitalism" Fundamental?, Journal of Political Economy 123, 725-748.

[22] Li, Bin and Zhixiong Zeng (2010). Fundamentals Behind House Prices, Economics Letters, 108, 205-207.

[23] Mas-Colell, Andreu, Michael D. Whinston and Jerry R. Green 1995, Microeconomic Theory, Oxford, Oxford University Press.

[24] Matsuyama, Kiminori (1990). Residential Investment and the Current Account, Journal of International Economics 28, 137-153.

[25] Nichols, Donald A. (1970). Land and Economic Growth, American Economic Review, $60(3), 332-340$.

[26] OECD (2015). OECD Tax Database, Paris, Table II.4, retrieved on February 9, 2016.

[27] Philippon, Thomas. 2015. "Has the US Finance Industry Become Less Efficient? On the Theory and Measurement of Financial Intermediation." American Economic Review, 105(4): 1408-38. 
[28] Piazzesi, Monica and Martin Schneider (2016). Housing and Macroeconomics, Elsevier, Handbook of Macroeconomics, John B. Taylor and Harald Uhlig (eds.), Vol. 2, forthcoming.

[29] Piketty, Thomas (2014). Capital in the 21st Century. Harvard University Press, Cambridge.

[30] Piketty, Thomas and Gabriel Zucman (2014a). Capital is Back: Wealth-Income Ratios in Rich Countries 1700-2010, Quarterly Journal of Economics 129, 12551310.

[31] Piketty, Thomas and Gabriel Zucman (2014b). Online Data Set for "Capital is Back: Wealth-Income Ratios in Rich Countries 1700-2010", http://gabriel-zucman.eu/capitalisback/

[32] Piketty, Thomas and Gabriel Zucman (2015). Wealth and Inheritance in the Long Run, in: Atkinson, Anthony and François J. Bourguignon (Eds.), Handbook of Income Distribution, Vol. 2B, Elsevier, Ch. 15, 1303-1368.

[33] Ricardo, David (1817). On the Principles of Political Economy and Taxation, London: John Murray.

[34] Rognlie, Matthew (2015). Deciphering the Fall and Rise in the Net Capital Share, Brookings Papers on Economic Activity, forthcoming.

[35] Sachs, Jeffrey and Peter Boone (1988). Japanese Structural Adjustment and the Balance of Payments, Journal of the Japanese and International Economics 2, 286327.

[36] Saiz, Albert (2010). The Geographic Determinants of Housing Supply, The Quarterly Journal of Economics 125 (3): 1253-1296.

[37] Stiglitz, Joseph E. (2015). New Theoretical Perspectives on the Distribution of Income and Wealth Among Individuals: Part IV. Land and Credit, NBER Working Paper 21192. 


\section{Online-Appendix A: House Capital Model}

In Online-Appendix A, we first summarize the dynamic system of our new model. We then invoke Walras' law as consistency check of the analytical derivation of the long run equilibrium. Moreover, we present additional results for the long run equilibrium that characterizes the amount of structures and housing services, factor income shares, and investment rates. Finally, we discuss the amendment of the land price to account for lower rural land prices than urban land prices and show transitional dynamics without the amendment.

\section{A.1 Dynamic System}

Recall $\pi=(1-\gamma) p B^{h} x^{\gamma}$ from (11) and $x=X / N$. For given $K_{0}, N_{0}, x_{0}$, the dynamic system reads as:

$$
\begin{aligned}
& \frac{\dot{C}}{C}=\left(1-\tau_{r}\right) r-\rho, \\
& \frac{\dot{q}^{N}}{q^{N}}+\frac{\pi}{q^{N}}=r, \\
& \frac{\dot{P}^{Z}}{P^{Z}}+\frac{R^{Z}}{P^{Z}}=r, \\
& \frac{\dot{q}^{X}}{q^{X}}+\frac{R^{X}}{q^{X}}-\delta^{X}=r, \\
& \dot{X}=B^{X} M^{\eta}\left(L^{X}\right)^{1-\eta}-\delta^{X} X, \\
& \dot{A}=r A+R^{Z} Z^{Y}+w L-C-p S, \\
& \dot{N}=\frac{q^{N}-\psi P^{Z}}{\xi}, \\
& \left(\frac{r+\delta^{K}}{\alpha}\right)^{\alpha}\left(\frac{w}{\beta}\right)^{1-\alpha}=B^{Y}\left(\frac{Z^{Y}}{L^{Y}}\right)^{1-\alpha-\beta}, \\
& R^{Z}=B^{Y}(1-\alpha-\beta)\left(\frac{\alpha}{\beta} \frac{w}{r+\delta^{K}}\right)^{\alpha}\left(\frac{L^{Y}}{Z^{Y}}\right)^{\alpha+\beta} . \\
& R^{X}=p B^{h} \gamma x^{\gamma-1}
\end{aligned}
$$




$$
\begin{gathered}
\frac{L^{X}}{M}=\left(\frac{1}{q^{X} \eta B^{M} B^{X}}\right)^{\frac{1}{1-\eta}}, \\
w=(1-\eta)\left(\eta B^{M}\right)^{\frac{\eta}{1-\eta}}\left(B^{X} q^{X}\right)^{\frac{1}{1-\eta}}, \\
Z^{Y}=Z-\psi N, \\
L^{X}+L^{Y}=L, \\
\theta C=p S \\
S=N B^{h} x^{\gamma}, \\
A=K+q^{N} N+q^{X} X \\
K=\frac{\alpha}{\beta} \frac{w}{r+\delta^{K}} L^{Y} .
\end{gathered}
$$

These are 18 equations and 18 endogenous variables: $X, N, A, C, q^{N}, P^{Z}, q^{X}, K, Z^{Y}, L^{X}, L^{Y}$, $M, S, r, w, R^{X}, R^{Z}, p$.

\section{A.2 Consistency Check Using Walras' Law}

We show that the market for the numeraire good clears in long run equilibrium, i.e. $Y=C+\delta^{K} K+p^{M} M$ holds in steady state (market for numeraire good clears, according to equilibrium condition 9 in Definition 1 , and $\dot{K}=\dot{N}=\dot{X}=0)$. Recall the following definitions hold.

$$
\begin{aligned}
\varrho & \equiv \frac{\beta}{1-\alpha}-\frac{\gamma(1-\eta)}{1-\gamma \eta} \\
\chi & \equiv \frac{\eta^{\eta}\left(\frac{\beta}{1-\eta}\right)^{\frac{\gamma \eta(1-\eta)}{1-\gamma \eta}}\left(\frac{\alpha}{r+\delta^{K}}\right)^{\frac{\alpha \eta}{1-\alpha}}\left(\frac{\nu}{\delta^{X}}\right)^{\frac{1-\eta}{1-\gamma \eta}}}{1-\nu} \frac{1-\mu}{\mu^{1-\eta+\frac{\beta \eta}{1-\alpha}}}\left(\frac{(1-\alpha-\beta) \gamma}{(1-\gamma)\left(r+\delta^{X}\right)}\right)^{\frac{\eta(1-\gamma)}{1-\gamma \eta}} \\
v & \equiv \frac{(1-\alpha-\beta)(1-\eta) \gamma \delta^{X}}{\beta(1-\gamma)\left(r+\delta^{X}\right)}, \\
D & \equiv \frac{L}{Z}
\end{aligned}
$$


In steady state, the following relationships hold (we suppress superscript $\left({ }^{*}\right)$ ):

$$
\begin{aligned}
& K=\frac{\alpha}{\beta} \frac{w}{r+\delta^{K}} L^{Y}, \\
& \frac{K}{Y}=\frac{\alpha}{r+\delta^{K}}, \\
& w=\beta\left(\frac{\alpha}{r+\delta^{K}}\right)^{\frac{\alpha}{1-\alpha}}\left(B^{Y}\right)^{\frac{1}{1-\alpha}}\left(\frac{\mu}{D}\right)^{\frac{1-\alpha-\beta}{1-\alpha}}, \\
& C=\frac{p S}{\theta}, \\
& \frac{L^{X}}{L}=\frac{v(1-\mu)}{(1-v) \mu}=1-\frac{L^{Y}}{L} \\
& \Longrightarrow \frac{L^{Y}}{L}=\frac{1}{1-v}-\frac{v}{1-v} \frac{1}{\mu}, \\
& \frac{S}{L}=\chi^{\gamma}\left(\frac{1-\mu}{\psi(1-v)}\right)^{1-\gamma} \frac{B^{h}}{D^{1-\gamma+\frac{(1-\alpha-\beta) \gamma \eta}{1-\alpha}}}\left(B^{M}\right)^{\gamma \eta}\left(B^{X}\right)^{\gamma}\left(B^{Y}\right)^{\frac{\gamma \eta}{1-\alpha}}, \\
& B^{h} p=\left(\frac{D}{\mu}\right)^{\varrho(1-\gamma \eta)} \frac{\left(\frac{\alpha}{r+\delta^{K}}\right)^{\frac{\alpha(1-\gamma \eta)}{1-\alpha}}\left(B^{Y}\right)^{\frac{1-\gamma \eta}{1-\alpha}}\left(\frac{\psi(1-\alpha-\beta)}{1-\gamma}\right)^{1-\gamma}}{\left(\eta B^{M}\right)^{\gamma \eta}\left(\frac{B^{X} \gamma}{r+\delta^{X}}\right)^{\gamma}\left(\frac{1-\eta}{\beta}\right)^{\gamma(1-\eta)}}, \\
& \frac{N}{Z}=\frac{1-\mu}{\psi(1-\nu)}, \\
& M=\left(L^{X}\right)^{\frac{\gamma(1-\eta)}{1-\gamma \eta}}\left(\frac{\gamma \eta p B^{M} B^{h}\left(\delta^{X} N\right)^{1-\gamma}\left(B^{X}\right)^{\gamma}}{r+\delta^{X}}\right)^{\frac{1}{1-\gamma \eta}} .
\end{aligned}
$$


We first derive

$$
\begin{aligned}
& \frac{Y-C-\delta^{K} K}{K}=\frac{Y}{K}-\frac{C}{K}-\delta^{K} \\
& =\frac{r+\delta^{K}}{\alpha}-\frac{\frac{p S}{\theta}}{\frac{1}{\beta} \frac{\alpha}{r+\delta^{K}} \beta\left(\frac{\alpha}{r+\delta^{K}}\right)^{\frac{\alpha}{1-\alpha}}\left(B^{Y}\right)^{\frac{1}{1-\alpha}}\left(\frac{\mu}{D}\right)^{\frac{1-\alpha-\beta}{1-\alpha}} L^{Y}}-\delta^{K} \\
& =-\frac{\chi^{\gamma}\left(\frac{1-\mu}{1-v}\right)^{1-\gamma}\left(\frac{D}{\mu}\right)^{\varrho(1-\gamma \eta)}\left(\frac{\alpha}{r+\delta^{K}}\right)^{\frac{\alpha(1-\gamma \eta)}{1-\alpha}}\left(\frac{1-\alpha-\beta}{1-\gamma}\right)^{1-\gamma}\left(\frac{\beta}{1-\eta}\right)^{\gamma(1-\eta)}}{\theta D^{1-\gamma+\frac{(1-\alpha-\beta) \gamma \eta}{1-\alpha}}\left(\frac{\alpha}{r+\delta^{K}}\right)^{\frac{1}{1-\alpha}}\left(\frac{\mu}{D}\right)^{\frac{1-\alpha-\beta}{1-\alpha}}\left(\frac{1}{1-v}-\frac{v}{1-v} \frac{1}{\mu}\right) \eta^{\gamma \eta}\left(\frac{\gamma}{r+\delta^{X}}\right)^{\gamma}}+ \\
& \frac{r+(1-\alpha) \delta^{K}}{\alpha} \\
& =-\frac{\left(\eta^{\eta}\left(\frac{v}{\delta^{X}}\right)^{\frac{1-\eta}{1-\gamma \eta}}\left(\frac{1-\alpha-\beta}{1-\gamma} \frac{\gamma}{r+\delta^{X}}\right)^{\frac{\eta(1-\gamma)}{1-\gamma \eta}}\left(\frac{\beta}{1-\eta}\right)^{\frac{\gamma \eta(1-\eta)}{1-\gamma \eta}}\right)^{\gamma} \frac{1-\mu}{1-v} \times}{\mu^{\left(1-\eta+\frac{\beta \eta}{1-\alpha}\right) \gamma} \theta D^{1-\gamma+\frac{(1-\alpha-\beta) \gamma \eta}{1-\alpha}} \frac{\alpha}{r+\delta^{K}}\left(\frac{1}{1-v}-\frac{v}{1-v} \frac{1}{\mu}\right) \eta^{\gamma \eta}\left(\frac{\gamma}{r+\delta^{X}}\right)^{\gamma}} \\
& \left(\frac{D}{\mu}\right)^{1-\frac{\beta \gamma \eta}{1-\alpha}-\gamma(1-\eta)}\left(\frac{1-\alpha-\beta}{1-\gamma}\right)^{1-\gamma}\left(\frac{\beta}{1-\eta}\right)^{\gamma(1-\eta)}+\frac{r+(1-\alpha) \delta^{K}}{\alpha} \\
& =-\frac{\left(\frac{v}{\delta^{X}}\right)^{\frac{(1-\eta) \gamma}{1-\gamma \eta}}\left(\frac{D}{\mu}\right)^{1-\frac{\beta \gamma \eta}{1-\alpha}-\gamma(1-\eta)}\left(\frac{1-\alpha-\beta}{1-\gamma}\right)^{\frac{1-\gamma}{1-\gamma \eta}}\left(\frac{\beta}{1-\eta}\right)^{\frac{\gamma(1-\eta)}{1-\gamma \eta}}}{\mu^{\left(1-\eta+\frac{\beta \eta}{1-\alpha}\right) \gamma} \theta D^{1-\gamma+\frac{(1-\alpha-\beta) \gamma \eta}{1-\alpha}} \frac{\alpha}{r+\delta^{K}}\left(\frac{\gamma}{r+\delta^{X}}\right)^{\frac{(1-\eta) \gamma}{1-\gamma \eta}}} \frac{1-\mu}{\frac{\mu-v}{\mu}}+ \\
& \frac{r+(1-\alpha) \delta^{K}}{\alpha} \\
& =\frac{r+(1-\alpha) \delta^{K}}{\alpha}-\frac{r+\delta^{K}}{\alpha} \frac{1}{\theta}\left(\frac{1-\alpha-\beta}{1-\gamma}\right)^{\frac{1-\gamma}{1-\gamma \eta}} \times \\
& \left(\frac{\beta v}{1-\eta}\right)^{\frac{\gamma(1-\eta)}{1-\gamma \eta}}\left(\frac{r+\delta^{X}}{\gamma \delta^{X}}\right)^{\frac{(1-\eta) \gamma}{1-\gamma \eta}} \frac{1-\mu}{\mu-v}
\end{aligned}
$$


For $Y=C+\delta^{K} K+p^{M} M$ to hold, this must be equal to

$$
\begin{aligned}
\frac{p^{M} M}{K} & =\frac{\left(L^{X}\right)^{\frac{\gamma(1-\eta)}{1-\gamma \eta}}\left(\frac{\gamma \eta\left(\frac{D}{\mu}\right)^{\varrho(1-\gamma \eta)}\left(B^{Y}\right)^{\frac{1-\gamma \eta}{1-\alpha}}\left(\frac{\psi(1-\alpha-\beta)}{1-\gamma}\right)^{1-\gamma}\left(\delta^{X} N\right)^{1-\gamma}\left(B^{X}\right)^{\gamma}}{\left(r+\delta^{X}\right)^{1-\gamma} \eta^{\gamma \eta}\left(B^{X} \gamma\right)^{\gamma}\left(\frac{1-\eta}{\beta}\right)^{\gamma(1-\eta)}}\right)^{\frac{1}{1-\gamma \eta}}}{\frac{\alpha}{r+\delta^{K}}\left(B^{Y}\right)^{\frac{1}{1-\alpha}}\left(\frac{\mu}{D}\right)^{\frac{1-\alpha-\beta}{1-\alpha}} L^{Y}} \\
& =\frac{\left(\frac{v}{1-v}\left[\frac{1}{\mu}-1\right]\right)^{\frac{\gamma(1-\eta)}{1-\gamma \eta}} \eta\left(\frac{\left(B^{Y}\right)^{\frac{1-\gamma \eta}{1-\alpha}}(1-\alpha-\beta)^{1-\gamma}\left(\delta^{X} \frac{1-\mu}{1-v}\right)^{1-\gamma}}{\left(r+\delta^{X}\right)^{1-\gamma}\left(\frac{1-\eta}{\beta}\right)^{\gamma(1-\eta)}}\right)^{\frac{1}{1-\gamma \eta}}\left(\frac{\gamma}{1-\gamma}\right)^{\frac{1-\gamma}{1-\gamma \eta}}}{\frac{\alpha}{r+\delta^{K}}\left(B^{Y}\right)^{\frac{1}{1-\alpha}}\left(\frac{1}{1-v}-\frac{v}{1-v} \frac{1}{\mu}\right) \mu^{\frac{1-\gamma}{1-\gamma \eta}}} \\
& =\left(\frac{\gamma(1-\alpha-\beta) \delta^{X}}{(1-\gamma)\left(r+\delta^{X}\right)}\right)^{\frac{1-\gamma}{1-\gamma \eta}}\left(\frac{\beta v}{1-\eta}\right)^{\frac{\gamma(1-\eta)}{1-\gamma \eta}} \frac{1-\mu}{\mu-v} \frac{r+\delta^{K}}{\alpha} \eta .
\end{aligned}
$$

Recall that $\mu$ is implicitly defined by

$$
\frac{1-\alpha-\beta}{1-\gamma}\left(\frac{1}{\theta}+\frac{\eta \gamma \delta^{X}}{r+\delta^{X}}\right) \frac{1-\mu}{\mu-v}=\frac{r+(1-\alpha) \delta^{K}}{r+\delta^{K}}
$$

The market for the numeraire good thus clears if

$$
\begin{aligned}
& \frac{r+(1-\alpha) \delta^{K}}{r+\delta^{K}} \\
= & \left(\frac{\gamma(1-\alpha-\beta) \delta^{X}}{(1-\gamma)\left(r+\delta^{X}\right)}\right)^{\frac{1-\gamma}{1-\gamma \eta}}\left(\frac{\beta v}{1-\eta}\right)^{\frac{\gamma(1-\eta)}{1-\gamma \eta}} \frac{1-\mu}{\mu-v} \eta+ \\
& \frac{1}{\theta}\left(\frac{1-\alpha-\beta}{1-\gamma}\right)^{\frac{1-\gamma}{1-\gamma \eta}}\left(\frac{\beta v}{1-\eta}\right)^{\frac{\gamma(1-\eta)}{1-\gamma \eta}}\left(\frac{r+\delta^{X}}{\gamma \delta^{X}}\right)^{\frac{(1-\eta) \gamma}{1-\gamma \eta}} \frac{1-\mu}{\mu-v} \\
\Longleftrightarrow & \left(\frac{1-\alpha-\beta}{1-\gamma}\right)^{\frac{\gamma(1-\eta)}{1-\gamma \eta}}=\left(\frac{\beta v}{1-\eta}\right)^{\frac{\gamma(1-\eta)}{1-\gamma \eta}}\left(\frac{r+\delta^{X}}{\gamma \delta^{X}}\right)^{\frac{\gamma(1-\eta)}{1-\gamma \eta}} \\
\Longleftrightarrow & \left(\frac{1-\alpha-\beta}{1-\gamma}\right)^{\frac{\gamma(1-\eta)}{1-\gamma \eta}}=\left(\frac{(1-\alpha-\beta) \gamma \delta^{X}}{(1-\gamma)\left(r+\delta^{X}\right)}\right)^{\frac{\gamma(1-\eta)}{1-\gamma \eta}}\left(\frac{r+\delta^{X}}{\gamma \delta^{X}}\right)^{\frac{\gamma(1-\eta)}{1-\gamma \eta}},
\end{aligned}
$$

which holds.

\section{A.3 Structures and Housing Services in Long Run Equilibrum}

Proposition A.1. (Long run "height" of structures and housing consumption). Under (A1), in long run equilibrium, 
(i) the amount of structures per unit of land, $X^{*} / Z$, is increasing in $D, B^{Y}, B^{X}, B^{h}$, $B^{M}$, and independent of $\psi$;

(ii) the amount of housing services per capita, $S^{*} / L$, is increasing in $B^{Y}, B^{X}, B^{h}$, $B^{M}$, and decreasing in both $D$ and $\psi$.

Proof. Inserting (86) into (83) and using (78), (96), (121) and (113) implies that the long run equilibrium amount of structure per unit of land is given by

$$
\frac{X^{*}}{Z}=\frac{1-\mu}{1-v}\left(\frac{\nu}{\delta^{X}} \frac{D}{\mu}\right)^{\frac{1-\eta}{1-\gamma \eta}}\left(\frac{\gamma \eta B^{M} B^{h} p^{*}}{\left(\frac{\rho}{1-\tau_{r}}+\delta^{X}\right) \psi^{1-\gamma}}\right)^{\frac{\eta}{1-\gamma \eta}}\left(B^{X}\right)^{\frac{1}{1-\gamma \eta}} .
$$

According to (64) and (113), we have

$$
B^{h} p^{*}=\left(\frac{D}{\mu}\right)^{\varrho(1-\gamma \eta)} \frac{\left(\frac{\alpha}{\frac{\rho}{1-\tau_{r}}+\delta^{K}}\right)^{\frac{\alpha(1-\gamma \eta)}{1-\alpha}}\left(B^{Y}\right)^{\frac{1-\gamma \eta}{1-\alpha}}\left(\frac{\psi(1-\alpha-\beta)}{1-\gamma}\right)^{1-\gamma}}{\left(\eta B^{M}\right)^{\gamma \eta}\left(\frac{B^{X} \gamma}{\frac{\rho}{1-\tau_{r}}+\delta^{X}}\right)^{\gamma}\left(\frac{1-\eta}{\beta}\right)^{\gamma(1-\eta)}}
$$

Substituting (174) into (173) and using the definition of $\varrho$ in (A1) yields

$$
\begin{aligned}
\frac{X^{*}}{Z} & =\chi D^{1-\eta+\frac{\beta \eta}{1-\alpha}}\left(B^{M}\right)^{\eta} B^{X}\left(B^{Y}\right)^{\frac{\eta}{1-\alpha}}, \text { where } \\
\chi & \equiv \frac{\eta^{\eta}\left(\frac{\beta}{1-\eta}\right)^{\frac{\gamma \eta(1-\eta)}{1-\gamma \eta}}\left(\frac{\alpha}{\frac{\rho}{1-\tau_{r}}+\delta^{K}}\right)^{\frac{\alpha \eta}{1-\alpha}}\left(\frac{\nu}{\delta^{X}}\right)^{\frac{1-\eta}{1-\gamma \eta}}}{1-v} \frac{1-\mu}{\mu^{1-\eta+\frac{\beta \eta}{1-\alpha}}}\left(\frac{1-\alpha-\beta}{1-\gamma} \frac{\gamma}{\frac{\rho}{1-\tau_{r}}+\delta^{X}}\right)^{\frac{\eta(1-\gamma)}{1-\gamma \eta}}(176)
\end{aligned}
$$

According to $(27)$ and $X=N x$, the consumption of housing services per capita is given by

$$
\frac{S}{L}=\frac{N}{L} B^{h}\left(\frac{X}{N}\right)^{\gamma}=\left(\frac{N}{Z}\right)^{1-\gamma} \frac{B^{h}}{D}\left(\frac{X}{Z}\right)^{\gamma} .
$$

Using (121) and (173) in (177), we obtain

$$
\frac{S^{*}}{L}=\chi^{\gamma}\left(\frac{1-\mu}{\psi(1-v)}\right)^{1-\gamma} \frac{B^{h}}{D^{1-\gamma+\frac{(1-\alpha-\beta) \gamma \eta}{1-\alpha}}}\left(B^{M}\right)^{\gamma \eta}\left(B^{X}\right)^{\gamma}\left(B^{Y}\right)^{\frac{\gamma \eta}{1-\alpha}}
$$

Parts (i) and (ii) follow from (175) and (178), respectively, and using that $\mu$ is independent of $D$ and $\mathbf{B}$. This concludes the proof. 
Since $\mathfrak{z}^{N *}=\psi N^{*} / Z$ is independent of population density, $D$, and productivity parameters, B, according to (119), the number of houses per unit of land, $N^{*} / Z$, is independent of $D$ and $\mathbf{B}$ as well. Thus, an increase in $D$ or $\mathbf{B}$ means that more structures are built per unit of land, e.g., houses become "higher" rather than more numerous in more densely populated and in more advanced regions, reflecting the opportunity costs of land in its alternative use in the $Y$ sector. Technological progress therefore implies that the amount of housing services increases as well. That would also hold if on each unit of land more houses could be built (decrease in $\psi$ ). Finally, because of decreasing returns in transforming structures on a piece of land into housing services, the per capita amount of housing services is decreasing in population density.

\section{A.4 Factor Income Shares and Investment Rates in Long Run Equilibrum}

We finally consider the labor share in total income, $\mathfrak{L}_{t}=w_{t} L_{t} / G D P_{t}$, the land income share in the housing sector, $\mathfrak{I}_{t}=R_{t}^{Z} Z_{t}^{N} / H_{t}$, and the investment (and savings) rate of the economy can be decomposed into a non-residential and residential (housing) investment rate, denoted by $\mathfrak{s}_{t}^{K} \equiv I_{t}^{K} / G D P_{t}$ and $\mathfrak{s}_{t}^{H} \equiv\left(I_{t}^{N}+q_{t}^{X} I_{t}^{X}\right) / G D P_{t}$, respectively, i.e.,

$$
\mathfrak{s}_{t} \equiv \frac{I_{t}^{K}+I_{t}^{N}+q_{t}^{X} I_{t}^{X}}{G D P_{t}}=\mathfrak{s}_{t}^{K}+\mathfrak{s}_{t}^{H}
$$

Proposition A.2. (Long run factor income shares and investment rates). Under (A1), in long run equilibrium, the labor share in total income is

$$
\mathfrak{L}^{*}=\frac{w^{*} L}{G D P^{*}}=\frac{\beta+\frac{\frac{\rho}{1-\tau_{r}}+(1-\alpha) \delta^{K}}{\frac{\rho}{1-\tau_{r}}+\delta^{K}} \frac{(1-\eta) \gamma \delta^{X}}{\left(\frac{\frac{\rho}{-\tau_{r}}+\delta^{X}}{\theta}+\eta \gamma \delta^{X}\right)}}{1+\frac{\frac{\rho}{1-\tau_{r}}+(1-\alpha) \delta^{K}}{\frac{\rho}{1-\tau_{r}}+\delta^{K}} \frac{\left(\frac{\rho}{1-\tau_{r}}+\delta^{X}(1+(1-\eta) \gamma)\right)}{\left(\frac{\rho}{\frac{\rho}{\tau_{r}}+\delta^{X}}+\eta \gamma \delta^{X}\right)}},
$$


the land income share in the housing sector is

$$
\mathfrak{I}^{*}=\frac{1-\gamma}{1+\frac{(1-\eta) \gamma \delta^{X}}{\frac{\rho}{1-\tau_{r}}+\delta^{X}}}
$$

and the economy's total investment rate is

$$
\mathfrak{s}^{*}=1-\iota^{*}
$$

Thus, $\mathfrak{L}^{*}, \mathfrak{I}^{*}$ and $\mathfrak{s}^{*}$ are independent of $D, \mathbf{B}, \psi$. Also net capital income shares $r^{*} \mathfrak{H}^{N D P *}$ and $r^{*} \mathfrak{N}^{N D P *}$, the non-residential investment rate, $\mathfrak{s}^{K *}$, and the residential investment rate, $\mathfrak{s}^{H *}$, are independent of $D, \mathbf{B}, \psi$.

Proof. Using (30), we have

$$
\mathfrak{L}_{t}=\frac{\frac{w_{t} L_{t}}{Y_{t}}}{1+\frac{p_{t} N_{t} h_{t}}{Y_{t}}+\frac{w_{t} L_{t}}{Y_{t}} \frac{L_{t}^{X}}{L_{t}}} .
$$

Using (120) and (133) together with (78), (95) and (113) in (183) confirms (180). Moreover, using $H=p N h+w L^{X}$, we have

$$
\mathfrak{I}_{t}=\frac{R_{t}^{Z} Z_{t}^{N}}{p_{t} N_{t} h_{t}+w_{t} L_{t}^{X}} .
$$

For the long run, we can write

$$
\mathfrak{I}^{*}=\frac{R^{Z *} \mathfrak{z}^{N *}}{p^{*} h^{*} \frac{N^{*}}{Z}+w^{*} l^{X *} D},
$$

where we used $\mathfrak{z}^{N}=Z^{N} / Z, l^{X}=L^{X} / Z$ and $D=L / Z$. Recall long run values $\mathfrak{z}^{N *}=\frac{1-\mu}{1-v}$, $l^{X *}=\frac{v(1-\mu)}{(1-v) \mu}$ and $N^{*} / Z=\frac{1-\mu}{\psi(1-v)}$, according to (81), (119), (120) and (121), respectively. Substitute these values together with (114), (115), (119), (120), (121) and (118) into (185) and employ (95) with $r=r^{*}$ as given by (37) to confirm (181). Finally, by using (29) and (179),

$$
\mathfrak{s}_{t}=1-\frac{C_{t}+p_{t} S_{t}}{G D P_{t}} .
$$


Recalling $N D P^{*}=C^{*}+p^{*} S^{*}$ (i.e. $\left.\iota^{*}=N D P^{*} / G D P^{*}\right)$ and using (41) in (186) confirms (182). With respect to net capital income shares, the result follows from part (iv) of Proposition 2 and Corollary 1. Also note that $\dot{K}=0$ implies $I^{K *}=\delta^{K} K^{*}$; thus, $\mathfrak{s}^{K *}=I^{K *} / G D P^{*}=\delta^{K} \mathfrak{K}^{G D P *}$, confirming its claimed properties by recalling Proposition 3. Finally, recall $\mathfrak{s}^{H *}=\mathfrak{s}^{*}-\mathfrak{s}^{K *}$ and (182). This concludes the proof.

\begin{tabular}{|c|c||c|c|c|c|c|c|c|c|}
\hline$\rho$ & $\tau_{r}$ & $\mathfrak{L}^{*}$ & $r^{*} \mathfrak{H}^{N D P *}$ & $r^{*} \mathfrak{N}^{N D P *}$ & $l^{X *}$ & $\mathfrak{z}^{N *}$ & $\mathfrak{s}^{*}$ & $\mathfrak{s}^{K *}$ & $\mathfrak{s}^{H *}$ \\
\hline \hline 0.02 & 0.15 & 60.3 & 9.1 & 6.6 & 5.1 & 36.0 & 22.3 & 17.4 & 25.7 \\
\hline 0.03 & 0.15 & 59.7 & 10.6 & 8.6 & 4.1 & 36.9 & 19.4 & 15.5 & 21.9 \\
\hline \hline 0.02 & 0.2 & 60.2 & 9.3 & 6.9 & 4.9 & 36.1 & 21.9 & 17.1 & 25.1 \\
\hline 0.03 & 0.2 & 59.6 & 10.9 & 8.9 & 3.9 & 37.0 & 18.9 & 15.1 & 21.3 \\
\hline \hline 0.02 & 0.25 & 60.1 & 9.6 & 7.2 & 4.7 & 36.3 & 21.4 & 16.8 & 24.5 \\
\hline 0.03 & 0.25 & 59.5 & 11.1 & 9.2 & 3.8 & 37.1 & 18.4 & 14.8 & 20.7 \\
\hline
\end{tabular}

Table A.1. Long run implications for labor income share, net capital income shares, allocation variables, and investment rates.

Notes: All values are expressed in percent. Results are based on the following set of parameters: $\alpha=0.28, \beta=0.69, \gamma=0.9, \eta=0.38, \theta=0.22, \delta^{X}=0.015, \delta^{K}=0.07$. Recall $\mathfrak{L}^{*}=\frac{w^{*} L}{G D P^{*}}, \mathfrak{K}^{N D P *}=\frac{K^{*}}{N D P^{*}}, \mathfrak{N}^{N D P *}=\frac{K^{*}+P^{Z *} Z^{Y *}}{N D P^{*}}, l^{X *}=\frac{L^{X *}}{L}, \mathfrak{z}^{N *}=\frac{Z^{N *}}{Z}, \mathfrak{s}^{*}=\frac{I^{K *}+I^{N *}+q^{X *} I^{X *}}{G D P^{*}}$, $\mathfrak{s}^{K *}=\frac{I^{K *}}{G D P^{*}}, \mathfrak{s}^{H *}=\frac{I^{N *}+q^{X *} I^{X *}}{G D P^{*}}$.

According to Table A.1, net income shares, the factor allocation and investment rates are not critically depending on $\rho$. The implied long-run labor share in income, $\mathfrak{L}^{*}$, is about 59 percent. Looking at the latest available year, the labor income share was 57.2 percent in the year 2012 in the US and 62.1 percent in 2011 in the UK (Karabarbounis and Neiman, 2014, "CLS KN merged"). For $\rho=0.03$, the capital shares with respect to housing and non-residential capital are 11.8 and 14.8 percent, respectively, and somewhat lower for $\rho=0.02$. Ronglie (2015) suggests that the G7-countries' average for these respective capital shares are about 10 and 20 percent in recent times, with only the housing capital share rising over time. The implied employment fraction in residential 
construction, $l^{X *}$, is 5.3 and 6.6 percent for $\rho$ equal to three and two percent, respectively. It is relatively high compared with the more recent US value of 2.7 percent used for calibrating the model. The result is associated with a higher stock of structures, $X$, in the long run compared to the current (off steady state) one, in line with our prediction of a rising $\mathfrak{H}$. A high construction labor employment share copes with the constant depreciation rate of structures, $\delta^{X}$, given a high value of $X$. The implied long run fraction of land devoted to the housing sector in the economy, $\mathfrak{z}^{N *}$, is about 17 percent.

The long run investment rate for the baseline calibration, $\mathfrak{s}^{*}$, is 14.3 and 16.9 percent for $\rho$ equal to three and two percent, respectively, and may be compared to the US gross private domestic investment rate of 16.5 percent for the year 2014 (Bureau of Economic Analysis, 2015a). For the period 1969-2014, the average ratio of US non-residential investment to GDP, a measure for $\mathfrak{s}^{K}$, was 12.6 percent, which approximately also was the average value of the 1970s, 1980s, 1990s and 2000s (Bureau of Economic Analysis, 2015c, Tab. 1.1.10). The value is close to the long run value for $\mathfrak{s}^{K *}$ that is implied by our model. The implied long run residential investment rate, $\mathfrak{s}^{H *}=\mathfrak{s}^{*}-\mathfrak{s}^{K *}$, is in the range of 3.6 to 4.7 percent.

\section{A.5 Adjustment of the Land Price}

A simple and conceptually straightforward possibility to discuss the urban-rural land valuation bias as follows. Let us think in terms of a model economy that encompasses two regions: one rural and one urban region. The value of land in this economy would be given by

$$
\bar{P}^{Z} Z^{Y}=P_{U}^{Z} Z_{U}^{Y}+P_{R}^{Z} Z_{R}^{Y}
$$

where $\bar{P}^{Z}$ denotes the average non-residential land price, $P_{U}^{Z}$ the urban land price, $P_{R}^{Z}$ the

rural land price, $Z_{U}^{Y}$ the quantity of urban land, and $Z_{R}^{Y}$ the quantity of rural land. From the perspective of this two-region model, the House Capital Model makes the following 
mistake: It values rural (non-residential) land at the urban land price, i.e.,

$$
P^{Z} Z^{Y}=P_{U}^{Z} Z_{U}^{Y}+\underbrace{P_{U}^{Z}}_{!} Z_{R}^{Y}
$$

When comparing model results to empirical data taken from wealth statistics, it seems appropriate to value overall non-residential land, $Z^{Y}$, at the average (across rural and urban regions) land price $\bar{P}^{Z}$ instead of $P^{Z}$. Is there a systematic relationship between $\bar{P}^{Z}$ and $P^{Z}$ such that we can correct for this valuation bias? ${ }^{40}$ Dividing (187) by (188) yields

$$
\begin{aligned}
\frac{\bar{P}^{Z}}{P^{Z}} & =\frac{P_{U}^{Z} Z_{U}^{Y}}{P_{U}^{Z} Z_{U}^{Y}+P_{U}^{Z} Z_{R}^{Y}}+\frac{P_{R}^{Z} Z_{R}^{Y}}{P_{U}^{Z} Z_{U}^{Y}+P_{U}^{Z} Z_{R}^{Y}} \\
& =\frac{1}{1+\frac{Z_{R}^{Y}}{Z_{U}^{Y}}}+\frac{1}{\frac{P_{U}^{Z} Z_{U}^{Y}}{P_{R}^{Z} Z_{R}^{Y}}+\frac{P_{U}^{Z}}{P_{R}^{Z}}}
\end{aligned}
$$

Hence, the average land price $\bar{P}^{Z}$, that does not suffer from the rural-urban bias, and the (biased) land price $P^{Z}$ are related according to

$$
\bar{P}^{Z}=\kappa P^{Z} \quad \text { with } \quad \kappa \equiv \frac{1}{1+\frac{Z_{R}^{Y}}{Z_{U}^{Y}}}+\frac{1}{\frac{P_{U}^{Z} Z_{U}^{Y}}{P_{R}^{Z} Z_{R}^{Y}}+\frac{P_{U}^{Z}}{P_{R}^{Z}}}
$$

Assuming that farmland is valued by 25 percent of the total non-residential land value, $P_{U}^{Z} Z_{U}^{Y} / P_{R}^{Z} Z_{R}^{Y}=4$, there is three times more farm land than economically used nonrural land, $Z_{R}^{Y} / Z_{U}^{Y}$, and non-rural land has 12-times higher a price than farm land, $P_{U}^{Z} / P_{R}^{Z}=12$, gives us $\kappa=0.31$. In this case, the land price resulting from the House Capital Model, $P^{Z}$, should be multiplied by 0.31 to obtain a measure for the average (non-residential) land price $\bar{P}^{Z}$ that accounts for the urban-rural land price dispersion.

\section{A.6 Housing wealth and Non-Residential Wealth under $\kappa=1$}

We finally provide the version of Figure 2 and 3 (main text) without correcting for the land valuation bias $(\kappa=1)$. It can be recognized that especially the results with

\footnotetext{
${ }^{40}$ The alternative procedure would be to extend the House-Kapital model to explicitly encompass a rural and an urban region. This is left for future research.
} 
respect to housing wealth do not change much.
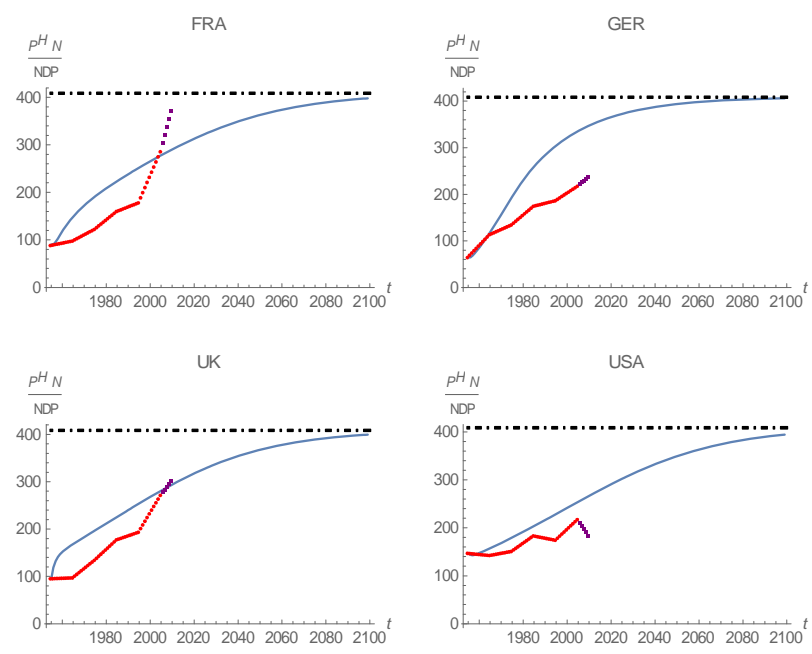

Figure A.1. Housing wealth (relative to NDP) from 1955 until 2100 under $\kappa=1$ Notes: cf. Figure 2.
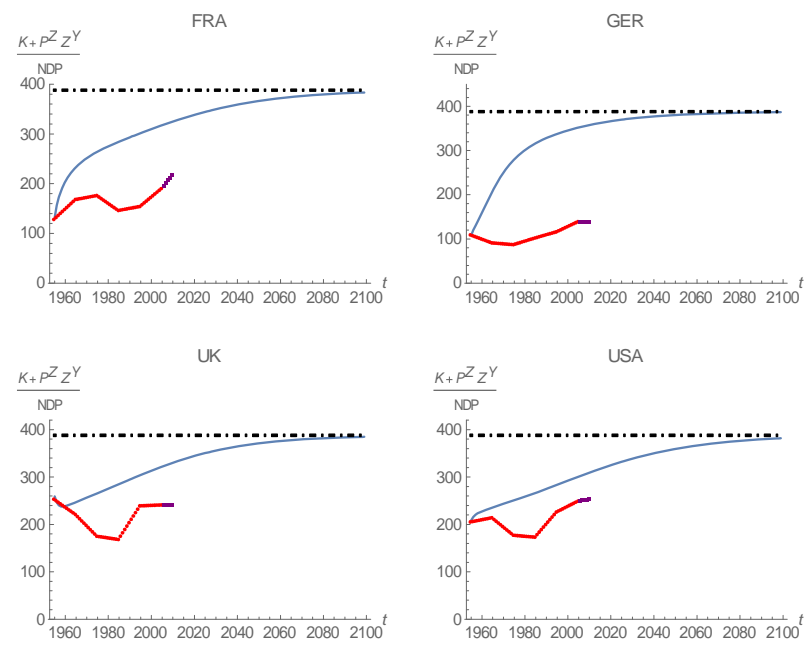

Figure A.2. Non-residential wealth (relative to NDP) from 1955 until 2100 under $\kappa=1$ Notes: cf. Figure 3.

\section{Additional Reference}

Bureau of Economic Analysis (2015c). Table 1.1.10.: Percentage Shares of Gross Domestic Product, Annual Data from 1969 to 2014, released on December 22, 2015, http://www.bea.gov//national/nipaweb/DownSS2.asp 


\section{Online-Appendix B: Canonical Model}

In Online-Appendix B, we first characterize analytically the long run equilibrium of the canonical model. We then invoke Walras' law as a consistency check of the analytical derivation of the long run equilibrium. Finally, we summarize the dynamical system of the canonical model.

\section{B.1 Long Run Equilibrium}

Define $l^{X} \equiv L^{X} / L, l^{Y} \equiv L^{Y} / L, k^{X} \equiv K^{X} / L, k^{Y} \equiv K^{Y} / L, k \equiv K / L, h \equiv H / L$ and $\bar{z} \equiv \bar{Z} / L$. Thus, (53) and (54) can be written as $k^{X}+k^{Y}=k$ and $l^{X}+l^{Y}=1$, respectively.

Proposition B.1. In the canonical model, (i) the long run allocation of labor, $\left(l^{X *}, l^{Y *}\right)$, is independent of both new land per capita, $\bar{z}$, and productivity parameters $B^{X}, B^{Y}, B^{H}$; (ii) the long run capital-labor ratio $\left(k^{*}\right)$ is independent of $\bar{z}, B^{X}, B^{H}$, and increasing in $B^{Y}$.

Proof of Proposition B.1. Denote by $p_{t}^{X}$ the price of structures at time $t$. Moreover, define $k^{X} \equiv K^{X} / L, k^{Y} \equiv K^{Y} / L$. Profit maximization in the $X$ and $Y$ sector then implies

$$
\begin{gathered}
\alpha B^{Y}\left(\frac{l^{Y}}{k^{Y}}\right)^{1-\alpha}=\gamma p^{X} B^{X}\left(\frac{l^{X}}{k^{X}}\right)^{1-\gamma}=r+\delta^{K}, \\
(1-\alpha) B^{Y}\left(\frac{k^{Y}}{l^{Y}}\right)^{\alpha}=(1-\gamma) p^{X} B^{X}\left(\frac{k^{X}}{l^{X}}\right)^{\gamma}=w .
\end{gathered}
$$

Combining (192) and (193) implies

$$
\begin{aligned}
k^{X} & =\frac{\gamma}{1-\gamma} \frac{w l^{X}}{r+\delta^{K}} \\
k^{Y} & =\frac{\alpha}{1-\alpha} \frac{w l^{Y}}{r+\delta^{K}} .
\end{aligned}
$$


Thus, using resource constraints $k^{X}+k^{Y}=k$ and $l^{X}+l^{Y}=1$, we obtain

$$
k=\frac{w}{r+\delta^{K}}\left(\frac{\gamma}{1-\gamma} l^{X}+\frac{\alpha}{1-\alpha}\left(1-l^{X}\right)\right) .
$$

Moreover, according to (192), (193) and resource constraints,

$$
\begin{aligned}
& p^{X}=\frac{(1-\alpha) B^{Y}\left(\frac{k-k^{X}}{1-l^{X}}\right)^{\alpha}}{(1-\gamma) B^{X}\left(\frac{k^{X}}{l^{X}}\right)^{\gamma}} \\
& w=(1-\alpha) B^{Y}\left(\frac{k-k^{X}}{1-l^{X}}\right)^{\alpha} .
\end{aligned}
$$

The current-value Hamiltonian of the representative housing firm associated with its profit maximization problem together with the necessary first-order conditions can be expressed as

$$
\begin{gathered}
\mathcal{H}^{H}=p H-p^{X} X-R^{Z} Z^{H}+q^{H}\left[B^{H} X^{\beta} \bar{Z}^{1-\beta}-\delta^{H} H\right] \\
{\left[\frac{\partial \mathcal{H}^{H}}{\partial X}=\right]-p^{X}+\beta q^{H} B^{H}\left(\frac{\bar{Z}}{X}\right)^{1-\beta}=0} \\
{\left[\frac{\partial \mathcal{H}^{H}}{\partial \bar{Z}}=\right]-R^{Z}+(1-\beta) q^{H} B^{H}\left(\frac{X}{\bar{Z}}\right)^{\beta}=0,} \\
{\left[-\frac{\partial \mathcal{H}^{H}}{\partial H}=\right]-p+\delta^{H} q^{H}=\dot{q}^{H}-r q^{H}}
\end{gathered}
$$

Substituting (49) into (200) and (201), we have

$$
\begin{gathered}
p^{X}=\beta q^{H} \frac{\tilde{B}^{H}}{B^{X}}\left(\frac{\bar{z}}{\left(k^{X}\right)^{\gamma}\left(l^{X}\right)^{1-\gamma}}\right)^{1-\beta}, \\
R=(1-\beta) q^{H} \tilde{B}^{H}\left(\frac{\left(k^{X}\right)^{\gamma}\left(l^{X}\right)^{1-\gamma}}{\bar{z}}\right)^{\beta},
\end{gathered}
$$


respectively, where we used $\tilde{B}^{H}=B^{H}\left(B^{X}\right)^{\beta}$. Combining (197) and (203) leads to

$$
q^{H}=\frac{(1-\alpha) B^{Y}\left(\frac{k-k^{X}}{1-l^{X}}\right)^{\alpha}}{(1-\gamma) \beta \tilde{B}^{H} \bar{z}^{1-\beta}} \frac{\left(l^{X}\right)^{1-\beta(1-\gamma)}}{\left(k^{X}\right)^{\beta \gamma}} .
$$

Setting $\dot{H}=0$ in (50) we get

$$
h=\frac{\tilde{B}^{H}}{\delta^{H}}\left(k^{X}\right)^{\beta \gamma}\left(l^{X}\right)^{\beta(1-\gamma)} \bar{z}^{1-\beta} .
$$

Using $S=H$, analogously to (76) and (77), utility maximization of the representative household yields

$$
\begin{gathered}
C=\frac{p H}{\theta}, \\
\frac{\dot{C}}{C}=r-\rho .
\end{gathered}
$$

In long run equilibrium, again, $\dot{C}=0$ implies $r^{*}=\rho$. Using $\dot{q}^{H}=0$ in (202) we find

$$
p=\left(r+\delta^{H}\right) q^{H}
$$

Moreover, setting $\dot{A}=0$ in (52) and using (207), $S=H,(51)$ and (209) leads to

$$
r k+w+R^{Z} \bar{z}=\left(\frac{r+(1+\theta) \delta^{H}}{\theta}\right) q^{H} h .
$$

Substituting (196), (198), (204), (205) and (206) into (210), we get

$$
l^{X}=\frac{\left[r+(1-\alpha) \delta^{K}\right] \beta \theta \delta^{H}(1-\gamma)}{(1-\alpha)\left(r+\delta^{K}\right)\left[r+(1+\beta \theta) \delta^{H}\right]+\beta \theta \delta^{H} r(\alpha-\gamma)} \equiv l^{X *} .
$$

This confirms part (i) of Proposition B.1. Substituting (198) into (196) leads to

$$
k=\frac{(1-\alpha) B^{Y}}{r+\delta^{K}}\left(\frac{\gamma}{1-\gamma} l^{X}+\frac{\alpha}{1-\alpha}\left(1-l^{X}\right)\right)\left(\frac{k-k^{X}}{1-l^{X}}\right)^{\alpha},
$$


Substituting $w=(1-\alpha) B^{Y}\left(k^{Y} / l^{Y}\right)^{\alpha}$ from (193) into (195) and using $l^{X}=l^{X *}$ we obtain

$$
k^{Y}=k-k^{X}=\left(\frac{\alpha B^{Y}}{r+\delta^{K}}\right)^{\frac{1}{1-\alpha}}\left(1-l^{X}\right) \equiv k^{Y *} .
$$

Substituting (213) into (212) and using $l^{X}=l^{X *}$ yields

$$
k=\left(\frac{\alpha B^{Y}}{r+\delta^{K}}\right)^{\frac{1}{1-\alpha}}\left(\frac{(\gamma-\alpha) l^{X *}}{\alpha(1-\gamma)}+1\right) \equiv k^{*} .
$$

Thus, in view of (211), also part (ii) of Proposition B.1 is confirmed.

Proposition B.2. In the canonical model, (i) the long run house price, $q^{H *}$, is decreasing in new land per capita, $\bar{z}$, increasing in $B^{Y}$, and decreasing in $B^{X}$ and $B^{H}$; (ii) the long run stock of houses per capita, $h^{*}$, is increasing in $B^{X}, B^{H}, B^{Y}$, and $\bar{z}$.

Proof of Proposition B.2. Substituting (198) into (194), we obtain

$$
k^{X}=\frac{\gamma}{1-\gamma} \frac{(1-\alpha) B^{Y} l^{X}}{r+\delta^{K}}\left(\frac{k-k^{X}}{1-l^{X}}\right)^{\alpha} .
$$

Next, substitute (215) into (205) and (206) and use both (213) and $l^{X}=l^{X *}$ to find

$$
\begin{gathered}
q^{H}=\frac{(1-\alpha)^{1-\beta \gamma}\left(B^{Y}\right)^{\frac{1-\beta \gamma}{1-\alpha}} \alpha^{\frac{\alpha(1-\beta \gamma)}{1-\alpha}}}{\gamma^{\beta \gamma}(1-\gamma)^{1-\beta \gamma} \beta \tilde{B}^{H}}\left(\frac{1}{r+\delta^{K}}\right)^{\frac{\alpha-\beta \gamma}{1-\alpha}}\left(\frac{l^{X *}}{\bar{z}}\right)^{1-\beta} \equiv q^{H *} \\
h=\frac{\tilde{B}^{H}}{\delta^{H}}\left(\frac{\gamma}{1-\gamma}\right)^{\beta \gamma}(1-\alpha)^{\beta \gamma} \alpha^{\frac{\alpha \beta \gamma}{1-\alpha}}\left(\frac{B^{Y}}{r+\delta^{K}}\right)^{\frac{\beta \gamma}{1-\alpha}}\left(l^{X *}\right)^{\beta} \bar{z}^{1-\beta} \equiv h^{*},
\end{gathered}
$$

respectively. Parts (i) and (ii) are confirmed by (216) and (217), respectively.

Proposition B.3. Let housing-wealth-to-GDP ratio be defined by $\mathfrak{H}_{t} \equiv \frac{q_{t}^{H} H_{t}}{Y_{t}+p_{t} H_{t}+q_{t}^{H} I_{t}^{H}}$. In the canonical model, a change in $B^{X}, B^{H}, B^{Y}$, and $\bar{z}$ do not affect (i) the long run housing-wealth-to-GDP ratio, (ii) the capital to GDP ratio, (iii) the labor share in GDP, (iv) the savings rate.

Proof of Proposition B.3. The "house-price-to-rent ratio" in the canonical model 
is $\mathfrak{p}_{t}=q_{t}^{H} / p_{t}$. Using $\dot{q}^{H}=0$ in (202), the long run value of the house-price-to-rent ratio is given by

$$
\mathfrak{p}^{*}=\frac{1}{r+\delta^{H}}
$$

Using $p^{*} / q^{H *}=r+\delta^{H}$, the definition of GDP in (56), $Y / L=B^{Y}\left(k^{Y}\right)^{\alpha}\left(l^{Y}\right)^{1-\alpha}$ from (47), and long run relationship $I^{H} / L=\delta^{H} h$ in $\mathfrak{H}_{t}=\frac{q_{t}^{H} H_{t}}{Y_{t}+p_{t} H_{t}+q_{t}^{H} I_{t}^{H}}$, we obtain

$$
\mathfrak{H}^{*}=\frac{q^{H *} h^{*}}{\left(\frac{Y}{L}\right)^{*}+p^{*} h^{*}+q^{H *}\left(\frac{I^{H}}{L}\right)^{*}}=\frac{1}{\frac{B^{Y}\left(k^{Y *}\right)^{\alpha}\left(l^{Y *}\right)^{1-\alpha}}{q^{H *} h^{*}}+r+2 \delta^{H}} .
$$

Using (216) and (217), we have

$$
q^{H *} h^{*}=\frac{(1-\alpha)\left(B^{Y}\right)^{\frac{1}{1-\alpha}}}{(1-\gamma) \beta \delta^{H}}\left(\frac{\alpha}{r+\delta^{K}}\right)^{\frac{\alpha}{1-\alpha}} l^{X *}
$$

According to $(213),(220)$ and $l^{Y *}=1-l^{X *}$, we obtain

$$
\frac{B^{Y}\left(k^{Y *}\right)^{\alpha}\left(l^{Y *}\right)^{1-\alpha}}{q^{H *} h^{*}}=\frac{(1-\gamma) \beta \delta^{H}}{1-\alpha} \frac{1-l^{X *}}{l^{X *}}
$$

Using (221) in (219) and recalling (211) confirms the part (i).

Using (56), the long run capital to GDP ratio, denoted by $\mathfrak{N}^{*}$, can be written as

$$
\mathfrak{N}^{*}=\frac{k^{*}}{\left(\frac{Y}{L}\right)^{*}+p^{*} h^{*}+q^{H *}\left(\frac{I^{H}}{L}\right)^{*}}=\frac{\frac{k^{*}}{q^{H *} h^{*}}}{\frac{B^{Y}\left(k^{Y *}\right)^{\alpha}\left(l^{{ }^{*}}\right)^{1-\alpha}}{q^{H *} h^{*}}+r+2 \delta^{H}} .
$$

Combining (214) and (220) implies

$$
\frac{k^{*}}{q^{H *} h^{*}}=\frac{\beta \delta^{H}}{(1-\alpha)\left(r+\delta^{K}\right)}\left(\gamma-\alpha+\frac{\alpha(1-\gamma)}{l^{X *}}\right)
$$

Using (221) and (223) in (222) and recalling (211) confirms the part (ii). Using (56), the long run labor share in GDP can be written as

$$
\mathfrak{L}^{*}=\frac{w^{*}}{\left(\frac{Y}{L}\right)^{*}+p^{*} h^{*}+q^{H *}\left(\frac{I^{H}}{L}\right)^{*}}=\frac{\frac{w^{*}}{q^{H *} h^{*}}}{\frac{B^{Y}\left(k^{Y *}\right)^{\alpha}\left(l^{*}\right)^{1-\alpha}}{q^{H *} h^{*}}+r+2 \delta^{H}} .
$$


Using $l^{Y}=1-l^{X}$ in (193) and (213), we have

$$
w^{*}=(1-\alpha)\left(B^{Y}\right)^{\frac{1}{1-\alpha}}\left(\frac{\alpha}{r+\delta^{K}}\right)^{\frac{\alpha}{1-\alpha}}
$$

Combining (225) and (220) implies

$$
\frac{w^{*}}{q^{H *} h^{*}}=\frac{(1-\gamma) \beta \delta^{H}}{l^{X *}}
$$

Using (221) and (226) in (224) and recalling (211) confirms the part (iii).

Finally, to prove part (iv), according to (56), the long run savings rate can be rewritten as

$$
\mathfrak{s}^{*}=1-\frac{\left(\frac{C}{L}\right)^{*}+p^{*}\left(\frac{S}{L}\right)^{*}}{\left(\frac{Y}{L}\right)^{*}+p^{*} h^{*}+q^{H *}\left(\frac{I^{H}}{L}\right)^{*}}=1-\frac{\left(\frac{1}{\theta}+1\right)\left(r+\delta^{H}\right)}{\frac{B^{Y}\left(k^{Y *}\right)^{\alpha}\left(l^{Y *}\right)^{1-\alpha}}{q^{H *} h^{*}}+r+2 \delta^{H}},
$$

where we divided both nominator and denominator by $q^{H *} h^{*}$ and used $(207),(S / L)^{*}=h^{*}$ and $p^{*} / q^{H *}=r+\delta$ to derive the second equation. Using (221) in (227) and recalling (211) concludes the proof.

\section{B.2 Consistency Check Using Walras' Law}

We show that the market for the numeraire good clears in long run equilibrium, where $\dot{K}=\dot{H}=0$. That is, it has to hold that

$$
\frac{Y^{*}}{L}=\frac{C^{*}}{L}+\delta^{K} \frac{K^{*}}{L}
$$

Since $Y / L=B^{Y}\left(k^{Y}\right)^{\alpha}\left(l^{Y}\right)^{1-\alpha}, C / L=p h / \theta$ (recall $(207)$ and $\left.S / L=h\right)$ and $K / L=k$, we have to check if $B^{Y}\left(k^{Y *}\right)^{\alpha}\left(l^{Y *}\right)^{1-\alpha}=p^{*} h^{*} / \theta+\delta^{K} k^{*}$, i.e.,

$$
\frac{B^{Y}\left(k^{Y *}\right)^{\alpha}\left(l^{Y *}\right)^{1-\alpha}}{q^{H *} h^{*}}=\frac{p^{*}}{\theta q^{H *}}+\frac{\delta^{K} k^{*}}{q^{H *} h^{*}} .
$$


Substituting (214), (220), (221) and $p^{*} / q^{H *}=r+\delta^{H}$ into (229) it should hold that:

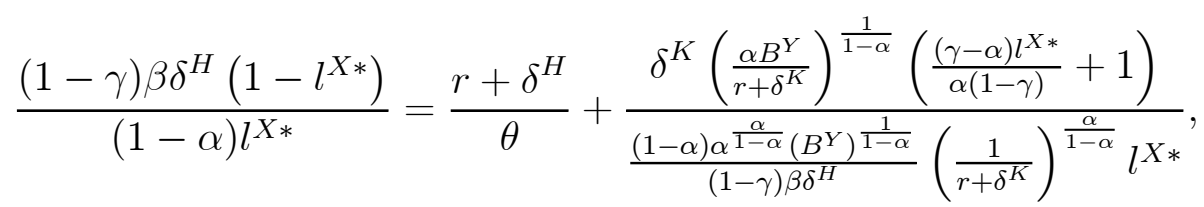

being equivalent to

$$
l^{X *}=\frac{\left[r+(1-\alpha) \delta^{K}\right](1-\gamma) \beta \theta \delta^{H}}{\left(r+\delta^{K}\right)\left[(1-\alpha)\left(r+\delta^{H}\right)+(1-\gamma) \beta \theta \delta^{H}\right]+\beta \theta \delta^{H} \delta^{K}(\gamma-\alpha)} .
$$

It is easy to show that

$$
\begin{aligned}
& \left(r+\delta^{K}\right)\left[(1-\alpha)\left(r+\delta^{H}\right)+(1-\gamma) \beta \theta \delta^{H}\right]+\beta \theta \delta^{H} \delta^{K}(\gamma-\alpha) \\
= & (1-\alpha)\left(r+\delta^{K}\right)\left[r+(1+\beta \theta) \delta^{H}\right]+\beta \theta \delta^{H} r(\alpha-\gamma) .
\end{aligned}
$$

Thus, (211) and (231) coincide.

\section{B.3 Dynamic System}

$$
\begin{gathered}
\dot{C}=r-\rho . \\
\dot{C}=r A+w L+R \bar{Z}-p H-C, \\
\dot{H}=\tilde{B}^{H}\left(K^{X}\right)^{\beta \gamma}\left(L^{X}\right)^{\beta(1-\gamma)} \bar{Z}^{1-\beta}-\delta^{H} H, \\
\frac{\dot{q}^{H}}{q^{H}}+\frac{p}{q^{H}}=r+\delta^{H} . \\
C=\frac{p H}{\theta}, \\
A=K+q^{H} H, \\
K^{X}+K^{Y}=K, \\
L^{X}+L^{Y}=L,
\end{gathered}
$$




$$
\begin{gathered}
K^{X}=\frac{\gamma}{1-\gamma} \frac{w L^{X}}{r+\delta^{K}} \\
K=\frac{w}{r+\delta^{K}}\left(\frac{\gamma}{1-\gamma} L^{X}+\frac{\alpha}{1-\alpha}\left(L-L^{X}\right)\right), \\
w=(1-\alpha) B^{Y}\left(\frac{K-K^{X}}{L-L^{X}}\right)^{\alpha}, \\
q^{H}=\frac{(1-\alpha) B^{Y}\left(\frac{K-K^{X}}{L-L^{X}}\right)^{\alpha}}{\left.(1-\gamma) \beta \tilde{B}^{H} \bar{Z}^{1-\beta}\right)^{1-\beta(1-\gamma)}}\left(K^{X}\right)^{\beta \gamma} \\
R^{Z}=(1-\beta) q^{H} \tilde{B}^{H}\left(\frac{\left(K^{X}\right)^{\gamma}\left(L^{X}\right)^{1-\gamma}}{\bar{Z}}\right)^{\beta} .
\end{gathered}
$$

Recall that $\tilde{B}^{H}=B^{H}\left(B^{X}\right)^{\beta}$. Initial state variables are $K_{0}=$ given and $H_{0}=$ given and $A_{0}=K_{0}+q_{0}^{H} H_{0}$ (notice that $A_{0}$ is a jump variable). These are 13 equations and 13 endogenous variables: $A, C, L^{X}, L^{Y}, K, K^{X}, K^{Y}, H, r, w, R^{Z}, p, q^{H}$. 